\title{
‡USGS
}

science for a changing world

In cooperation with the Western Area Power Authority and the Bureau of Reclamation

\section{Airborne Digital-Image Data for Monitoring the Colorado River Corridor below Glen Canyon Dam, Arizona, 2009- Image-Mosaic Production and Comparison with 2002 and 2005 Image Mosaics}

By Philip A. Davis

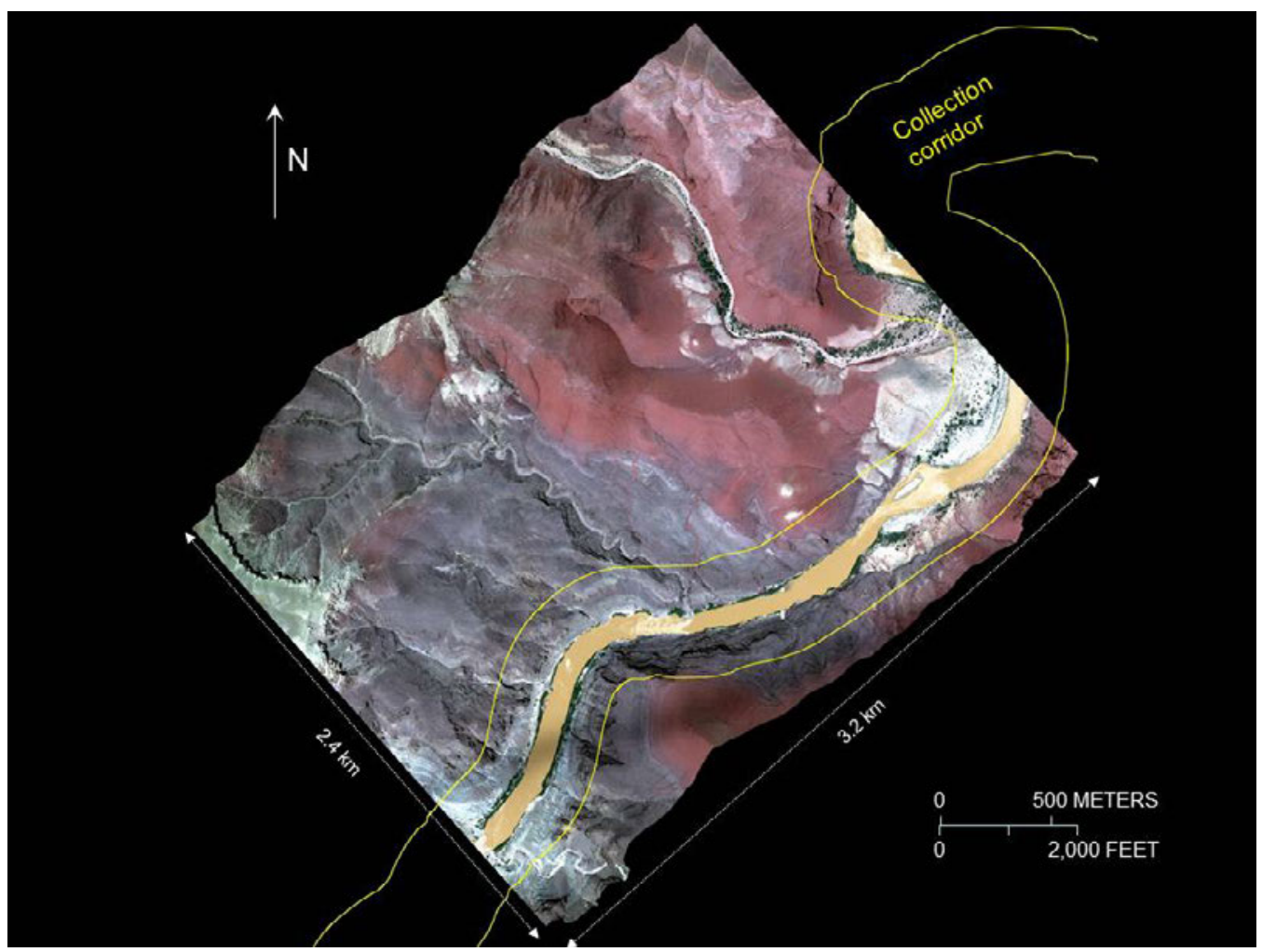

Open-File Report 2012-1139

U.S. Department of the Interior

U.S. Geological Survey 


\section{U.S. Department of the Interior \\ KEN SALAZAR, Secretary}

\section{U.S. Geological Survey \\ Marcia K. McNutt, Director}

U.S. Geological Survey, Reston, Virginia: 2012

For product and ordering information:

World Wide Web: http://www.usgs.gov/pubprod

Telephone: 1-888-ASK-USGS

For more information on the USGS-the Federal source for science about the Earth,

its natural and living resources, natural hazards, and the environment:

World Wide Web: http://www.usgs.gov

Telephone: 1-888-ASK-USGS

Suggested citation:

Davis, P.A., 2012, Airborne digital-image data for monitoring the Colorado River corridor below Glen Canyon Dam, Arizona, 2009-Image-mosaic production and comparison with 2002 and 2005 image mosaics: U.S. Geological Survey Open-File Report 2012-1139, 82 p. (Available at $h t t p: / / p u b s . u s g s . g o v / o f / 2012 / 1139 /$.

Any use of trade, product, or firm names is for descriptive purposes only and does not imply endorsement by the U.S. Government.

Although this report is in the public domain, permission must be secured from the individual copyright owners to reproduce any copyrighted material contained within this report.

COVER

Flightline image segment south of the Little Colorado River showing the average length and swath width of the SH52 flightline segments. The 500-meter-wide collection corridor is superposed on a natural-color image. $\mathrm{km}$, kilometers. 


\section{Contents}

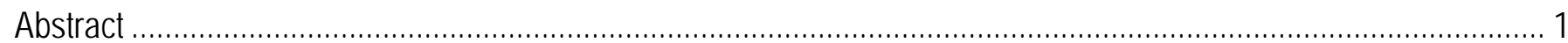

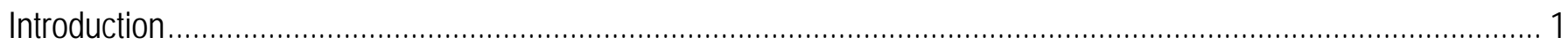

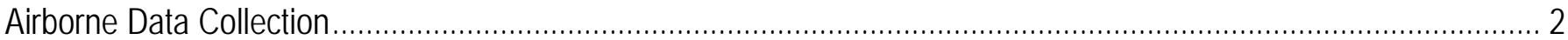

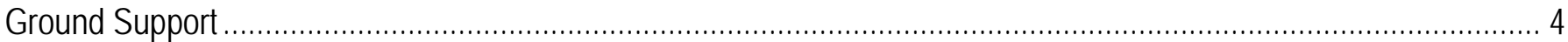

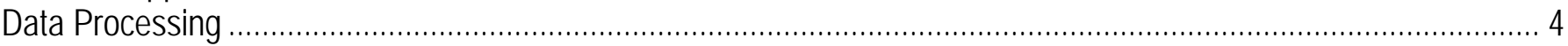

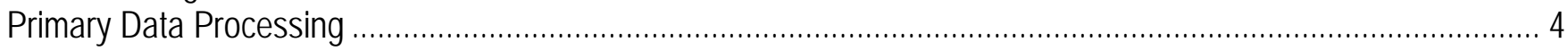

Sensor Performance and Secondary Data Processing ……..................................................................... 5

Image-Band Saturation ……………………………

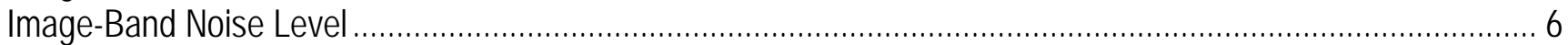

Image-Band Dynamic Range ………..........................................................................................

Image-Band Linearity and Sensitivity ………………………........................................................

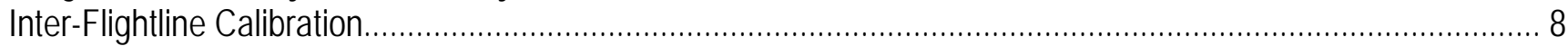

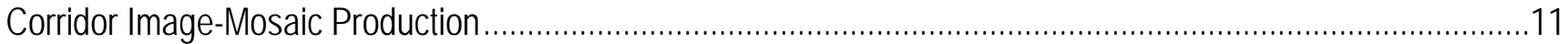

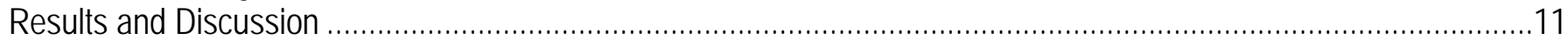

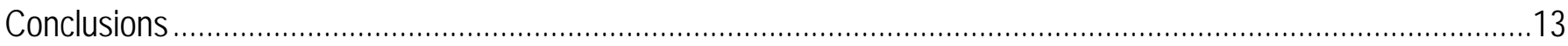

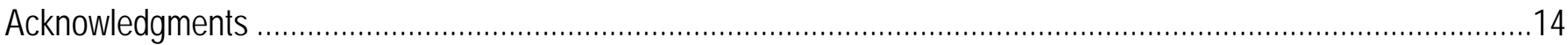

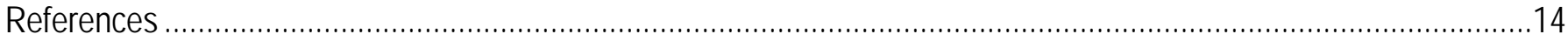

\section{Figures}

1. Map of the Colorado River corridor in Arizona that is monitored by the U.S. Geological Survey's Grand Canyon

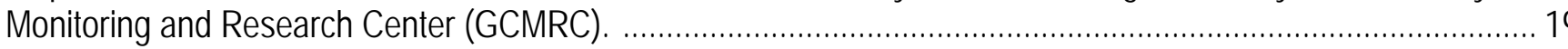

2. Map of sets of parallel flightlines constituting flight blocks (lettered A-M) proposed for the 2009 airborne digitalimage data collection for the Arizona part of the Colorado River ecosystem below Glen Canyon Dam.

3. Relevant stream gage data during the early part of flight mission. Afternoon monsoon showers produced discharge spikes at the Little Colorado River (LCR) stream gage $09402300(A)$, which reached the Grand Canyon stream gage $09402500(B)$ within 3 hours and required 10 hours to clear the collection area. The Paria River stream gage $09382000(C)$ near Lees Ferry (river mile 0.0) showed no appreciable inflow to the mainstem, which retained the dam's prescribed low steady flow levels down to the LCR .................................... 21

4. Variation in solar-elevation angle (black curvilinear line) during the daily extended flight window. ........................ 22

5. Map of the global-positioning-system (GPS) base stations (red crosses) operated on the rims of the Grand Canyon during data collection.

6. Map of the ground-control panels (red dots) that were positioned before data collection and used during aerotriangulation to improve positional accuracy of the imagery and vertical accuracy of the digital surface model (DSM).

7. Map of the actual 42 subblocks of flightlines that were collected during the mission........................................... 26

8. Enlarged view of figure 7 at the Little Colorado River showing the number and amount of sidelap of subblock flightlines and the amount of flightline overlap between adjacent subblocks.

9. Flightline image segment south of the Little Colorado River showing the average length and swath width (in kilometers, km) of the SH52 flightline segments.

10. Natural-color image shown in figure 9, subset for the collection area.

11.A, Natural-color images of two overlapping flightline image segments exhibiting surface smearing on opposite sides of the river. $B$, Enlarged images of the west side of the Colorado River showing basal smearing on the top image but not on the bottom image. $C$, Enlarged images of the east side of the river showing scarp and vegetation smearing on the bottom image but not on the top image. 
12. Comparison of digital values within the SH52 band imagery with reflectance values for corresponding wavelengths and ground locations that included various bare-ground, vegetated, and manmade surfaces within the Colorado River ecosystem. Bands 1 through 4 are shown in $A$ through $D$, respectively.

13. Average percent-reflectance values within $\mathrm{SH} 52$ wavelength bands, extracted from ground-reflectance spectra, for materials that commonly occur within the $(A)$ xeric zone (Atriplex canescens or fourwing saltbush, Artemisia Iudoviciana or sagebrush, and Quercus turbinella or shrub live oak, Prosopis glandulosa or mesquite), (B) riparian zone (Baccharis salicifolia or baccharis, Tamarix ramossima or tamarisk, Pluchea sericea or arrowweed, and Salix exigua or willow), and $(C)$ riparian wetland areas (Phragmites arundinacea or phragmites, Carex aquatilis or sedge, Equisetum ferrisii or equisetum, Cynodon dactylon or marsh grass, and Aristida oligantha or yellow grass) within the Colorado River ecosystem.

14. A, Scatter diagram of calibrated band-3 image digital numbers (DN) for flightline M5_05261918 versus uncalibrated band-3 image DN for flightline M4_05251853 within the overlap region of the two flightline subblocks. $B$, Similar diagram comparing band-3 image DN within sidelap region between calibrated flightline K1_ 05241815 versus uncalibrated flightline K1_05282020.

15. Scatter diagrams of dependent/independent-image cosine-zenith-angle ratios versus their image digital number (DN) regression slopes for the inter-subblock flightline cross correlations, where $A$ shows the simple cosine relation and $B$ shows the cosine-squared relation.

16. Map of the Colorado River ecosystem, showing the U.S. Geological Survey quarter-quadrangle map-tile scheme (green boxes) used to segment the corridor's image mosaic into image tiles.

17. Natural-color image of a section of map tile SE35113G4 (river mile 230.0) showing color discontinuity within the mainstem between clear (green) and sediment-laden (brown) water, as a result of mosaicking image data collected before and after upstream tributary floods triggered by monsoonal storms.

18. Map of the Colorado River ecosystem, showing locations of scarp smears (red asterisk) and areas of cloud shadow or overcast (green boxes) within the final 2009 image mosaic.

19. Natural-color image of point 1 location in figure 18 showing scarp smears and distortion of circular building at the Glen Canyon Dam within map tile SW36111H4.

20. Natural-color image of point 2 location in figure 18 showing subtle scarp smears on the left bank of the Colorado River (river left) and shoreline smears on river right within map tile NE36111G6.............................48

21. Natural-color image of point 3 location in figure 18 showing minor scarp smear within map tile SE36111A8....... 49

22. Natural-color image of point 4 location in figure 18 showing scarp smears within map tile NE36112C6..............50

23. Natural-color image of point 5 location in figure 18 showing very minor scarp smears within map tile NE36112C7.

24. Natural-color image of point 6 location in figure 18 showing obvious scarp smears on $(A)$ the left bank of the Colorado River (river left) and $(B)$ river right within map tile SE36113B2.

25. Natural-color image of a part of box 3 in figure 18 showing scattered cloud shadows and the east edge of a section that is overcast within map tile NE35113G6.

26. Comparison of $(A) 2009,(B) 2005$, and $(C) 2002$ natural-color image quality for a sandbar area at river mile 30.7 within image tile SW36000B7.

27. Comparison of $(A) 2009,(B) 2005$, and $(C) 2002$ natural-color image quality of metagranitic terrain near

Phantom Ranch (river mile 87.0; fig. 1) within map tile NW36112A1.

28. Comparison of $(A) 2009,(B) 2005$, and $(C) 2002$ natural-color image quality for anthropogenic disturbance near Phantom Ranch (river mile 87.0; fig. 1) within image tile NW36112A1

29. Comparison of $(A) 2009,(B), 2005$, and $(C) 2002$ natural-color image quality at petroglyph site at river mile -10.2 within image tile SE36111H5.

30.A, Part of Hereford's (1996) geologic and geomorphologic map of the Palisades Creek area (fig. 1) at river mile

65.9. $B$, Legend from Hereford's (1996) map describing units depicted in figure $30 A$.

31. Comparison of $(A) 2009,(B) 2005$, and $(C) 2002$ natural-color image quality for the area shown in figure 30 within map tile SW36111B7. 
32. Comparison of $(A)$ 2009, $(B)$ 2005, and (C) 2002 natural-color image quality for anthropogenic features at Phantom Ranch (river mile 87.0; fig. 1) within map tile NW36112A1.

33. Natural-color image taken in 2009 of a vegetated area at river mile 68.5 within map tile NW36111A7.

34. Comparison of $(A)$ 2009, $(B) 2005$, and (C) 2002 natural-color image quality for the vegetated area shown in figure 33.

35. Natural-color image taken in 2009 of an area upstream of figures 33 and 34 at river mile 67.5 showing very distinct color differences among various types of vegetation

36. Comparison of $(A)$ 2002, (B) 2005, and (C) 2009 natural-color image of a beach area downstream of Phantom Ranch (river mile 87.1; fig. 1) within image tile NW36112A1 showing steady increase in stand diameter between 2002 and 2009.

\section{Tables}

1. Image ground resolution predicted from flight altitudes for 2009 airborne digital-image data collected for the Arizona part of the Colorado River ecosystem below Glen Canyon Dam.....

2. Global positioning system (GPS) base stations, with calculated errors, operated along the Grand Canyon's rims during 2009 overflights for airborne digital-image data collection for the Arizona part of the Colorado River ecosystem below Glen Canyon Dam.

3. Defects within the image mosaic for 2009 airborne digital-image data collected for the Arizona part of the Colorado River ecosystem below Glen Canyon Dam 


\section{Conversion Factors}

SI to Inch/Pound

\begin{tabular}{lll}
\hline \multicolumn{1}{c}{ Multiply } & By & \multicolumn{1}{c}{ To obtain } \\
\hline centimeter $(\mathrm{cm})$ & Length & \\
millimeter $(\mathrm{mm})$ & 0.3937 & inch (in.) \\
meter $(\mathrm{m})$ & 0.03937 & inch (in.) \\
kilometer $(\mathrm{km})$ & 3.281 & foot (ft) \\
meter $(\mathrm{m})$ & 0.6214 & mile (mi) \\
\hline & 1.094 & yard (yd) \\
\hline cubic meter $\left(\mathrm{m}^{3}\right)$ & Volume & \\
cubic meter $\left(\mathrm{m}^{3}\right)$ & 264.2 & gallon (gal) \\
cubic centimeter $\left(\mathrm{cm}^{3}\right)$ & 0.0002642 & million gallons (Mgal) \\
cubic meter $\left(\mathrm{m}^{3}\right)$ & 0.06102 & cubic inch (in $\left.{ }^{3}\right)$ \\
cubic meter $\left(\mathrm{m}^{3}\right)$ & 35.31 & cubic foot $\left(\mathrm{ft}^{3}\right)$ \\
cubic meter $\left(\mathrm{m}^{3}\right)$ & 1.308 & cubic yard $\left(\mathrm{yd}^{3}\right)$ \\
\hline & 0.0008107 & acre-foot $($ acre-ft) \\
\hline cubic meter per second $\left(\mathrm{m}^{3} / \mathrm{s}\right)$ & Flow rate & \\
\hline
\end{tabular}

Inch/Pound to SI

\begin{tabular}{lcc}
\hline Multiply & By & To obtain \\
\hline mile $(\mathrm{mi})$ & Length & \\
\hline & 1.609 & kilometer $(\mathrm{km})$ \\
\hline cubic feet per second $\left(\mathrm{ft}^{3} / \mathrm{s}\right)$ & Flow rate & \\
\hline
\end{tabular}

Vertical coordinate information is referenced to the North American Vertical Datum of 1988 (NAVD 88). Horizontal coordinate information is referenced to the North American Datum of 1983 (NAD 83). Altitude, as used in this report, refers to distance above the vertical datum. 


\title{
Airborne Digital-Image Data for Monitoring the Colorado River Corridor below Glen Canyon Dam, Arizona, 2009- Image-Mosaic Production and Comparison with 2002 and 2005 Image Mosaics
}

By Philip A. Davis

\begin{abstract}
Airborne digital-image data were collected for the Arizona part of the Colorado River ecosystem below Glen Canyon Dam in 2009. These four-band image data are similar in wavelength band (blue, green, red, and near infrared) and spatial resolution (20 centimeters) to image collections of the river corridor in 2002 and 2005. These periodic image collections are used by the Grand Canyon Monitoring and Research Center (GCMRC) of the U.S. Geological Survey to monitor the effects of Glen Canyon Dam operations on the downstream ecosystem. The 2009 collection used the latest model of the Leica ADS40 airborne digital sensor (the SH52), which uses a single optic for all four bands and collects and stores band radiance in 12-bits, unlike the image sensors that GCMRC used in 2002 and 2005. This study examined the performance of the SH52 sensor, on the basis of the collected image data, and determined that the SH52 sensor provided superior data relative to the previously employed sensors (that is, an early ADS40 model and Zeiss Imaging's Digital Mapping Camera) in terms of band-image registration, dynamic range, saturation, linearity to ground reflectance, and noise level. The 2009 image data were provided as orthorectified segments of each flightline to constrain the size of the image files; each river segment was covered by 5 to 6 overlapping, linear flightlines. Most flightline images for each river segment had some surface-smear defects and some river segments had cloud shadows, but these two conditions did not generally coincide in the majority of the overlapping flightlines for a particular river segment. Therefore, the final image mosaic for the 450-kilometer $(\mathrm{km})$-long river corridor required careful selection and editing of numerous flightline segments (a total of 513 segments, each $3.2 \mathrm{~km}$ long) to minimize surface defects and cloud shadows. The final image mosaic has a total of only $3 \mathrm{~km}$ of surface defects. The final image mosaic for the western end of the corridor has areas of cloud shadow because of persistent inclement weather during data collection. This report presents visual comparisons of the 2002, 2005, and 2009 digital-image mosaics for various physical, biological, and cultural resources within the Colorado River ecosystem. All of the comparisons show the superior quality of the 2009 image data. In fact, the 2009 four-band image mosaic is perhaps the best image dataset that exists for the entire Arizona part of the Colorado River.
\end{abstract}

\section{Introduction}

The Grand Canyon Monitoring and Research Center (GCMRC) of the U.S. Geological Survey (USGS) periodically collects airborne image data for the Colorado River corridor within Arizona (fig. 1) to allow scientists to study the impacts of Glen Canyon Dam water release on the corridor's natural and 
cultural resources. These data are collected from just above Glen Canyon Dam (in Lake Powell) down to the entrance of Lake Mead, for a total distance of 450 kilometers $(\mathrm{km})$, concentrating on a 500-meter (m) swath centered on the river's mainstem and its seven main tributaries (fig. 1). Historically, image data (mostly color infrared) were acquired every year as analog photographic film. However, this practice was curtailed in 2002 because film scanning and orthorectification of analog imagery became too costly and because new digital sensors could (1) obtain acceptable ground resolution (15-20 centimeters, $\mathrm{cm}$ ) and positional accuracy (near $30 \mathrm{~cm}$ ), (2) collect multispectral image data with a higher dynamic range (12 bit) than photographic film, and (3) simultaneously collect stereopanchromatic imagery to build a digital surface model (DSM) for image rectification, all at a lower cost than the analog film process (Davis, 2004). After the 2002 data collection, it was also decided that the period of data collection could be reduced to a 4-year cycle without losing critical monitoring capability.

A 4-year remote-sensing study (Davis, 2004) recommended the digital-image approach and also determined the specifications for collecting and processing the digital-image data based on sensor capabilities and GCMRC monitoring requirements. These specifications were subsequently revised, based on the results from the 2002 and 2005 digital-image collections. These two previous datasets presented three problems for scientific analysis: (1) some image bands were not coregistered because all band images were not acquired with a single lens, (2) there was extensive surface smearing within the final image mosaics that were delivered by the contractors, and (3) the gain on the 2002 near-infrared detector was set too low, which caused signal saturation for the more chlorophyll-rich vegetation and limited classification of some vegetation species.

For the 2009 data collection, GCMRC employed a new-generation imaging sensor (a Leica ADS40 airborne digital sensor, model SH52) that would preclude some of the problems listed above. This report discusses the 2009 SH52 data collection, the performance of this sensor in terms of data quality, and the rigorous processing procedures that were used to circumvent the limitations of commercial data processing and to produce the best multispectral-image database for the entire Arizona part of the Colorado River ecosystem (CRE). The CRE extends from the forebay of Glen Canyon Dam to the westernmost boundary of Grand Canyon National Park (fig. 1) — a segment of the river containing natural and cultural resources managed by several Federal agencies and Native American tribes within the Glen Canyon Dam Adaptive Management Program.

\section{Airborne Data Collection}

The CRE specifications for data collection considered the recommendations of Davis (2004) with modifications based on GCMRC evaluations of the data collected in 2002 and 2005. Revised specifications consisted of (1) at least four, coregistered image bands covering the visible and nearinfrared wavelength regions; (2) 12-bit data acquired, stored, and delivered with the detector gain for each wavelength-band set so as not to produce signal saturation within the CRE; (3) 15-cm intrinsic ground resolution (without resolution enhancement using the panchromatic imagery); (4) a 30-cm positional accuracy in the orthorectified imagery; (5) a 1-m-cell digital surface model (DSM) with 25cm vertical accuracy; (6) daily image acquisition between 10:30 a.m. and 2:00 p.m. to constrain the range in phase angle and consequent range in surface reflectance, with some narrower CRE sections having more constrained collection windows to minimize canyon-wall shadows (fig. 2); and (7) seamless, 12-bit image mosaics of each band, sectioned to match the boundaries of the USGS 1:24,000scale map quadrangles for the imaged areas. The CRE airborne image data are always collected at a low-steady flow rate (226 cubic meters per second, $\mathrm{m}^{3} / \mathrm{s}$ ) from the Glen Canyon Dam, which provides a constant baseline for monitoring and exposes more of the channel substrate than under the dam's normal daily fluctuating flows. Image data were collected around the Memorial Day period, when power 
demands are low, the sun elevation is high (close to summer solstice), and the skies are generally most clear. Two aircraft systems were deployed to reduce the time necessary for data collection, even though eight collection days were allotted, which included a contingency for 2 to 3 days of inclement weather. Abnormally inclement weather in 2009 resulted in two initial days with no data collection. Very limited collection occurred beyond river mile (RM) 100 (river miles are measured relative to Lees Ferry, which is mile 0; river miles are negative upstream of Lees Ferry) on three additional days as a result of heavy monsoonal storms that produced discharge spikes from the Little Colorado River (figs. 1 and $3 A, B$ ), which required about 24 hours to clear the collection corridor. The only major tributary between the dam and the Little Colorado River is the Paria River (fig. 1), which produced only minor discharge spikes during the unusually early monsoonal storms (fig. 3C). The mid-day monsoons were preceded by cloud buildup over the canyon that started near 11:00 a.m.. As a result of the persistent daily monsoons, the daily collection window was widened, but even the wider window and an extended (12 day) collection period did not produce imagery free of cloud shadows beyond river mile 240. Fortunately, the GCMRC does not typically monitor the lower river section beyond river mile 240, because that river section is inundated by upper Lake Mead.

The new ADS40 SH52 push-broom, multispectral sensor was employed for the 2009 image collection because the sensor can collect imagery that meets CRE specifications. This sensor's performance was previously assessed and found to be comparable to, or better than, aerial photography (Fricker, 2007; Kellenberger and Nagy, 2008; Markelin and others, 2008). The sensor has a nadirlooking, gyro-stabilized optic system with a focal length of 62.77 millimeters (mm), a $64^{\circ}$ across-track field of view, and a separate charged-coupled-device (CCD) array for each of its four wavelength bands, which are the blue (430-490 nanometers, nm), green (535-585 nm), red (610-660 nm), and nearinfrared (835-885 nm) wavelength bands. The single lens for all four wavelength bands ensures band image registration, unlike earlier ADS40 models. A beam splitter behind the lens separates the reflected ground signal into the four wavelength beams and focuses each beam onto its respective CCD array. There are three additional lenses and CCD arrays that collect panchromatic (520-760 nm) images; the lenses look fore $\left(+27^{\circ}\right)$, near nadir $\left(+2^{\circ}\right)$, and aft $\left(-14^{\circ}\right)$ along track, providing three separate stereo image pairs for each surface element. Parallel flightlines with 50-90 percent sidelap magnify the number of stereo pairs and increase aerotriangulation and DSM accuracies. All of the CCD arrays have 12,000 elements; the photon flux impinging on each CCD element is converted to and stored as 12-bit values, which provide a superior dynamic range relative to 8-bit sensor systems.

Although the focal length of the SH52 lens could obtain 15-cm ground resolution at flight altitudes above the canyon's rims, flight restrictions within particular sections of the corridor (due to commercial flight paths in flight blocks A, B, and F; fig. 2) required an increase in the desired flight altitudes in those few corridor sections, which reduced the data's ground resolution in those sections (table 1). Continual buildup of cloud cover near the beginning of the desired daily collection window, and its persistence within most of that window, forced a widening of the collection window, which increased the data's range in phase angle. The phase angle is the angle between solar incidence and the airborne detector. Because the airborne detector looks nadir, the phase angle only varied with the solarincidence angle, which can be represented by either the solar-zenith angle (measured from vertical) or its complement, the solar-elevation angle. Figure 4 shows the variation in the collection's solarelevation angle as a function of time within the daily flight window, as well as the number of flightlines collected at each time or solar-elevation increment. 


\section{Ground Support}

Each collection aircraft was equipped with a global positioning system (GPS) receiver that operated at a 1-second epoch, to determine the sensor's position, and an inertia measurement unit (IMU) that operated at 200 hertz (Hz), to determine the sensor's pointing geometry. The aircraft GPS could receive data from both U.S. and Russian (Glonas) GPS satellites. The aircraft GPS system alone cannot determine the sensor's position to GCMRC's desired accuracy. Thus, numerous canyon-rim GPS base stations were operated (fig. 5; table 2) that also received data from both U.S. and Russian satellites at a 1-second epoch. There were generally two ground GPS receivers (base stations) operating within a 30$\mathrm{km}$ distance of the collection aircraft for most sections of the CRE. All rim base stations were within the Arizona Federal Base Network. The receivers recorded dual-frequency (L1/L2) carrier-phase and pseudo-range measurements from each visible GPS satellite. Each base station was operational 1 hour before aircraft takeoff and acquired data until all aircraft had landed each day. Fixed base stations near the CRE that operate continually were also used when within aircraft range. Each day, the GPS basestation data were processed in static mode to verify their published positions and to detect problems. The airborne GPS and IMU data were processed with the base-station data in both forward and reverse chronologic directions to obtain trajectory positions.

To further strengthen the positional accuracy of the final DSM and orthorectified imagery, GCMRC positioned 125 ground-control panels on the canyon floor throughout the CRE before flight operations (fig. 6). There are certain sections of the CRE without surveyed ground control and, for these sections, GCMRC had to accept a possible lower positional accuracy in the final data products.

\section{Data Processing}

The airborne data collection resulted in 266 flightlines throughout the CRE. Data were collected in 13 major blocks (fig. 2), consisting of 42 subblocks (fig. 7) that each represent a semilinear segment of the river corridor. Within each subblock, 5 to 6 parallel flightlines were collected with 50-90 percent sidelap (fig. 8); flightlines also overlapped between adjacent subblocks (fig. 8). The large overlap provided multiple image looks for most panchromatic picture elements, which improved photogrammetric solutions, and provided nadir multispectral image coverage for most surfaces within a particular sinuous river segment, which produces less surface distortion during orthorectification. Data processing consisted of two stages - a first stage performed by the contractor who collected the data and a second stage done by GCMRC.

\section{Primary Data Processing}

The initial phase of data processing was performed by the data-collection contractor and consisted of (1) determining tie points between all flightline images to determine image relative position; (2) determining the absolute position of the flightline images using solutions from the airborne GPS/IMU system and the ground GPS base stations; (3) incorporating the ground-control-panel data to produce a final aerotriangulation block adjustment for each flightline panchromatic and multispectral image dataset; (4) deriving the DSM from the panchromatic imagery, which was then used to orthorectify the multispectral imagery; and (5) normalizing cross-track surface brightness in each band's orthorectified image to remove differential sun-angle effects across the canyon floor, which helps to produce more surface-normal radiance values on both sides of the canyon within a flightline. The spatial resolution of the delivered image data was $20 \mathrm{~cm}$, which was the average resolution from all the flightline blocks. Comparison of the resultant DSM and orthorectified imagery with the ground control 
panels indicated a vertical error of $38 \mathrm{~cm}$ and a positional error of $19 \mathrm{~cm}$, respectively, at the 1-sigma level.

The final orthorectified multispectral image data were delivered in 1-gigabyte flightline segments due to the large size of each flightline. Each of the resulting 760 flightline segments had an average surface length of $3.2 \mathrm{~km}$ and swath width of $2.4 \mathrm{~km}$ (fig. 9). The file name of each image segment contained its flight block letter, acquisition date and time, band name, and line-segment number. Visual examination of all the rectified multispectral image segments noted surface smearing along abrupt slopes (fig. 10). For the most part, surface smearing within an image segment was restricted to one side of the collection corridor (fig. 11). Multiple, overlapping image segments were thus required to produce an image mosaic of the river corridor that minimized surface smear, as well as cloud and topographic shadows. All line segments were visually examined, proceeding from the Glen Canyon Dam down to Lake Mead, to determine which line segments were needed to produce an image mosaic with minimal defects. This initial survey indicated the need for 360 line segments, but 513 line segments were ultimately required to produce the final image mosaic with minimal defects because of undetected defects during the initial line-segment review. Given the average 3.2-km length of each line segment, the image processing required about $1,640 \mathrm{~km}$ of flightline image data to produce a minimumerror mosaic of the 450-km-long river corridor, or an average of six image segments per river mile.

The digital number (DN) within a band image represents the total energy (radiance) recorded by that band's detector, which includes solar radiation reflected from the ground surface and from the atmosphere (before reaching the surface), and is a function of each detector's gain and offset that scales the incoming radiation to a particular bit range. Preliminary examination of the band-radiance values on vegetation and bare sand throughout the corridor found the blue-, green-, and red-band radiance values to have relative correspondence to the spectral values of such surfaces within the GCMRC groundspectral library. However, the near-infrared-band radiance values were consistently lower than the redband radiance values on bare sand, unlike the band relations observed for bare sand in the GCMRC ground-spectral library. It is necessary that all the band data have at least a relative correspondence to spectral reality (that is, GCMRC's ground-spectral library) so that established logic and algorithms could be used in the analysis of these image data. Therefore, this near-infrared anomaly had to be corrected, but before performing any such adjustments to the image data, many other related performance characteristics of the sensor and its four detectors had to be understood. The following section presents the results from quantitative analyses of the relevant performance parameters.

\section{Sensor Performance and Secondary Data Processing}

There are several parameters that determine a sensor's performance and the capability of its processed data to accurately and consistently map surface characteristics. These parameters pertain to each wavelength band and consist of saturation, noise level, dynamic range, linearity, sensitivity, and radiometry. The following sections discuss spectral reflectance, which is the fraction of incident solar radiation that is reflected from a surface element and controlled by the intrinsic properties of the surface element and by the angular orientation of the surface element to the incident solar radiation.

\section{Image-Band Saturation}

The SH52 band detectors collect reflected and scattered radiance in a 12-bit range (0-4,095 values), but the sensor's analog-to-digital converter produces 14 -bit data (0-16,383 values). The contractor's data processing (step 5) expanded this range even further to unsigned 16-bit data (0-65,535 values). It was desired to reduce the delivered data back to its original 14-bit range, both to restore the data's intrinsic recorded range and to decrease the time for subsequent image processing and analysis. 
Before doing so, the band values of the most highly reflective surfaces (for example, white painted and metallic roofs, water riffles, monkey flower (Mimulus cardinalis) plants, and clean quartz sand) were examined to determine whether this range reduction would result in any band's saturation. Examination of the band digital numbers within these surfaces showed that only portions of water-riffle surfaces exceeded a 14-bit value, which commonly occurs when riffle-surface slopes equal the solar-incidence angle and act like natural mirrors that reflect most of the incident solar radiation. Saturation on the small riffle patches will not adversely affect subsequent surface mapping. Therefore, a digital-number range conversion was performed on data for all four bands equally by multiplying each band's digital number by a simple bit-conversion ratio $(16,383 / 65,535)$.

Saturation in any image band will limit the discrimination and mapping of surface materials that typically have band-radiance values that exceed the saturation DN in the band images. Band image saturation was evaluated by interactively Gaussian stretching the image values of the brightest surface areas within the line segments and visually searching for areas of constant high DN with only minimal brightness modulation. Except for small riffle patches, no other natural surfaces exhibited DN saturation. The only manmade surfaces that appeared to have DN saturation were either metallic or painted white, and even those surfaces were somewhat mottled in their DN. The average and standard deviation of the image DN on these manmade surfaces were 3,357 \pm 107 in band 1 (blue), 5,305 \pm 259 in band 2 (green), 5,131 \pm 420 in band 3 (red), and 4,734 \pm 226 in band 4 (near infrared). The standard deviations that were 3 to 8 percent of the mean DN of these manmade surfaces suggest that the surfaces were not uniform in composition, unless the noise levels of the image data are that high. Many of the riffles had band values much higher than these manmade surfaces. Average band DN values of the brighter riffles were 5,443 in band 1, 9,091 in band 2, 9,071 in band 3, and 8,222 in band 4. The brighter riffle areas were quite small in area (a few picture elements each), which makes it difficult to determine if their surfaces were actually saturated. Even so, these riffle values set a higher limit on band-saturation levels within the image data than the manmade surfaces and indicate that band saturation will not be an issue for image analysis and classification.

\section{Image-Band Noise Level}

The noise levels for the four image bands set a lower limit on the discrimination and mapping of surface materials. Surface materials whose intrinsic spectral-band values differ by less than the band noise levels cannot be mapped reliably. The noise level of an image band is determined from the standard deviation of that band's image DN within flat areas of uniform composition, such as calm, deep, clean water; fresh asphalt or concrete; or new metal surfaces. Band noise levels were evaluated on pockets of calm, deep, clean water above Lees Ferry, on new concrete pads at the dam facility, and on new National Park Service roof tops at Lees Ferry. The average and standard deviation values for each band within the selected target areas were extracted. The deep-water area provided the darkest target with the following average and standard deviation band values: $200 \pm 9$ for band 1, 246 \pm 10 for band 2, $202 \pm 10$ for band 3, and $275 \pm 14$ for band 4 . The band average-DN values indicate a low uniform radiance spectrum consistent with clean water. The band standard deviations indicate a 4 to 5 percent noise level at these low radiance levels. A dark-brown roof target had band DN standard deviations similar to the water target, but with twice the average band-radiance values, thus the noise levels on that roof surface had a range of 1.3 to 2.0 percent. A tan-colored roof and fresh concrete pad provided average band-radiance values in the range of 1,300 to 2,700 with band standard deviation values that were about 50 percent higher than those of the water target (that is, standard deviations of 13 for band 1 , 15 for band 2, 21 for band 3, and 16 for band 4). The manmade surfaces might not have been as uniform 
as they visually appeared. A later section, Image-Band Linearity and Sensitivity, will discuss what these noise levels mean in terms of relative reflectance and, ultimately, the limits on material discrimination.

\section{Image-Band Dynamic Range}

The dynamic range of a sensor's band data is determined from the saturation and noise levels (Markelin and others, 2008). Based on the riffle-saturation values and calm-water noise values discussed in the previous sections, the dynamic ranges of the collected SH52 data are 5,434 for band 1, 9,081 for band 2, 9,061 for band 3, and 8,208 for band 4. Thus, the DN range in band 1 is slightly higher than 12-bit data, whereas the DN ranges in the other three bands are within 14-bit data $(0-16,383)$. Markelin and others (2008) found the dynamic ranges of SH52 test data to be 9 bits for band 1, 10 bits for bands 2 and 3, and 11 bits for band 4 . Their test data might not have had the initial processing that was performed on the GCMRC 2009 data, which could have artificially increased band dynamic range in the 2009 data.

\section{Image-Band Linearity and Sensitivity}

Band linearity is the degree to which surface reflectance and image DN within a particular band are linearly related. Image classification can be performed more efficiently and results are generally more reliable when higher linear correlation exists between a band's recorded DN and its corresponding surface reflectance. The band-image DN were extracted at locations where ground spectroradiometric data had been collected; the relation between the extracted band-image DN and their respective ground band reflectance is shown in figure 12. Linear correlation coefficients $\left(R^{2}\right)$ for the four sets of band data are quite high (fig. 12), suggesting a high degree of linearity, but most of the ground-reflectance data for bands 1 and 2 are clustered at low-reflectance values, with their correlations being influenced by one or two high-reflectance samples. Removal of the high-reflectance samples from bands 1 and 2 results in a correlation coefficient of 0.715 for band 1 and 0.739 for band 2. Markelin and others (2008) performed a similar analysis of ADS040 data for European target areas and found the correlation coefficient for band 1 data to be 0.943 and that of the other three bands to be between 0.982 and 0.997; similar to the band correlations derived in this study based on the full range of ground samples. Therefore, the results obtained herein using the full range of reflectance data appear sound and the sensor data are indeed linear.

The sensitivity of a sensor's band data determines the degree to which surface materials can be discriminated. The linear relations between band DN and ground reflectance (fig. 12) indicate that the sensitivity (in terms of percent reflectance per band DN) in band 1 through band 4 is 0.059, 0.028, 0.022, and 0.028 percent, respectively. These levels of band sensitivity are good and should provide a level of material discrimination that is near the intrinsic limits provided by the four wavelength bands. However, sensors can be very sensitive and still be very noisy, which can overshadow or defeat high sensitivity. On the basis of the band DN noise levels that were presented in a previous section and the sensitivity data above, the band noise levels can now be restated as band-reflectance values. This conversion resulted in band-reflectance noise levels of $0.53,0.28,0.22$, and 0.39 percent for bands 1 through 4, respectively. These values establish tangible limits on the discrimination among, or detectability of, different materials during image classification. As stated near the end of the primary data processing section, the radiance values of band 4 were found to be consistently lower than that of band 3 on bare sand surfaces throughout the river corridor. However, the GCMRC ground-reflectance data indicate that band 4 is consistently higher than band 3 on bare sand (fig. 13A). A correction factor of 1.274 was thus determined for band 4 , based on the observed DN-reflectance relations between the SH52 bands 3 and 4 and the reflectance relation between band 3 and band 4 in GCMRC ground- 
reflectance data for bare sand surfaces. Applying this correction factor to the band-4 data used in figure 12 increases the sensitivity of band 4 to 0.022 percent, which lowers that band's reflectance noise level to 0.31 percent.

The average ground-spectral values within the SH52 wavelength bands for sand, alluvium, and the more common flowering and stressed vegetation species within the CRE are shown in figure 13. Where particular vegetation types (that is, baccharis, Baccharis salicifolia; tamarisk, Tamarix ramossima; and arrowweed, Pluchea sericea) exhibit a large range in their reflectance values, the minimum and maximum spectra are both shown. Discrimination among different vegetation types within the CRE, using sensors with four broad, visible-to-near-infrared wavelength bands, is a difficult task because some vegetation types have similar reflectance spectra and some types exhibit a range of spectral reflectance. Therefore, potential problems in discriminating these materials were evaluated by differencing the average ground-spectral-band values of each pair of species. If the absolute difference in any band did not exceed twice that band's reflectance noise level, then the pair's band-reflectance values were deemed indistinguishable. If all four bands for two materials were indistinguishable, then there is a high probability that one of the two (or both) materials would be misclassified using the SH52 imagery. The results of this evaluation suggest that most of the materials shown in figure 13 can be discriminated from each other using the SH52 image data. However, tamarisk and sagebrush (Artemisia ludoviciana) are only different in their band-4 reflectance, and the same is true for baccharis and marsh grass (Cynodon dactylon). Considering the large range in measured band-4 reflectance for both tamarisk and baccharis, one of the vegetation types within each of the two vegetation pairs will probably be misclassified using the SH52 imagery.

Leaf pigments (chlorophyll, carotenoids, and anthocyanins) absorb sunlight within the blue- and red-wavelength regions (Sims and Gamon, 2002), as shown in the GCMRC flowering vegetation spectra in figure 13. Drought or low-temperature stress decreases leaf pigment content, which in turn raises band-1 and band-3 reflectance values (Baynes, 2007), as shown by the "dormant" arrowweed and yellow grass (Aristida oligantha) spectra in figures $13 B$ and $C$, respectively. Reflectance spectra of different plants under stress can cause confusion during image classification. Dead plants, ground litter, and dormant or senescent woody plants typically have very low reflectance in all four SH52 wavelength bands (fig. 13C), which makes their identification extremely difficult and can result in them being confused with damp sand or soil. A previous attempt to distinguish and map CRE vegetation at the association level proved to be extremely difficult, especially for dormant or senescent woody species and ground litter (Ralston and others, 2008). That study used the earliest ADS40 model whose sensor had a limited (8 bit) dynamic range, band misregistration, and near-infrared band saturation. The new ADS40 SH52 data should provide better discrimination among CRE vegetation species, possibly among their dormant or dead occurrences, and definitely among various geologic materials.

\section{Inter-Flightline Calibration}

During the contractor's initial data processing, GCMRC requested that no attempt be made to normalize the band DN between different flightlines because GCMRC examination of test cases produced by the contractor's procedure noted erroneous spectral-band relations relative to GCMRC ground spectra. Therefore, a procedure to calibrate the flightlines had to be developed that would not only retain the correct spectral-band relations but also normalize the effects of variable acquisition (environmental) conditions by cross-correlating the band DN within flightline overlap areas to produce consistent flightline band DN throughout the collection corridor. The image-DN radiance values were not converted to ground reflectance, using the relations listed in figure 12, because that conversion 
might result in a loss of surface information within shaded areas and possibly reduce the dynamic range of the band data.

Before developing this cross-correlation technique, the edges of all flightline image segments were trimmed to remove non-coincident band data and image elements that were averaged with nondata (zeros) during orthorectification resampling. The flightline subblock to which all other flightline subblocks would be normalized had to be selected such that the normalization process would not saturate either end of any band's dynamic range. Therefore, all subblock images were digitally searched to locate the subblock with the least atmospheric scattering and with bare-ground areas having very high band radiance, but the lowest red/near-infrared band ratio. Flight subblock L1 (fig. 7), between river miles 47 (below Eminence Break; fig. 6) and 60 (at the Little Colorado River, LCR), best met these criteria. Subblock L1 was acquired on May $29^{\text {th }}$ at 12:12 p.m. local time, when the solar elevation angle was $75^{\circ}$ and the solar azimuth angle was $166^{\circ}$ (as measured from true north). This river segment trends $\mathrm{S} 22^{\circ} \mathrm{E}$ (or $168^{\circ}$ measured from true north) and was therefore parallel to the down-sun direction during L1 image acquisition, which was not the case for most subblocks.

Designing a flightline cross-calibration procedure required an evaluation of potential environmental parameters that effect recorded radiance at each of the sensor's detectors. The relations between surface reflectance and the major environmental variables that determine a detector's incident radiance (Slater, 1980; Moran and others, 1992) is shown by the following equation:

$$
L_{\lambda}^{T}=\frac{\left[\left(E_{o \lambda} * \tau_{z \lambda} * \cos \varphi_{z}+E_{d \lambda}\right) * \tau_{\nu \lambda} * R_{\lambda} * \cos \theta_{s}\right]}{\pi}+L_{\lambda}^{A},
$$

where $L_{\lambda}^{T}$ is the total recorded radiance at the detector within wavelength band $\lambda$ (watts per square meter $\times$ steradian $\times$ micrometer, W/m ${ }^{2}$ sr $\left.\mu \mathrm{m}\right) ; E_{\mathrm{o} \lambda}$ is the incident solar-spectral irradiance on a surface-normal element (watts per square meter $\times$ micrometer, $\mathrm{W} / \mathrm{m}^{2} \mu \mathrm{m}$ ); $\tau_{\mathrm{z} \lambda}$ is the atmospheric transmission from the Sun to the ground; $\varphi_{\mathrm{z}}$ is the solar-zenith angle (measured from vertical); $E_{\mathrm{d} \lambda}$ is the downwelling spectral irradiance at the surface due to scattered solar flux in the atmosphere $\left(\mathrm{W} / \mathrm{m}^{2} \mu \mathrm{m}\right) ; \tau_{\mathrm{v} \lambda}$ is the atmospheric transmission from the ground to the sensor; $R_{\lambda}$ is the reflectance (ratio) of the surface element within wavelength band $\lambda$, controlled mostly by surface albedo; $\theta_{\mathrm{s}}$ is the surface element slope; and $L_{\lambda}^{A}$ is the upwelling atmospheric radiance, which is solar radiation scattered within the atmosphere and in the direction of the sensor within wavelength band $\lambda\left(\mathrm{W} / \mathrm{m}^{2} \mathrm{sr} \mu \mathrm{m}\right)$ and is commonly referred to as atmospheric haze. Both atmospheric transmission terms have an optical thickness $(\delta)$ parameter (for example, $\tau_{z \lambda}=e^{\frac{-\delta}{\cos \theta_{z}}}$ ). The total radiance that reached the sensor was converted to a 14-bit integer using each detector's gain $\left(G_{\lambda}\right)$ and bias $\left(B_{\lambda}\right)$ settings, both of which remained constant for each detector throughout the data collection. The conversion of a detector's incident radiance to its recorded DN is represented by the following equation:

$$
D N_{\lambda}=G_{\lambda} *\left(L_{\lambda}^{T}+B_{\lambda}\right)
$$

Inter-flightline cross-calibration compared each wavelength band's DN for corresponding surface elements within overlapping parts of different flightlines, thus the detector gain and bias and the surface slope $\left(\theta_{\mathrm{s}}\right)$ and the surface reflectance $\left(R_{\lambda}\right)$ for each surface element can be considered invariant for a particular band image pair. The 2009 image collection used a nadir viewing angle, therefore, $\tau_{\mathrm{v} \lambda}$ is 1.0. However, the Sun-to-ground atmospheric transmission $\left(\tau_{\mathrm{z} \lambda}\right)$ cannot be ignored even under clear sky 
conditions because the solar-zenith angle $\left(\varphi_{z}\right)$ changes with time of day (for example, hourly change on solar-elevation angle, the complement to zenith angle, is shown in fig. 4). A study by Moran and others (1992) determined that the most accurate method for deriving accurate ground-reflectance values from satellite multispectral imagery, based on the factors in equation 1, was a rather complex model derived by Herman-Browning (1965). Evaluating more simple solutions to the model, Chavez (1996) showed that $\cos \varphi_{\mathrm{z}}$ was a good approximation for $\tau_{\mathrm{z} \lambda}$. The downwelling radiance $\left(E_{\mathrm{d} \lambda}\right)$ is only an issue at nearinfrared wavelengths $(0.77-1.20 \mu \mathrm{m})$, which would theoretically affect the near-infrared image data, although Chavez (1996) ignored downwelling radiance and successfully reproduced surface reflectance from visible- and near-infrared-wavelength satellite data. Under scattered-cloud or overcast conditions, such as occurred during this data collection, the incident solar flux $\left(E_{\mathrm{o} \lambda}\right)$ and atmospheric optical thickness $(\delta)$ would modulate and therefore vary the radiance reaching the sensor for a particular surface element between different days and even between different flightlines on a given day. Although the solar flux is different in the four wavelength bands, its modulation by cloud cover would present the same fractional decrease or increase in all bands, but that would not be true for optical thickness. The scattered monsoonal storm cells undoubtedly produced variable amounts of atmospheric vapor that

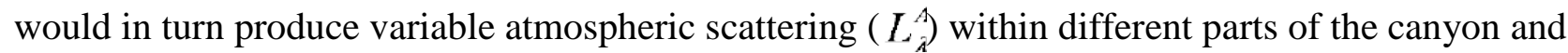
within the same location on different days. For a given atmospheric condition, the amount of atmospheric scattering within the ADS40 wavelength bands exponentially decreases with increasing wavelength ( $1 / \lambda^{4}$ under Rayleigh conditions), which increases the recorded radiance (or DN) much more in band 1 than in band 4 . Considering the factors discussed above, equation 1 can be simplified to the following equation:

$$
L_{\lambda}^{T}=\frac{\left[\left(E_{o \lambda} * \cos ^{2} \varphi_{z}\right) * R_{\lambda} * \cos \theta_{s}\right]}{\pi}+L_{\lambda}^{A} .
$$

When comparing a particular band's DN for corresponding image elements between two overlapping flightlines, the surface slope $\left(\theta_{\mathrm{s}}\right)$ and intrinsic reflectance $\left(R_{\lambda}\right)$ and the detector gain $\left(G_{\lambda}\right)$ and bias $\left(B_{\lambda}\right)$ would be the same and the correlation would be controlled mostly by the environmental factors (that is, $E_{\mathrm{o} \lambda}, \tau_{\mathrm{z} \lambda}, L_{\lambda}^{A}$ ). Correlation of band data between two overlapping flightlines would essentially correlate the two band-image linear relations, which would also result in a linear relation. These inter-flightline band relations were modeled by collecting the image-band DN of corresponding surface elements between overlapping flightlines. For each inter-flightline correlation, a digital-image mask was produced for the independent (base) image having water, land, and exclusion polygons with different numeric codes. The exclusion areas consisted of image smears, cloud shadows, and topographic shadows because these variable features within either flightline would produce erroneous solutions. The image-pair analysis provided a separate solution for land elements and for combined land and water elements. The solution derived from only land elements was used when the Colorado River's sediment load was different between an image pair (fig. 14), which was common for the corridor below the LCR because of storm-induced sediment surges from flooding in that tributary. The analyses of both sets of collected band data for each pair of overlapping flightlines used two different methods for linear regression-(1) a least-squares method that minimized the chi-square error statistic and (2) a method that used a robust least absolute deviation approach that gives less weight to outlier data points. Both regression methods were applied twice to the land and land-water datasets; the first application used all the individual data points and the second application used the average dependent (y) image values for each independent (x) image value. The second application gave more equal weight to less populated, but potentially important, image DN that might better define the true linear relations for an image pair. 
Thus, eight linear solutions were obtained for each band within an image pair. The band data collected for each image pair were also examined graphically to detect and remove anomalous image issues, which required reanalysis of the edited images. The ultimate test of the different band solutions for each image pair was to apply each set of band equations to the dependent image, to mosaic the midsection of the modified dependent image onto its overlapping independent image, and to inspect the resulting mosaic for visible seams along edges of the modified subsection. This procedure initially used the L1 images as the independent data and progressively cross-correlated adjacent subblocks, both upstream and downstream of subblock L1, using the most recent correlated and modified subblock image as the independent data for each successive subblock.

Comparison of the regression slopes from all the flightline cross-correlations with their corresponding values of $\frac{\cos \varphi_{z y}}{\cos \varphi_{z x}}$ (in fig. 15A) and $\left(\frac{\cos \varphi_{z y}}{\cos \varphi_{z x}}\right)^{2}$ (in fig. 15B) shows that the cosine squared function has a more direct relation to the cross-correlation slopes, and, therefore, $\cos \varphi_{z}$ may be a surrogate for atmospheric transmission, as suggested by Chavez (1996). However, the correlation coefficient is quite low (0.366), even excluding the anomalous outlier points (that is, points greater than one standard deviation from the regression line, which are colored red and yellow in fig. 15). The string of anomalously high slope values (red points, fig.15) consist mostly of flightlines upstream of the L1 subblock and mostly within the M6 and M7 subblocks (fig. 7). The cluster of anomalously low slope values (yellow points, fig. 15) consist of flightlines downstream of the L1 subblock and mostly within the K1 subblock (fig. 7). No consistent reason could be found for either group of anomalous points. Other flightlines collected near the same time on the same days (thus the same atmospheric conditions), or for river segments having similar orientations to solar azimuth, do not have anomalous slope values.

\section{Corridor Image-Mosaic Production}

Construction of the image mosaic for the CRE started at Glen Canyon Dam and proceeded downstream to the entrance of Lake Mead (fig. 1), incrementally producing a single image tile due to the large size of each map tile for the CRE (the image tiles correspond to USGS quarter quadrangle map boundaries as shown in fig. 16). The flightline image having the least surface distortion and cloud and topographic shadows was used as the base image (until its quality degraded); defects within the base image were covered with higher quality sections of overlapping flightline images. Image mosaicking extended well into the adjacent downstream image tile before subsetting the mosaic along the current image-tile boundary, to provide a seamless image-tile transition, with a 20 -m overlap between adjacent image tiles. The image tiles were visually examined by an independent scientist to detect and record image defects. All recorded image defects were then evaluated with the flightline image coverage and, where possible, defects were removed.

\section{Results and Discussion}

The defects remaining in the final image mosaic consist of (1) scarp or scarp-base surface smear, (2) cloud shadow or areas of overcast, and (3) abrupt changes in mainstem color. Upstream of the LCR, there are no noticeable mainstem color changes, but downstream of the LCR there are noticeable, and several abrupt, mainstem color changes (fig. 17 shows the worst instance). The highest priority was to produce a flawless image mosaic for all land area because, beyond the LCR, the mainstem water had suspended sediment whose concentration (and water color) varied daily because of monsoonal storms that produced periodic LCR sediment input. 
Table 3 lists the specific locations having surface smear or cloud shadow, and figure 18 shows their general locations. There are only six areas with surface smear; examples for the six areas are shown in figures 19-24. The surface smear in each of the first five areas is very minor (figs. 19-23) and their combined length is only $1.6 \mathrm{~km}$. Area 6 (1.3 km long) has surface smear on both sides of the river-river left has very minor scarp smears (fig. 24A), and river right has the worst surface smears (figs. 18 and 24B), but the smearing is confined to basal scarps above the $7,079 \mathrm{~m}^{3} / \mathrm{s}$ flow stage, where most GCMRC monitoring does not occur. The combined 2.9-km length of surface smear within the corridor's entire image mosaic represents a very minor fraction of the 450-km-long corridor and is significantly less than the surface smear in the 2002 and 2009 image mosaics.

There are three areas that have scattered cloud shadows or are mostly overcast (green boxes in fig. 18). The area within box 3 in figure 18 has the most extensive overcast condition (for example, fig. 25) because the weather never improved during data collection at the west end of the collection area. Although cloud cover is not desirable because it inhibits standardized, corridorwide image analysis for resource monitoring, it is not a detrimental factor for two reasons. First, GCMRC does not generally monitor the CRE beyond river mile 240 (fig. 18), where the largest area of overcast conditions resides (box 3 in fig. 18), because this part of the river is typically inundated by upper Lake Mead. Second, the image data having cloud shadows or extensive overcast conditions can still be analyzed and interpreted, but analyses will require special attention within sunlit-shadow transition zones and adjustments in analytical procedures for shadowed/overcast areas to take into account the reduced solar flux (and consequently surface reflectance) relative to the majority of the sunlit image mosaic. In spite of the cloud-shadow areas and small stretches of surface smear, the quality of the 2009 image mosaic is excellent compared to GCMRC's previous (2002 and 2005) digital-image mosaics. In fact, the 2009 image mosaic is by far the best image database that now exists for the entire CRE, considering the database's quality, consistency, resolution and number of wavelength bands.

Visual comparisons between the 2009 image mosaic and the 2005 and 2002 image mosaics demonstrate that this may be the best image database that now exists for the entire CRE for the various physical, cultural, and biological resources that are monitored within the CRE. For example, the main physical resources monitored by GCMRC consist of unconsolidated sediment deposits that serve as terrestrial and aquatic habitats and camping beaches. The deposits range from fine-grained sandbars to coarse-grained debris flows and their associated cobble bars. These deposits are affected by dam flow releases, aeolian redistribution, and mass wasting. Figure 26 compares 2009, 2005, and 2002 naturalcolor images for an area within South Canyon (RM 30.7; fig. 1) where sandbars are routinely ground surveyed. This image set demonstrates the superior clarity and color fidelity and the absence of surface defects within the 2009 image data (fig. 26A) compared to the 2005 (fig. 26B) and 2002 (fig. 26C) digital-image mosaics. The 2009 image (fig. 26A) provides superior potential to delineate and map the areal extent and geomorphology of subaerial sandbars, as well as their adjacent shallow-water deposits (mainly upstream of the LCR in 2009) compared to the previous image data (figs. 26B, $C$ ). The superior clarity and color fidelity of the 2009 image data, which also extend to bedrock geology within the river corridor (as shown by fig. 27, depicting the granitic terrain near Phantom Ranch at RM 87.0; fig. 1), can assist USGS geologists who produce geologic maps of the Grand Canyon. The 2009 image data accurately depict differences in the alluvium (for example, along the Bright Angel Trail across the river from Phantom Ranch; figs. 1 and 28) that are directly related to changes in the underlying bedrock and can be used to infer contacts between buried bedrock units, a fact which also means that the image data might be used to detect eolian redistribution of sandbar deposits into and within adjacent alluvial units.

Three important issues related to cultural resources within the Grand Canyon are (1) human disturbance of archaeological sites, (2) direct or indirect (arroyo) erosion of archaeological sites 
resulting from rain-induced overland flow events, and (3) potential reduction in beach area available for camping resulting from sandbar erosion or vegetation encroachment. Surficial disturbance of arid and semiarid terrain, especially by repetitive walking and trampling, can be detected in image data with sufficient resolution and color fidelity because repetitive traverses across such terrain decreases grain and aggregate size and exposes less weathered material, both of which produce a brighter surface. The path to a petroglyph site in Glen Canyon at RM -10.2 (figs. 1 and 29) demonstrates this effect. The superior color fidelity of the bedrock and alluvium in the 2009 data (fig. 29A) relative to that in the 2005 (fig. 29B) and 2002 (fig. 29C) image mosaics is obvious. In terms of monitoring alluvial and fluvial modifications at archaeological sites along the river corridor, the 2009 image data provide the superior color fidelity and discrimination needed to map geologic and geomorphologic surficial units and the modification and redistribution of these surficial materials with time. For example, comparison of the geomorphic map of Hereford (1996; fig. 30) with the 2009, 2005, and 2002 natural-color images of the Palisades Creek area (RM 67.5; figs. 1 and 31) suggests that the color detail provided by 2009 image data would allow detection of subtle temporal changes in geomorphic unit areal distribution, gully erosion, and arroyo development, if such data can be obtained in future collections. The 2009 image data also provide a useful tool for monitoring current human habitations within Grand Canyon, as demonstrated by the time series represented by image mosaics of Phantom Ranch (fig. 32).

The ability to easily and accurately map changes in vegetated area within the corridor can support a diverse range of management and research activities, such as monitoring campsite quality and monitoring avian and insect habitat quality, which influences the aquatic foodbase. Changes in climate and dam flow release can also affect the composition of the vegetation along the corridor (for example, xeric versus riparian, native versus nonnative). The 2009 image data provide superior capability for mapping vegetation, relative to previous GCMRC image data, because of the data's large dynamic range, lack of band saturation, and high color fidelity. This is demonstrated for a vegetation site within the Palisades Creek area (RM 68.5; fig. 33); the 2009 image shows distinct color differences between vegetation types (fig. 34A), where it is obvious that previous mapping efforts using the 2002 image data (fig. 34C, which are superimposed on the images) confused tamarisk and arrowweed, both of which are very distinct in the 2009 data and less distinct in the 2005 data (fig. 34B). Upstream of this site at RM 67.5 (fig. 35), the 2009 image data clearly show the dark-green honey mesquite (Prosopis glandulosa), green tamarisk, brighter green coyote willow (Salix exigua) (all with texture), and the smoother, darkgreen wetlands vegetation. The precise coregistration of the 2002, 2005, and 2009 image data underlines their utility for change-detection analyses, such as quantifying the growth and expansion rates of vegetation (for example, vegetation encroachment on camping beaches), as shown by the image series for a beach area near Phantom Ranch (RM 87.0; fig. 36).

\section{Conclusions}

Analysis of the ADS40 SH52 four-band digital imagery collected for the Arizona part of the Colorado River ecosystem in 2009 indicates (1) no appreciable signal saturation in any band image, (2) the blue-band image has a 12-bit dynamic range, whereas the other three bands (green, red, and nearinfrared) have a 14-bit dynamic range; (3) the image DN values in all bands are linear relative to ground reflectance; and (4) the band-image noise levels, in terms of relative reflectance, are $0.53,0.28,0.22$, and 0.31 percent in the blue, green, red, and near-infrared wavelength images, respectively. This level of image noise allows discrimination and classification of the various geologic, geomorphic, and vegetation units of interest to GCMRC for monitoring the effects of Glen Canyon Dam operations on physical, biological, and cultural resources within the CRE. The flightline cross-correlations applied in this study and the careful selection of optimal flightline segments for the final image mosaic retained the 
intrinsic dynamic range of the data, insured band-DN consistency throughout the canyon, and minimized image defects in the final image mosaic. The final mosaic contains only $2.9 \mathrm{~km}$ of scarpsmear defects, most of which are minor, within the entire 450-km length of the corridor mosaic.

The final corridor image mosaic consists of 143 overlapping, seamless image tiles that correspond to USGS quarter-quadrangle map boundaries. This report provides visual comparisons of the 2009 image mosaic, relative to the 2002 and 2005 image mosaics, for various monitoring objectives within the CRE. These image comparisons demonstrate the superior image clarity, surface color fidelity, and dynamic range of the 2009 image mosaic relative to the two previous digital data collections. Although the GCMRC will be analyzing these data for a number of ecosystem parameters, the data are available, upon request, to the general public.

\section{Acknowledgments}

The author wishes to thank the multitudes of people involved in the data collection that were not directly involved in this report. Mike Ebersole, Grand Canyon Interagency Aviation Officer, National Park Service; Robert Mesko, Contract Officer, U.S. Army Corps of Engineers; Richard Clayton, Thomas Ryan, and Malcolm Wilson, Bureau of Reclamation; Jeffrey Ackerman, Jennifer Turnbull, and Jeanette Telshow, Western Area Power Authority (Montrose); Burt Hawkes and Clayton Palmer, Western Area Power Authority (Salt Lake City); Carol Fritzinger, Logistics Coordinator, GCMRC; Mark Santee, Helicopter Pilot, Bureau of Reclamation; Thomas Gushue, Keith Kohl, Erik Hornaday, Meagan Polino, Robert Tusso, GCMRC; Nate Schott, Matthew Kaplinski, Joseph Hazel, and Jered Hansen, Northern Arizona University; Michael Dennis, Earl Watts, GCMRC Contractors; Emmet McGuire, Jeff Kennedy, Nancy Hornewer, Michael Hoering, USGS Arizona Water Science Center; and Karen Koestner, U.S. Forest Service, for GPS basestation operations; and the planning, ground, and flight crews at EarthData who made every effort to acquire the best data under very difficult weather conditions. Funding for this work was provided through the Glen Canyon Adaptive Management Program of the U.S. Bureau of Reclamation.

\section{References}

Baynes, Jack, 2007, The reflectance signature of canopy components-Implications for the interpretation of remotely sensed images: Annals of Tropical Research, v. 29, p. 21-31.

Chavez, P.S., 1996, Image-based atmospheric corrections-revisited and improved: Photogrammetric Engineering and Remote Sensing, v. 62, p. 1025-1036.

Davis, P.A., 2004, Review of results and recommendations from the GCMRC 2000-2003 remotesensing initiative for monitoring environmental resources within the Colorado River ecosystem: U.S Geological Survey Open-File Report 2004-1206, 73 p., accessed May 29, 2012, at http://pubs.usgs.gov/of/2004/1206/.

Fricker, Peter, 2007, Raising the bar for multi-band, high-resolution airborne imagery, in Fritsch, D., ed., Photogrammetrische Woche 2007 [Photogrammetric Week 2007]: University of Stuttgart, Institute für Photogrammetrie, p. 71-79, accessed May 29, 2012, at http://www.ifp.unistuttgart.de/publications/phowo07/phowo07.htm.

Hereford, Richard, 1996, Map showing surficial geology and geomorphology of the Palisades Creek area, Grand Canyon National Park, Arizona: U.S. Geological Survey Miscellaneous Investigations Map I-2449, 1:2,000 scale.

Herman, B.M., and Browning, S.R., 1965, A numerical solution to the equation of radiative transfer: Journal of Atmospheric Science, v. 22, p. 59-66. 
Kellenberger, T.W., and Nagy, P., 2008, Potential of the ADS40 aerial scanner for archaeological prospection in Rheinau, Switzerland: International Archives of the Photogrammetry, Remote Sensing and Spatial Information Sciences, International Society for Photogrammetry and Remote Sensing Congress Beijing 2008, v. XXXVIII, part B4, p. 1871-1878, accessed May 29, 2012, at http://www.isprs.org/proceedings/XXXVII/congress/4_pdf/326.pdf.

Markelin, Lauri, Honhavaara, Eija, Peltoniemi, Jouni, Ahokas, Eero, Kulttinen, Risto, Hyppa, Juha, Suomalainen, Juha, and Kukko, Antero, 2008, Radiometric calibration and characterization of largeformat digital photogrammetric sensors in a test field: Photogrammetric Engineering and Remote Sensing, v. 74, p. 1487-1500.

Moran, M.S., Jackson, R.D., Slater, P.N., and Teillet, P.M., 1992, Evaluation of simplified procedures for retrieval of land surface reflectance factors from satellite sensor output: Remote Sensing of Environment, v. 41, p. 169-184.

Ralston, B.E., Davis, P.A., Weber, R.M., and Rundall, J.M., 2008, A vegetation database for the Colorado River ecosystem from Glen Canyon dam to the western boundary of Grand Canyon National Park, Arizona: U.S. Geological Survey Open-File Report 2008-1216, 37 p., accessed May 29, 2012, at $h t t p: / / p u b s . u s g s . g o v / o f / 2008 / 1216 /$.

Sims, D.A., and Gamon, J.A., 2002, Relationships between leaf pigment content and spectral reflectance across a wide range of species, leaf structures and developmental stages: Remote Sensing of Environment, v. 81, p. 337-354.

Slater, P.N., 1980, Remote sensing—Optics and optical Systems: Reading, Mass., Addison-Wesley, $575 \mathrm{p}$. 
Table 1. Image ground resolution predicted from flight altitudes for 2009 airborne digital-image data collected for the Arizona part of the Colorado River ecosystem below Glen Canyon Dam. [m, meters]

\begin{tabular}{ccc}
\hline Flightline Block $^{1}$ & $\begin{array}{c}\text { Flight Altitude } \\
(\mathbf{m})\end{array}$ & $\begin{array}{c}\text { Estimated Ground Resolution } \\
(\mathbf{m})\end{array}$ \\
\hline A & 9,000 & 0.29 \\
B & 7,700 & 0.24 \\
C & 6,550 & 0.21 \\
D & 7,050 & 0.22 \\
E & 5,650 & 0.18 \\
F & 8,650 & 0.27 \\
G & 6,600 & 0.21 \\
H & 6,200 & 0.20 \\
I & 6,150 & 0.20 \\
J & 6,000 & 0.19 \\
K & 6,550 & 0.21 \\
L & 6,050 & 0.19 \\
M & 5,950 & 0.19 \\
\hline
\end{tabular}

${ }^{1}$ Flightline block locations shown in figures 2 and 7. 
Table 2. Global positioning system (GPS) base stations, with calculated errors, operated along the Grand Canyon's rims during 2009 overflights for airborne digital-image data collection for the Arizona part of the Colorado River ecosystem below Glen Canyon Dam.

[m, meters; cm, centimeters]

\begin{tabular}{|c|c|c|c|c|c|}
\hline Station symbol ${ }^{1}$ & Northing (m) & Easting (m) & Ellipsoid height (m) & Horizontal error $(\mathrm{cm})$ & Vertical error (cm) \\
\hline ABYSS & $561,057.576$ & $189,312.040$ & $2,054.508$ & 0.18 & 0.47 \\
\hline AIRP & $567,493.740$ & $21,773.478$ & 870.271 & 0.22 & 0.51 \\
\hline AZPG & $655,431.227$ & $253,814.755$ & $1,302.735$ & 0.00 & 0.00 \\
\hline BIG & $575,161.874$ & 233,739.986 & $1,690.953$ & 0.40 & 2.15 \\
\hline CAVE & $590,404.577$ & $155,223.038$ & $1,888.063$ & 0.45 & 2.37 \\
\hline DAVN & $586,850.842$ & $110,161.410$ & $1,427.843$ & 0.22 & 0.55 \\
\hline DSVW & $559,039.783$ & $221,146.269$ & $2,263.384$ & 1.10 & 5.65 \\
\hline DWARF & $552,686.893$ & $41,964.056$ & $1,457.172$ & 0.44 & 2.38 \\
\hline EMIN & $599,267.977$ & $221,056.277$ & $1,742.547$ & 0.25 & 0.61 \\
\hline EMIN1 & $599,273.182$ & $221,047.556$ & $1,741.408$ & 0.27 & 1.45 \\
\hline FRAZ & $531,156.394$ & $108,815.597$ & $1,816.051$ & 0.30 & 0.80 \\
\hline JACK & $640,337.139$ & $237,023.460$ & $1,153.351$ & 0.43 & 2.31 \\
\hline LFRG & $650,118.387$ & $241,496.162$ & 968.944 & 0.25 & 0.69 \\
\hline SALT & $578,405.105$ & $233,101.608$ & $1,701.717$ & 0.44 & 2.35 \\
\hline SBPT & $588,226.775$ & $130,326.855$ & $1,717.381$ & 0.36 & 1.90 \\
\hline SHIV & $537,295.752$ & $72,979.489$ & $1,824.667$ & 0.41 & 2.30 \\
\hline SIGN & $573,510.323$ & $173,712.793$ & $2,042.394$ & 0.34 & 1.33 \\
\hline T96 & $510,194.575$ & $84,733.737$ & $1,592.401$ & 0.25 & 0.71 \\
\hline TEA & $556,125.538$ & $42,402.075$ & $1,433.709$ & 1.34 & 6.66 \\
\hline TMP314 & $657,246.653$ & $255,080.846$ & $1,275.208$ & 1.07 & 5.11 \\
\hline TMP336 & $550,360.875$ & $193,708.997$ & 1,991.339 & 0.77 & 3.59 \\
\hline WHIT & $575,507.991$ & $92,400.167$ & $1,650.435$ & 0.26 & 1.47 \\
\hline
\end{tabular}

${ }^{1}$ Station locations shown on figure 5. 
Table 3. Defects within the image mosaic for 2009 airborne digital-image data collected for the Arizona part of the Colorado River ecosystem below Glen Canyon Dam.

[River miles are measured relative to Lees Ferry, which is mile 0; river miles are negative upstream of Lees Ferry]

\begin{tabular}{lcccc}
\hline Type of defect & Map location $^{1}$ & River mile & Map quadrangle & Description \\
\hline Surface smear & Point 1 & -16.0 & SW36111H4 & Building and scarp smears \\
Surface smear & Point 2 & $4.6-5.3$ & NE36111G6 & Scarp and shoreline smears \\
Surface smear & Point 3 & 76.5 & SE36111A8 & Very minor scarp smears \\
Surface smear & Point 4 & $149.1-149.4$ & NE36112C6 & Minor scarp smears \\
Surface smear & Point 5 & 156.0 & NE36112C7 & Very minor scarp smears \\
Surface smear & Point 6 & $184.5-185.4$ & SE36112B2 & Scarp smears \\
Cloud shadows & Box 1 & $174.7-176.4$ & NE36113B1 & Scattered cloud shadows \\
Cloud shadows & Box 2 & $196.4-206.2$ & All 36113A3 & Scattered cloud shadows and \\
overcast areas \\
Cloud shadows & Box 3 & $240.0-280.0$ & NW35113G5 to & Scattered cloud shadows and \\
\end{tabular}

${ }^{1}$ Locations shown on figure 18. 


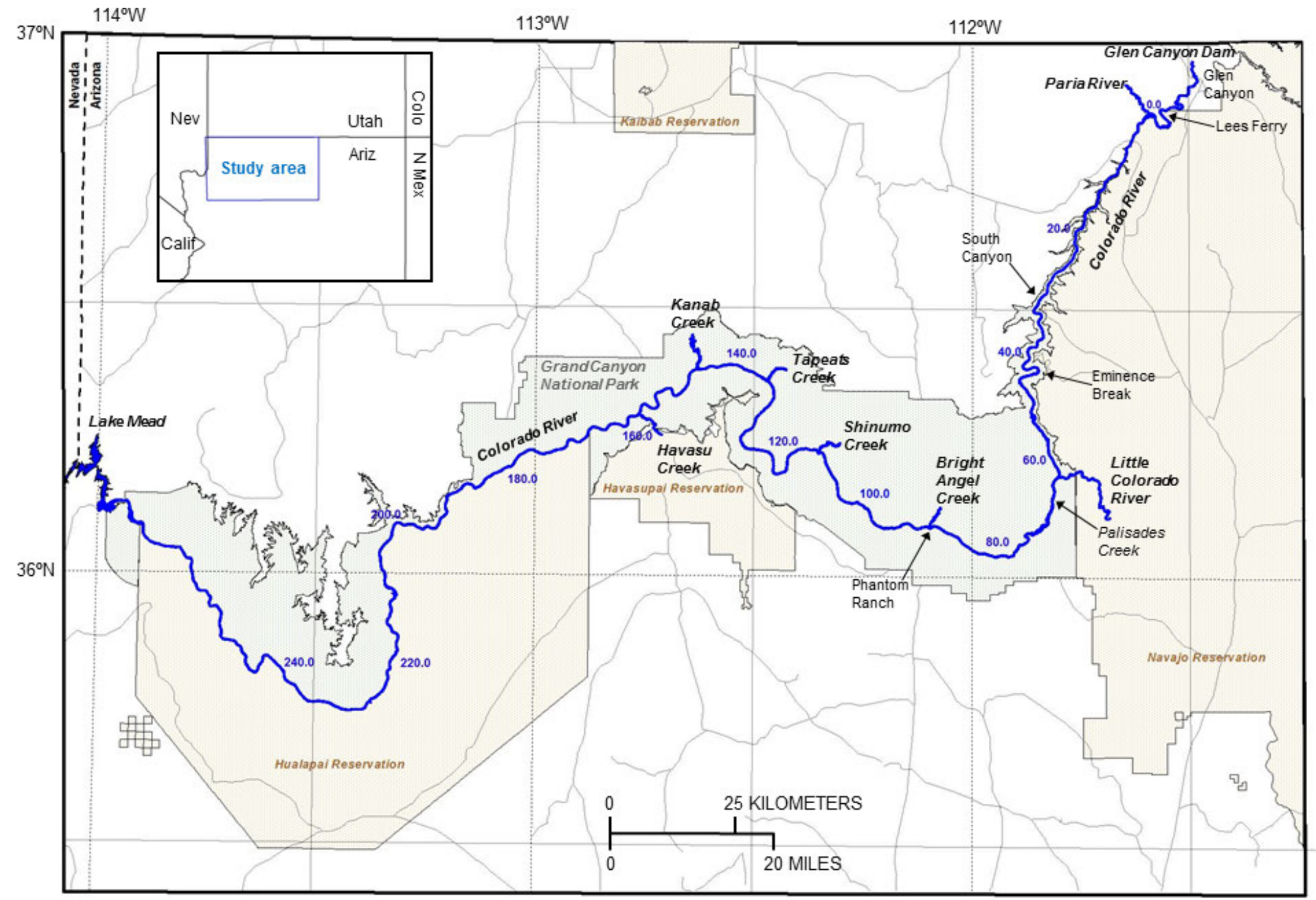

Figure 1. Map of the Colorado River corridor in Arizona that is monitored by the U.S. Geological Survey's Grand Canyon Monitoring and Research Center (GCMRC). Blue line traces the course of the Colorado River; gray lines are roads and trails. Blue decimal numbers are river miles from Lees Ferry (river mile 0.0; river miles are negative upstream of Lees Ferry); Glen Canyon Dam is at river mile -16.0 . 


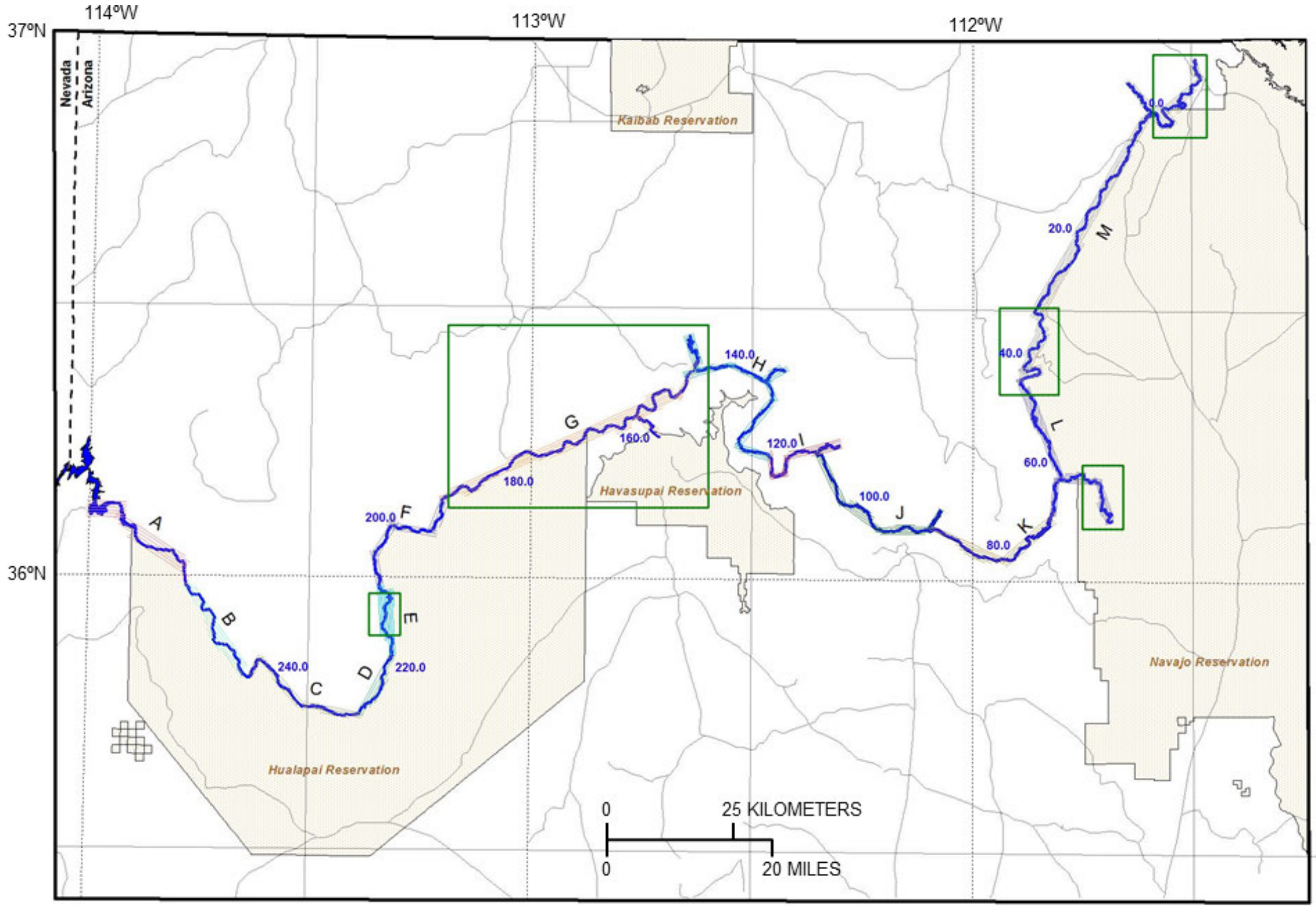

Figure 2. Map of sets of parallel flightlines constituting flight blocks (lettered A-M) proposed for the 2009 airborne digital-image data collection for the Arizona part of the Colorado River ecosystem below Glen Canyon Dam. Flightline colors within each flight block were arbitrarily assigned to distinguish flight blocks. Green boxes are river segments that required more time-constrained data acquisition (11 a.m. and 1 p.m.). 
A

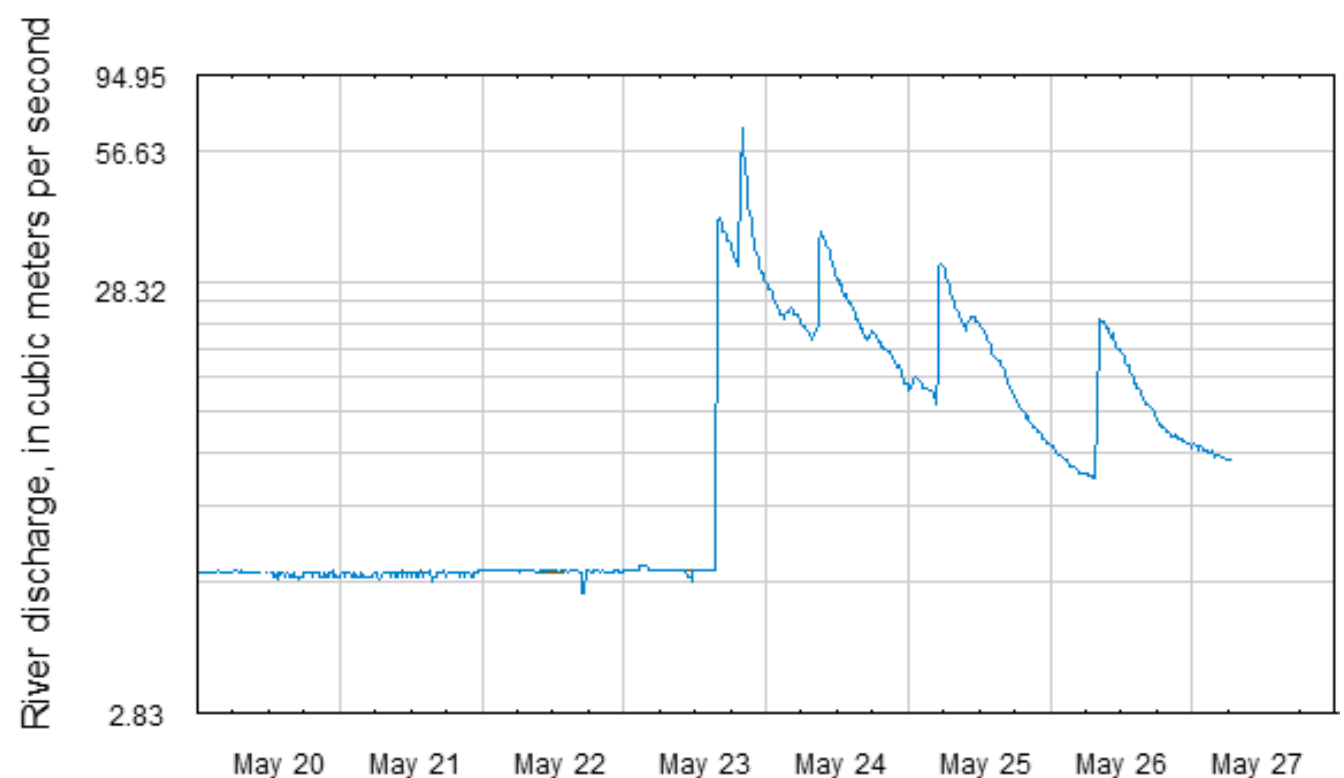

Date 2009

$B$

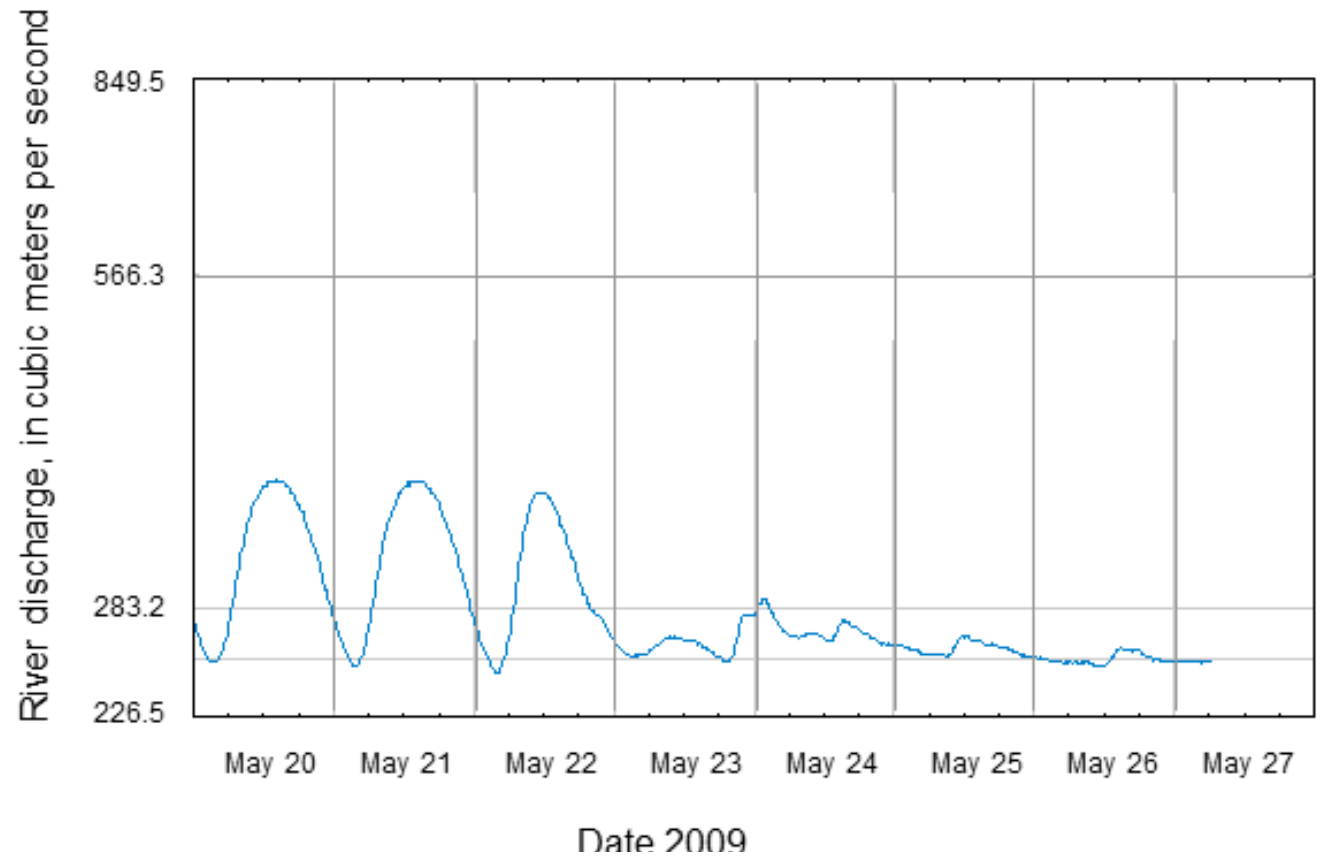

Figure 3. Relevant stream gage data during the early part of flight mission. Afternoon monsoon showers produced discharge spikes at the Little Colorado River (LCR) stream gage $09402300(A)$, which reached the Grand Canyon stream gage 09402500 (B) within 3 hours and required 10 hours to clear the collection area. The Paria River stream gage 09382000 (C) near Lees Ferry (river mile 0.0) showed no appreciable inflow to the mainstem, which retained the dam's prescribed low steady flow levels down to the LCR. 
C

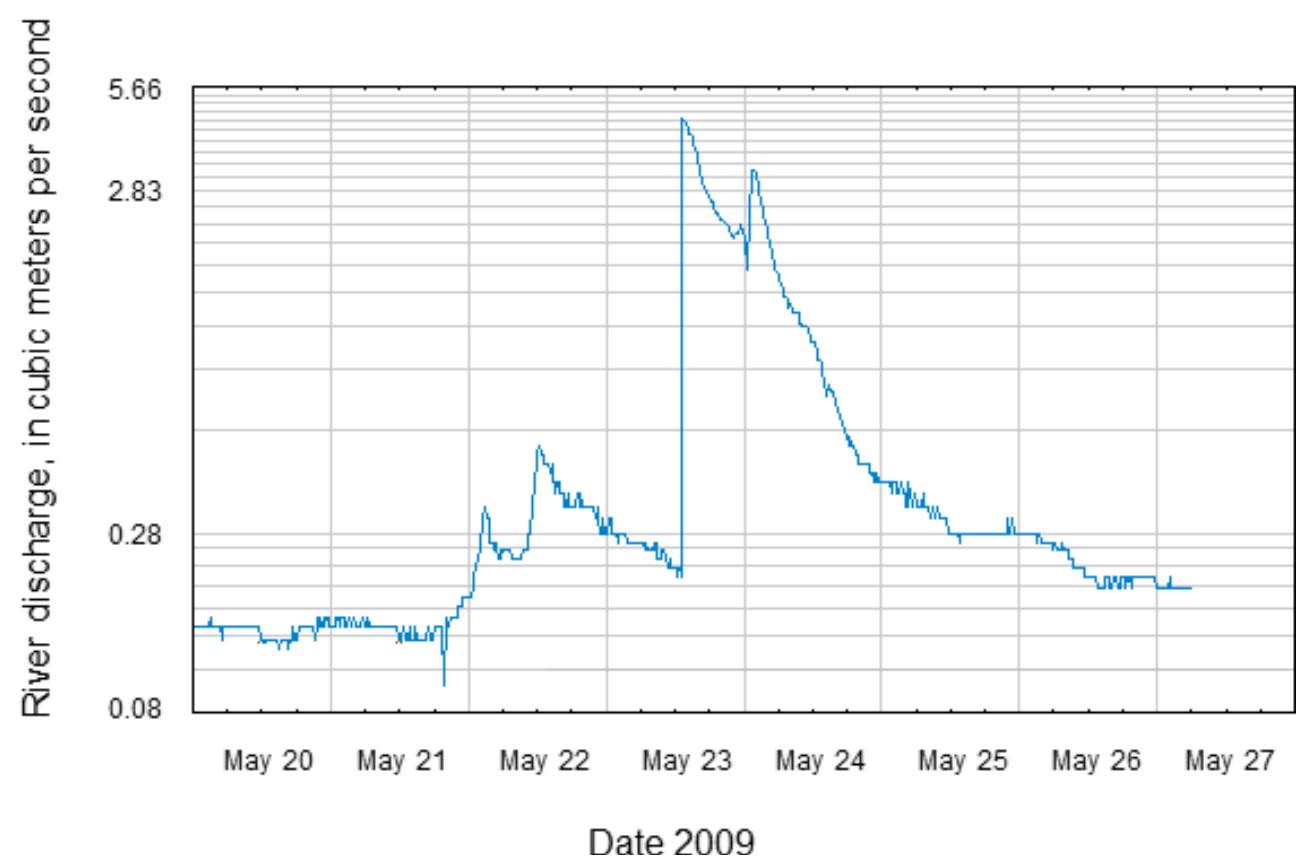

Figure 3.-Continued. 


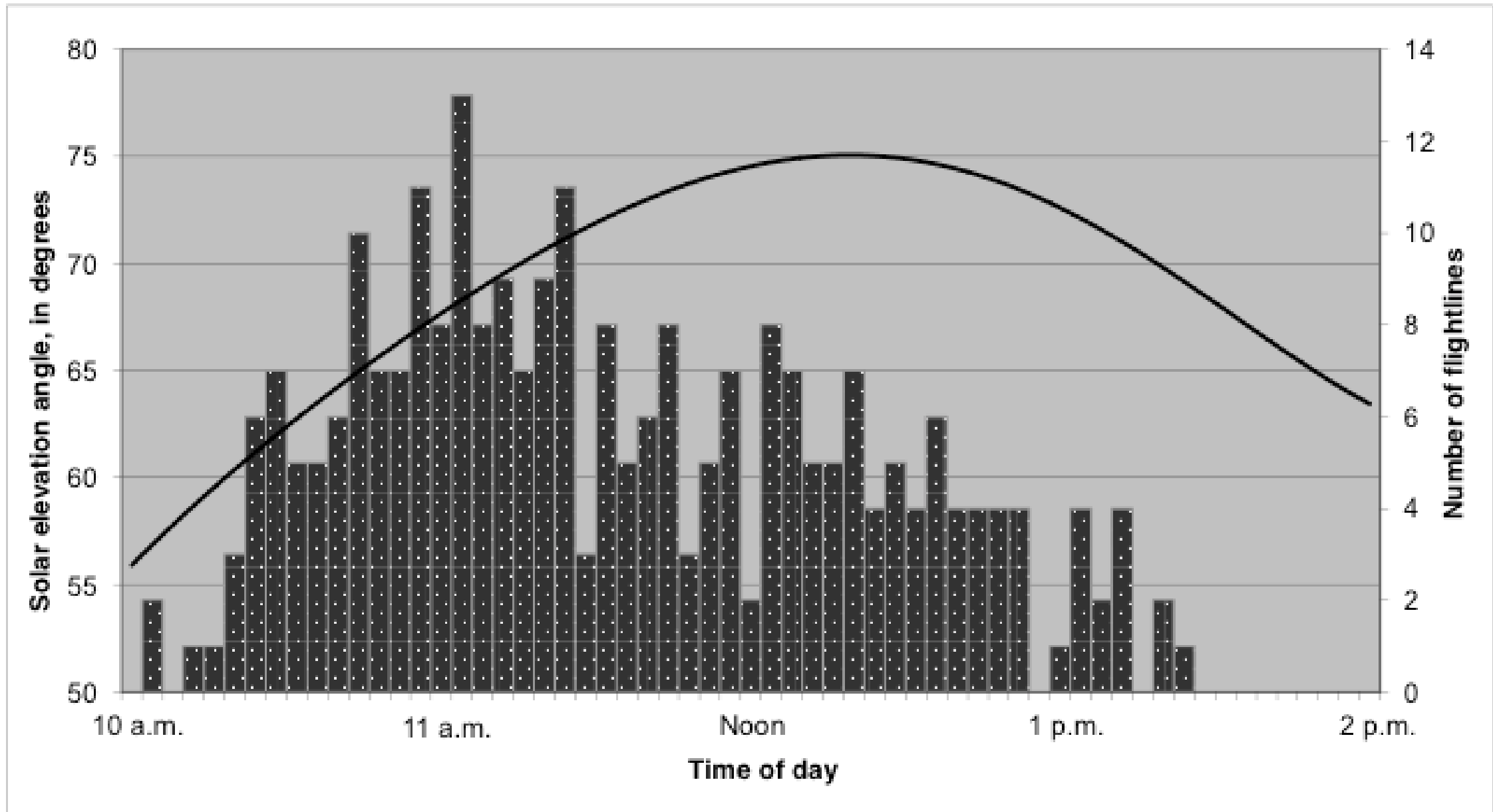

Figure 4. Variation in solar-elevation angle (black curvilinear line) during the daily extended flight window. Numbers of flightlines acquired at different times are shown as vertical bars. 


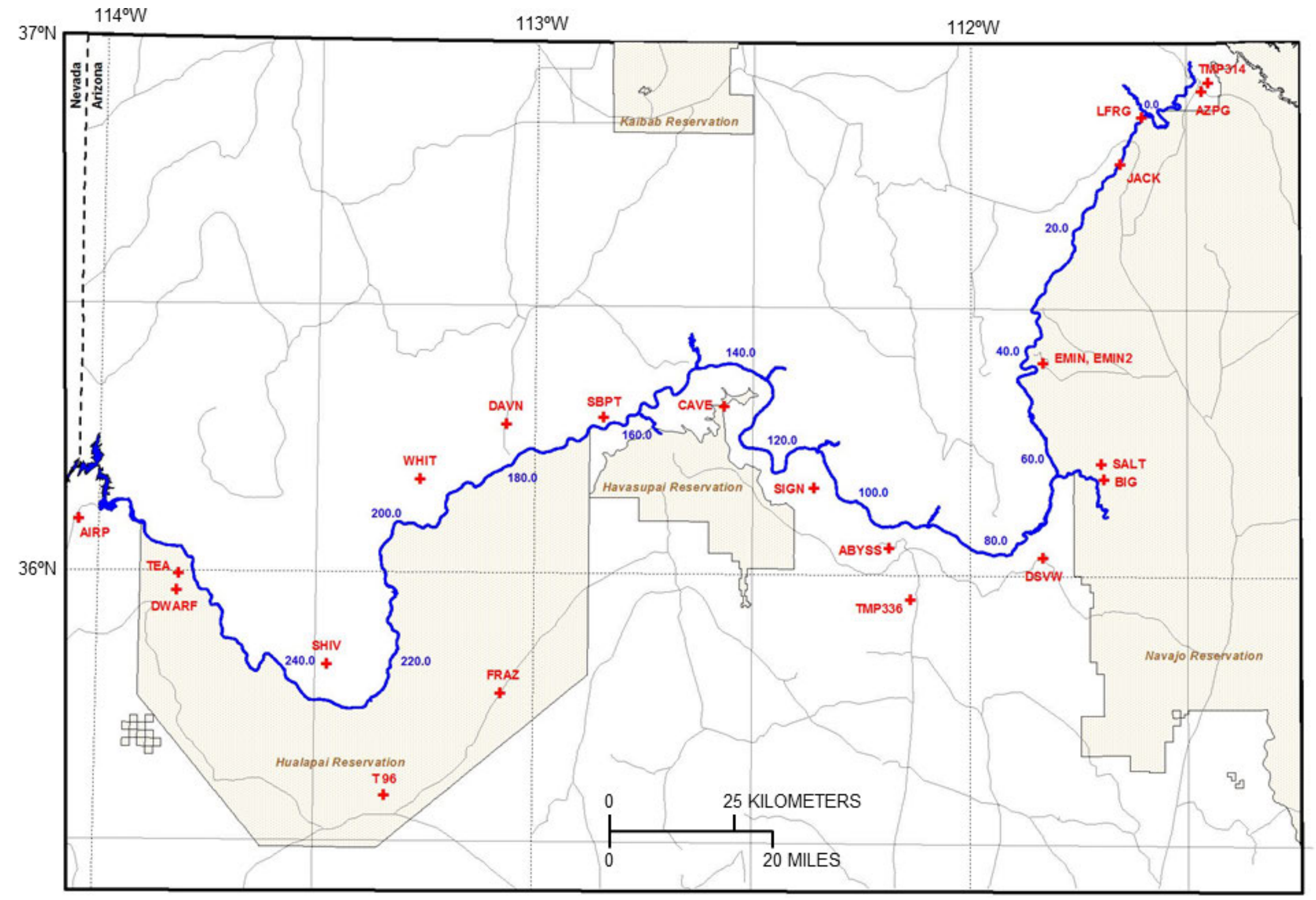

Figure 5. Map of the global-positioning-system (GPS) base stations (red crosses) operated on the rims of the Grand Canyon during data collection. 


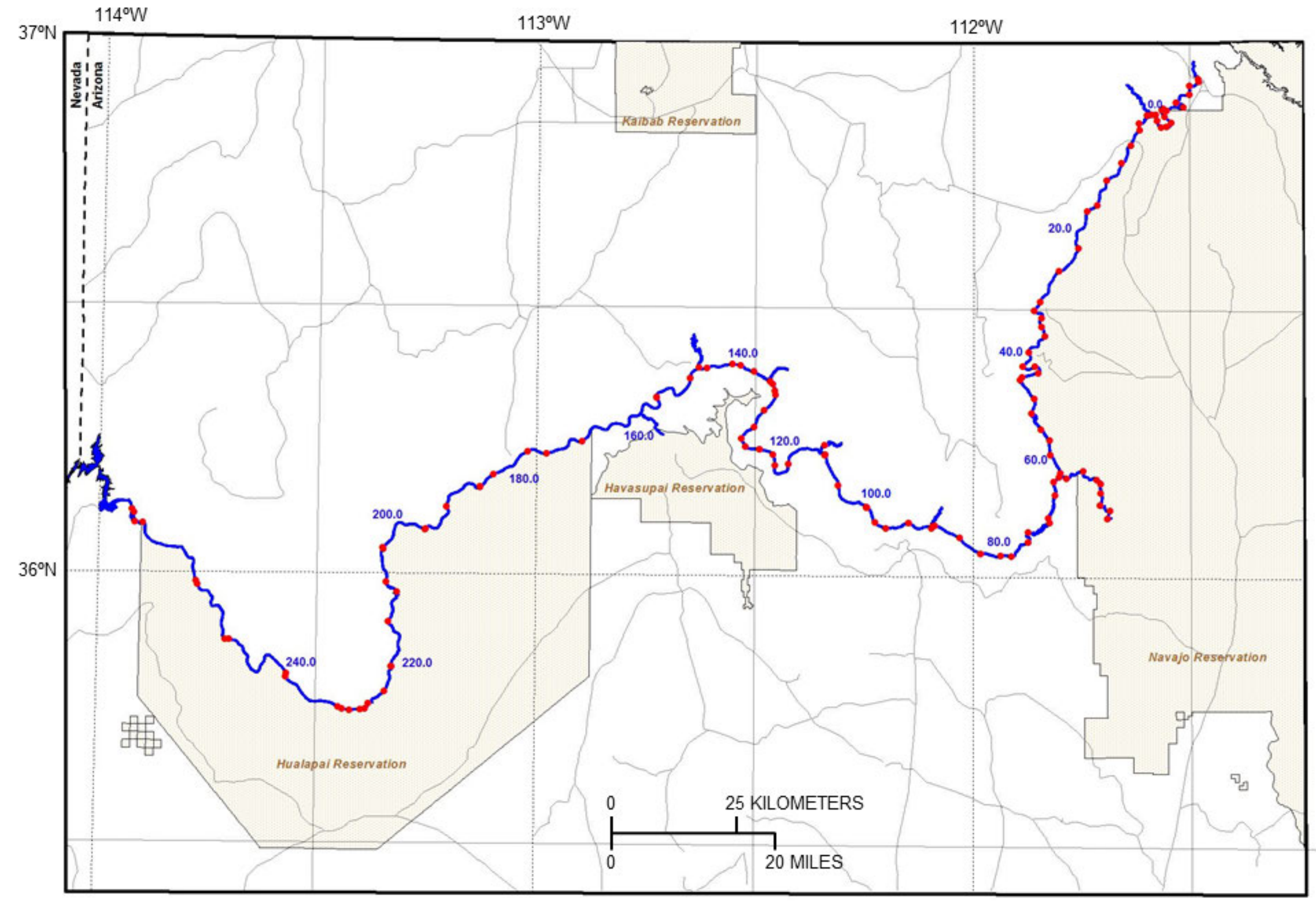

Figure 6. Map of the ground-control panels (red dots) that were positioned before data collection and used during aerotriangulation to improve positional accuracy of the imagery and vertical accuracy of the digital surface model (DSM). 


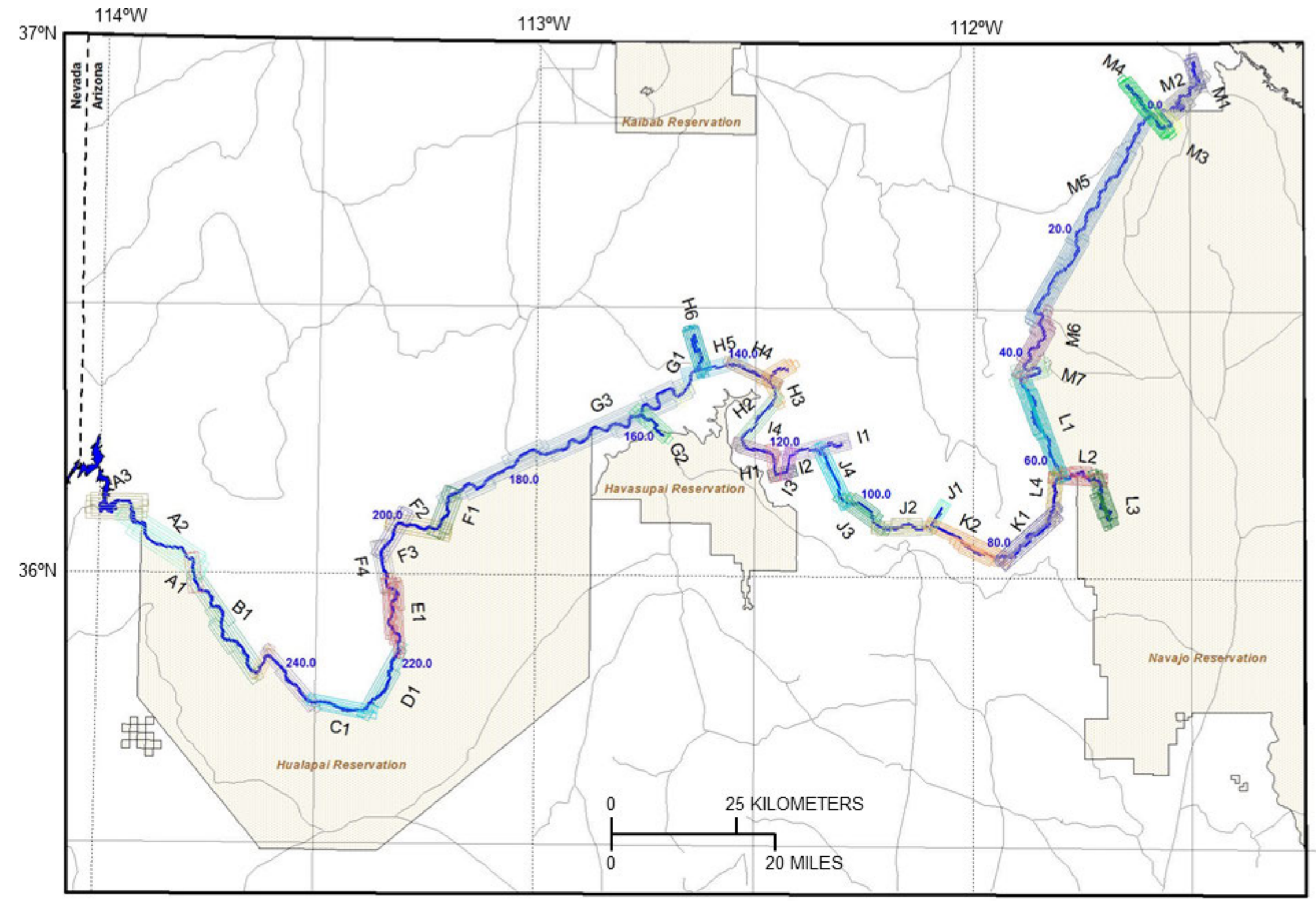

Figure 7. Map of the actual 42 subblocks of flightlines that were collected during the mission. 


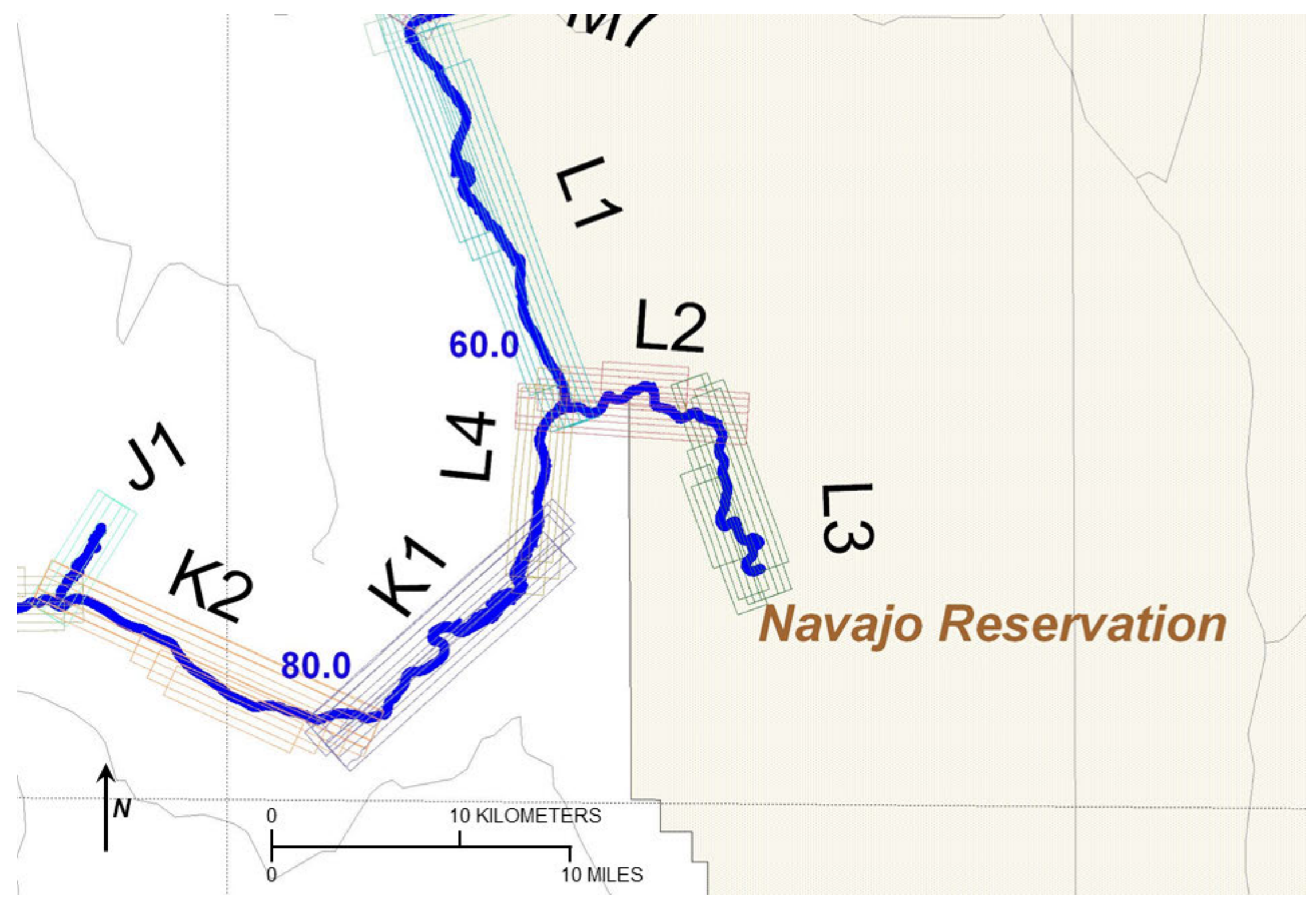

Figure 8. Enlarged view of figure 7 at the Little Colorado River showing the number and amount of sidelap of subblock flightlines and the amount of flightline overlap between adjacent subblocks. 


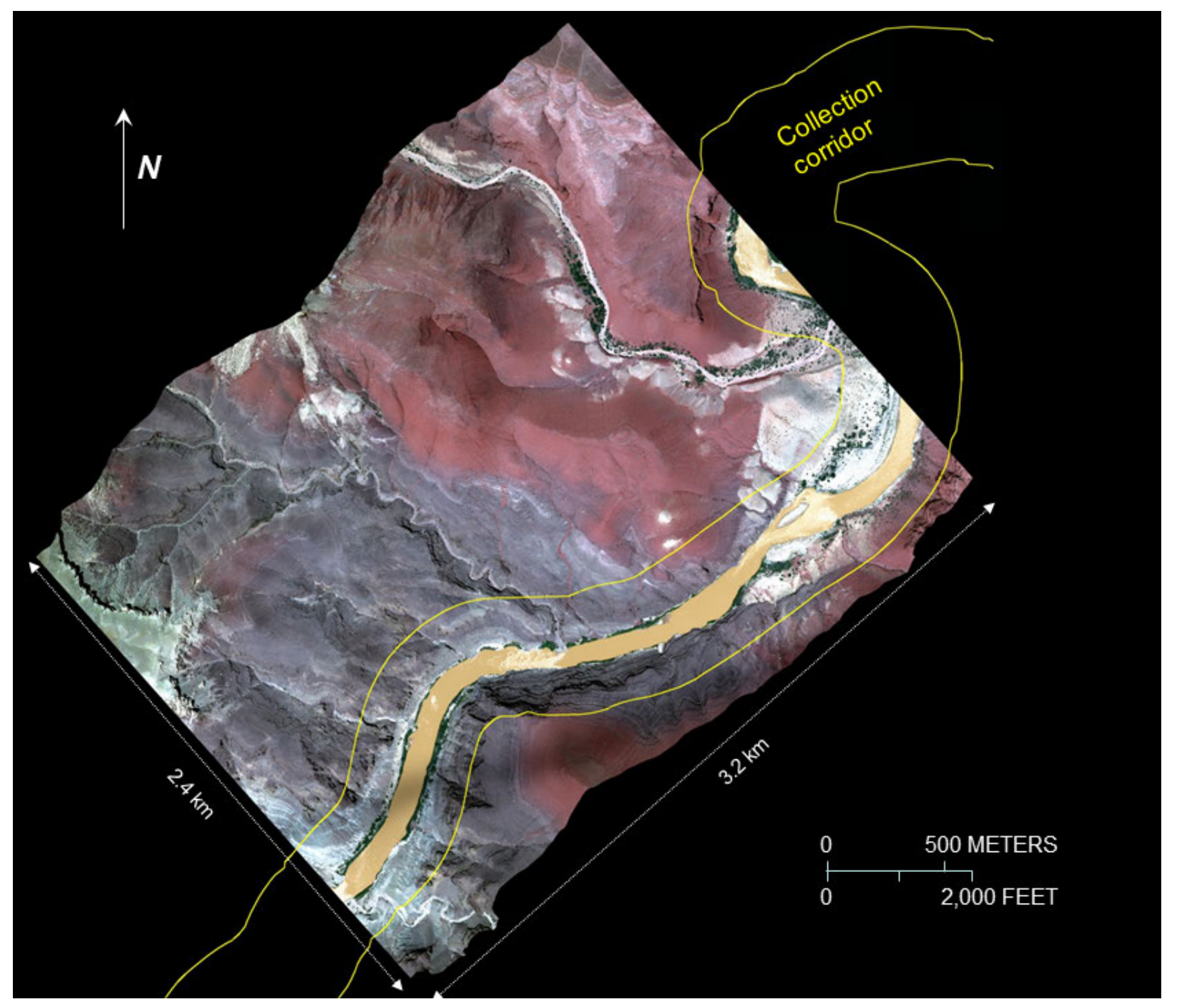

Figure 9. Flightline image segment south of the Little Colorado River showing the average length and swath width (in kilometers, $\mathrm{km}$ ) of the SH52 flightline segments. The 500-meter-wide collection corridor is superposed on the natural-color image. 


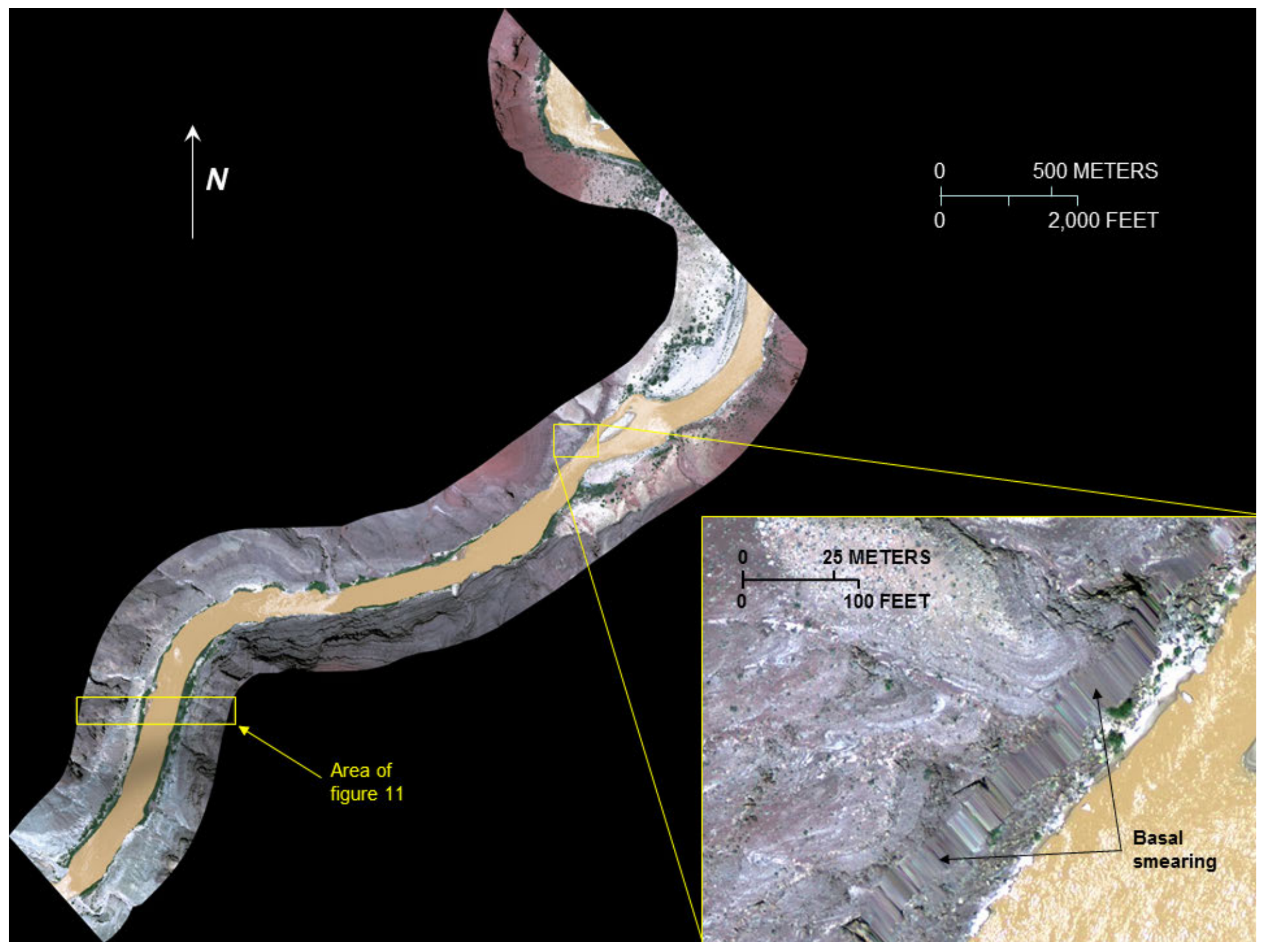

Figure 10. Natural-color image shown in figure 9, subset for the collection area. Example of basal surface smearing is shown as an inset. 


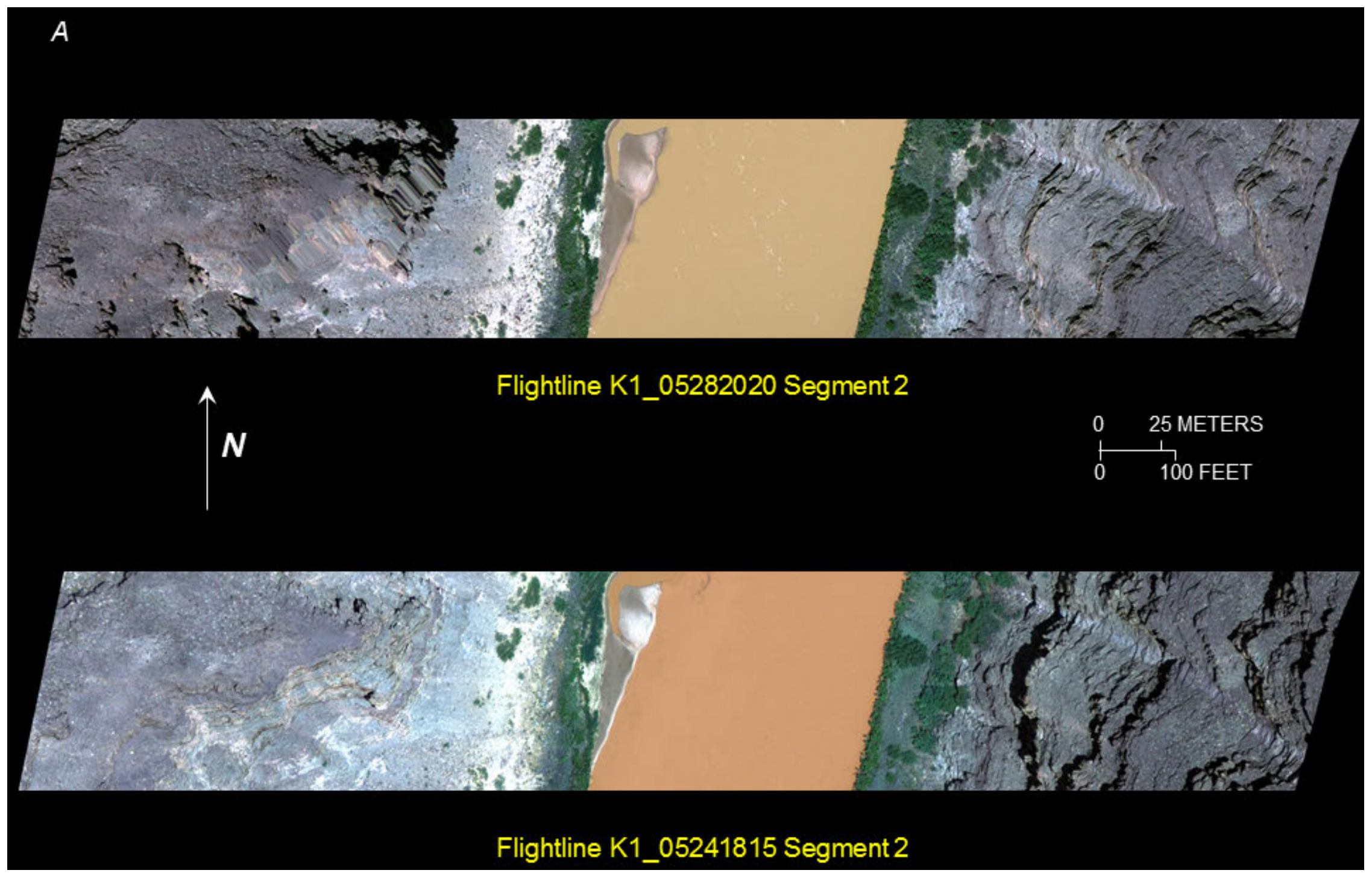

Figure 11. A, Natural-color images of two overlapping flightline image segments exhibiting surface smearing on opposite sides of the river. The top image was acquired on May 28, 2009, at 1:30 p.m., and the bottom image was acquired on May 24, 2009, at 11:15 a.m. The water color difference that is obvious between the image dates is the result of variations in suspended sediment load. $B$, Enlarged images of the west side of the Colorado River showing basal smearing on the top image but not on the bottom image. $C$, Enlarged images of the east side of the river showing scarp and vegetation smearing on the bottom image but not on the top image. 


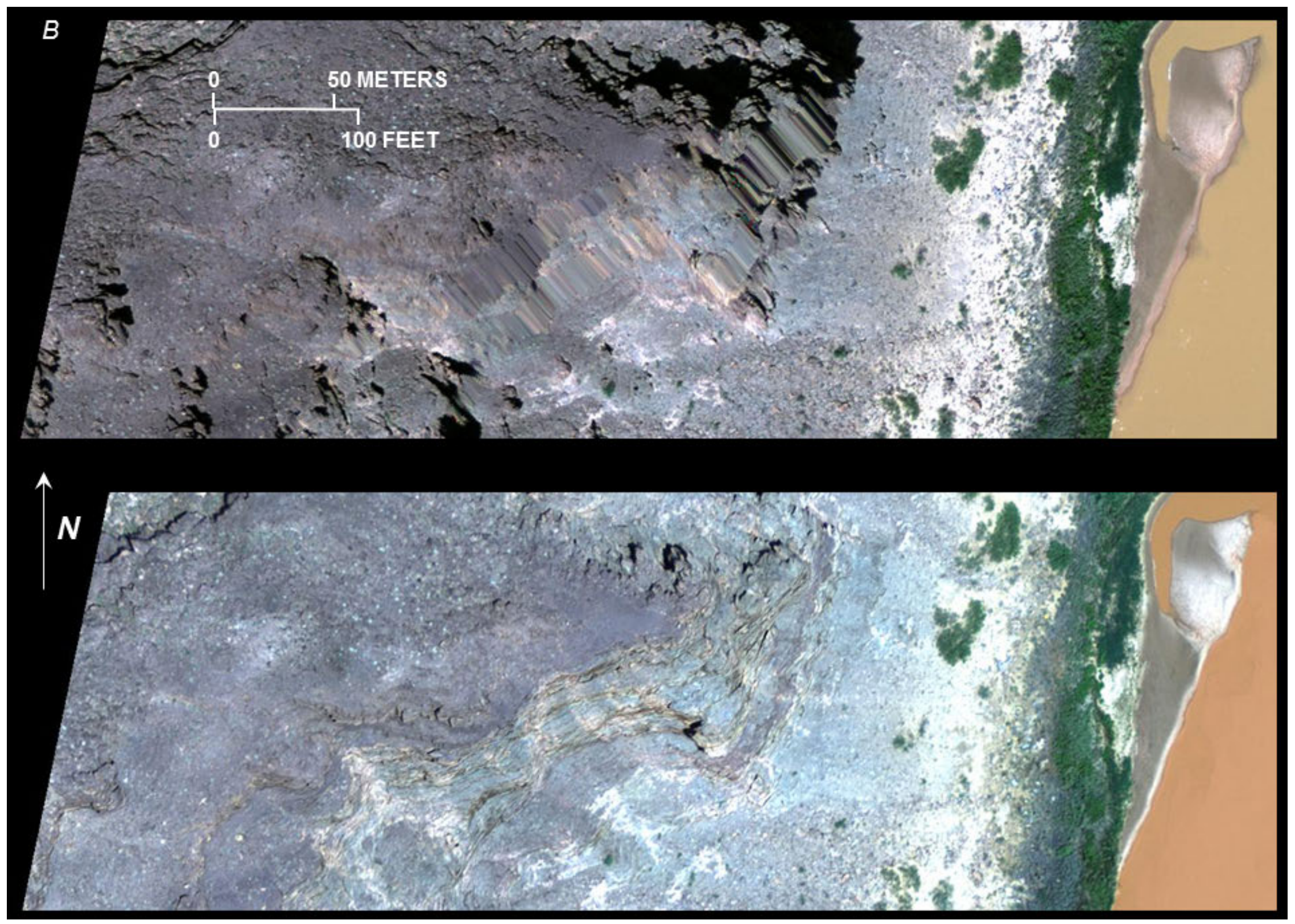

Figure 11.-Continued. 


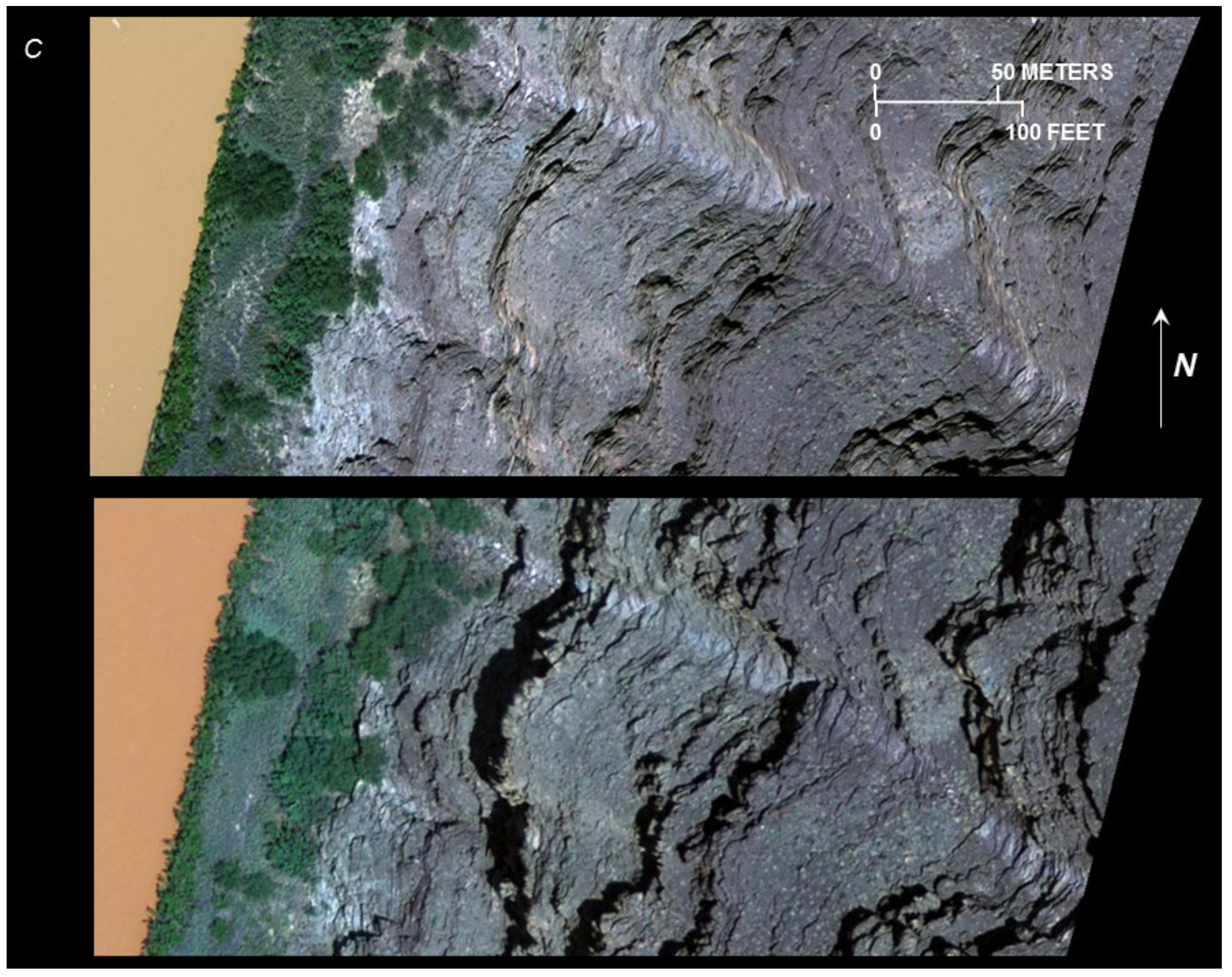

Figure 11.-Continued. 


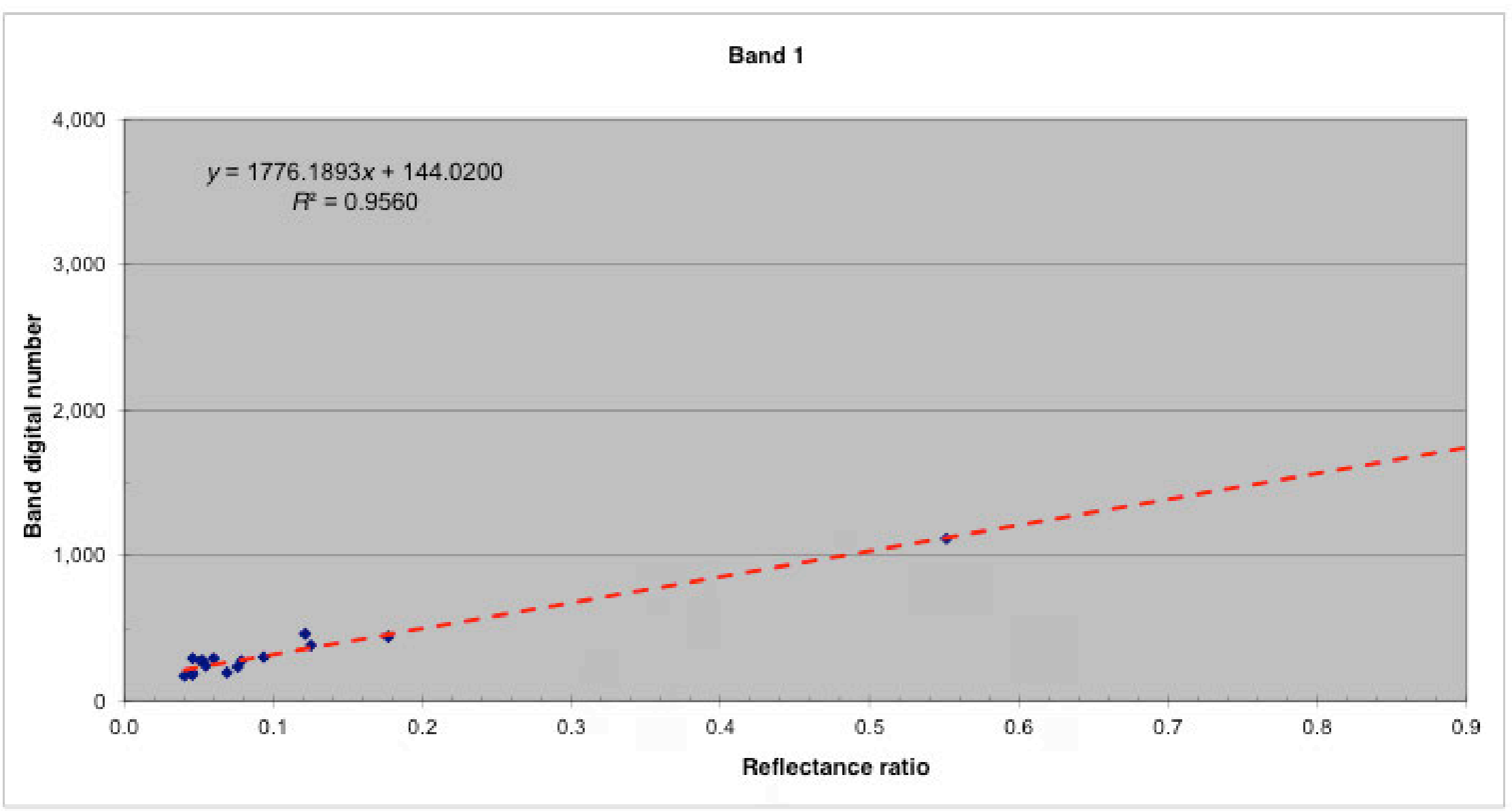

Figure 12. Comparison of digital values within the SH52 band imagery with reflectance values for corresponding wavelengths and ground locations that included various bare-ground, vegetated, and manmade surfaces within the Colorado River ecosystem. Bands 1 through 4 are shown in $A$ through $D$, respectively. Line within each plot is the least-squares linear regression of the point data. Each line's regression equation and correlation coefficient $\left(R^{2}\right)$ are also shown. 


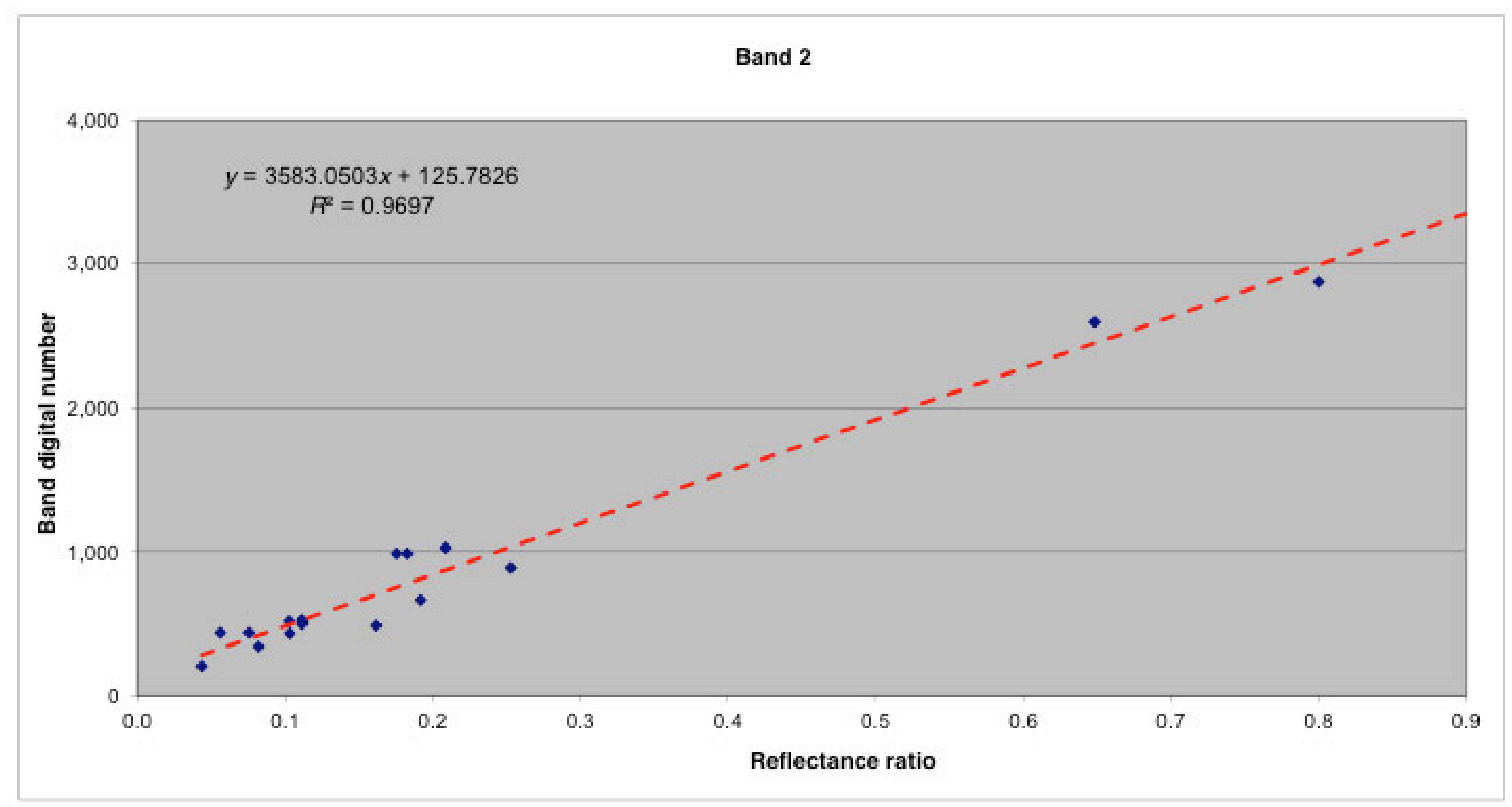

Figure 12.-Continued. 
C

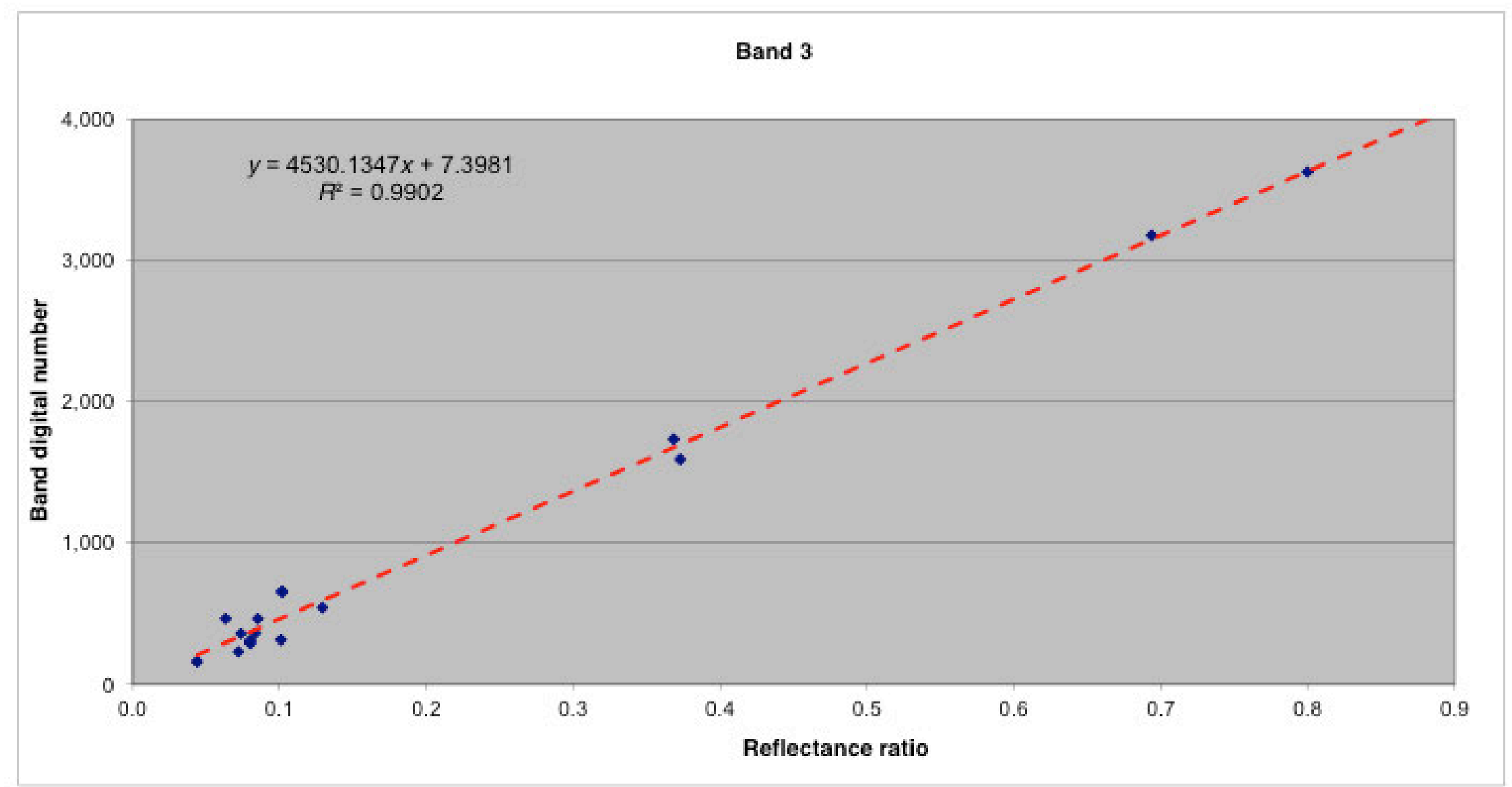

Figure 12.-Continued. 


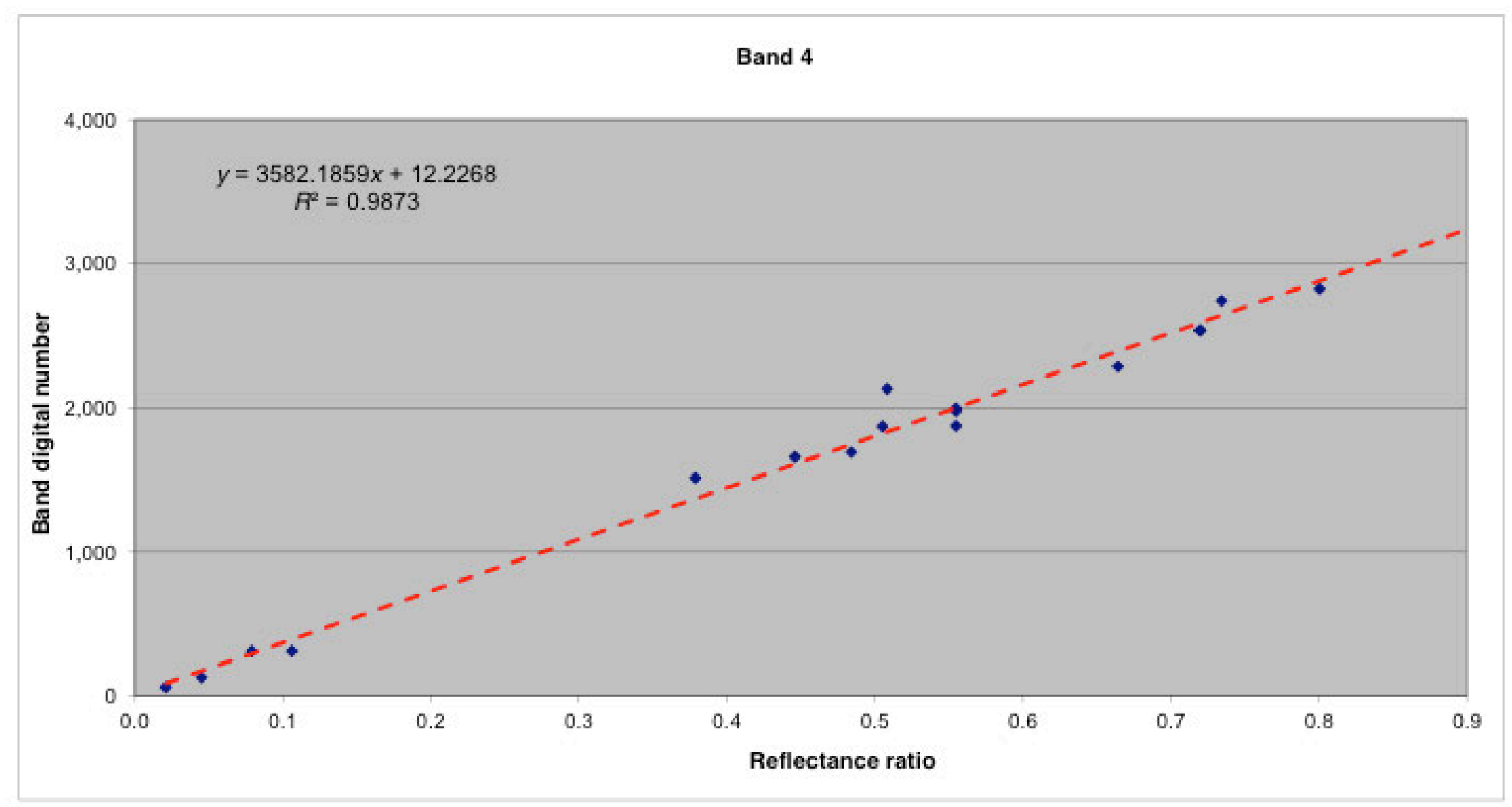

Figure 12.-Continued. 


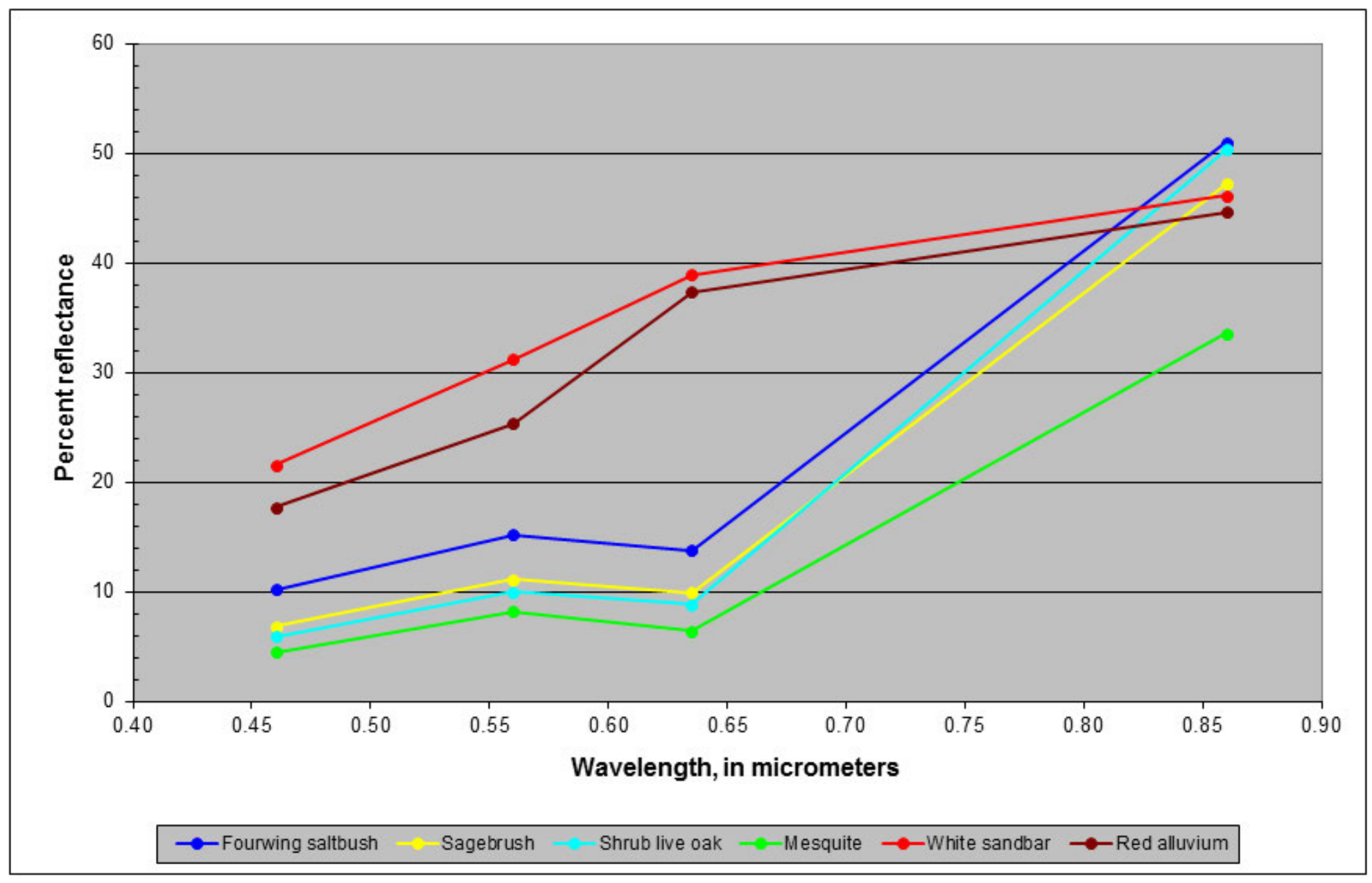

Figure 13. Average percent-reflectance values within SH52 wavelength bands, extracted from ground-reflectance spectra, for materials that commonly occur within the (A) xeric zone (Atriplex canescens or fourwing saltbush, Artemisia ludoviciana or sagebrush, and Quercus turbinella or shrub live oak, Prosopis glandulosa or mesquite), (B) riparian zone (Baccharis salicifolia or baccharis, Tamarix ramossima or tamarisk, Pluchea sericea or arrowweed, and Salix exigua or willow), and (C) riparian wetland areas (Phragmites arundinacea or phragmites, Carex aquatilis or sedge, Equisetum ferrisii or equisetum, Cynodon dactylon or marsh grass, and Aristida oligantha or yellow grass) within the Colorado River ecosystem. 


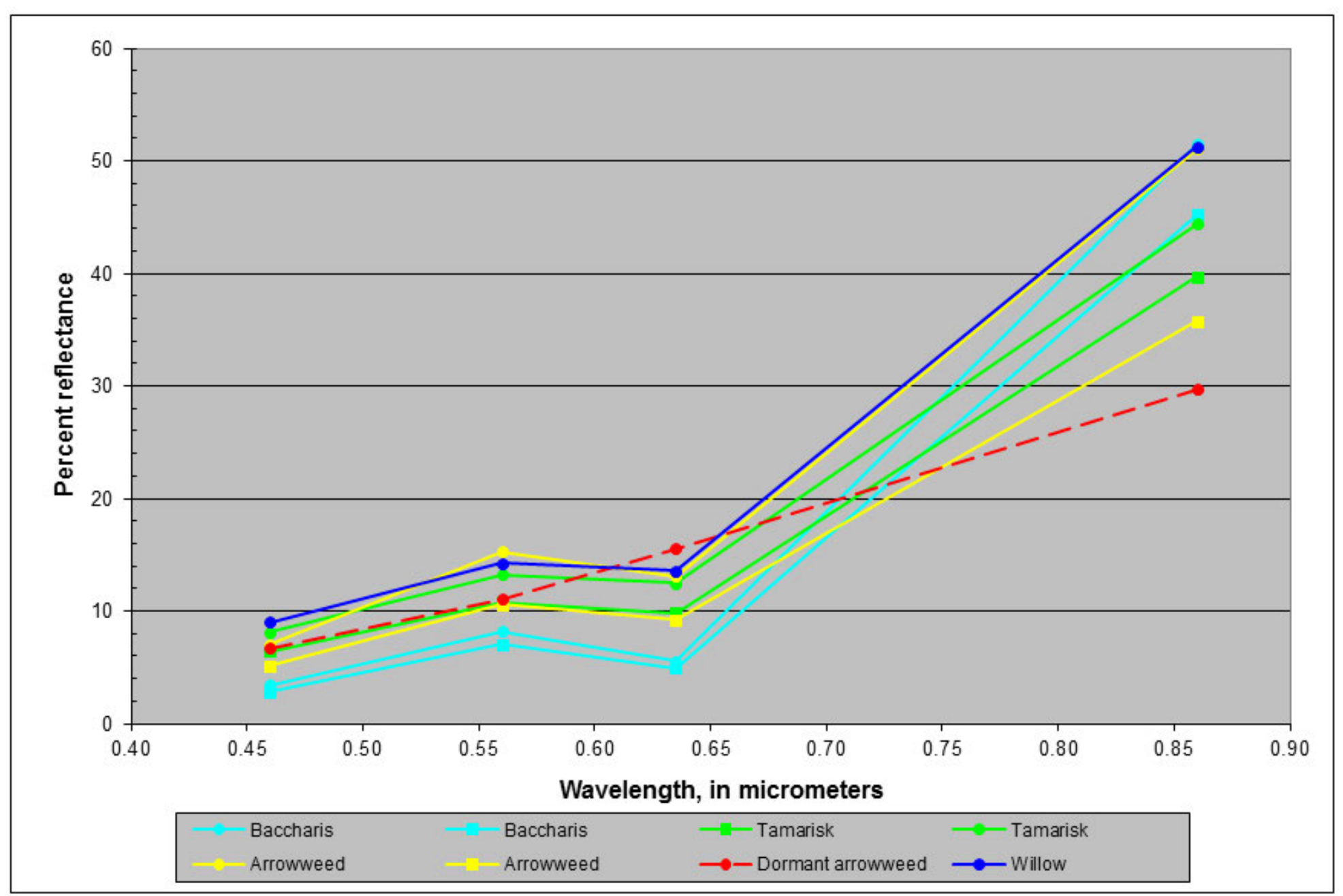

Figure 13.-Continued. 


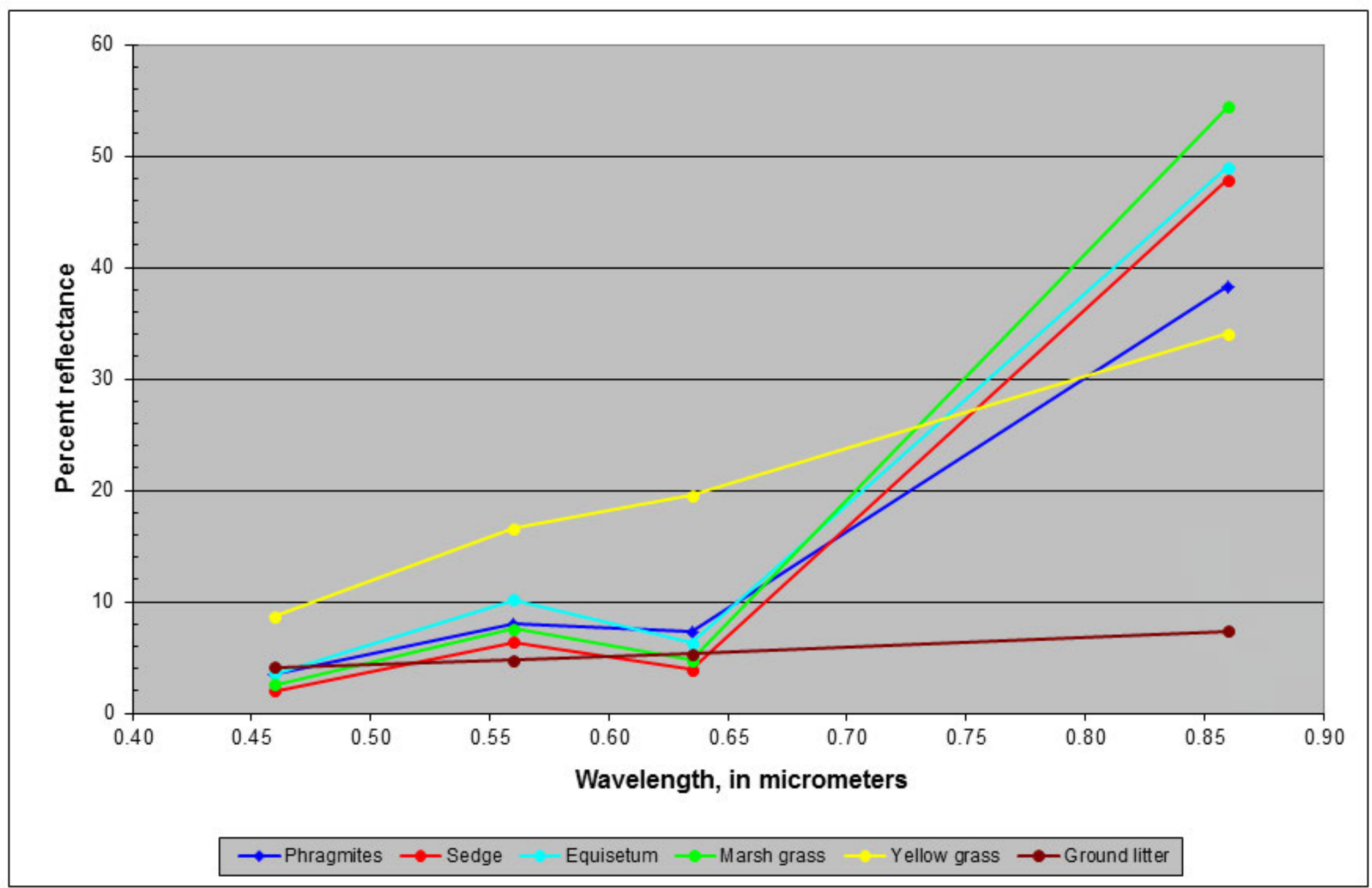

Figure 13.-Continued. 
$A$

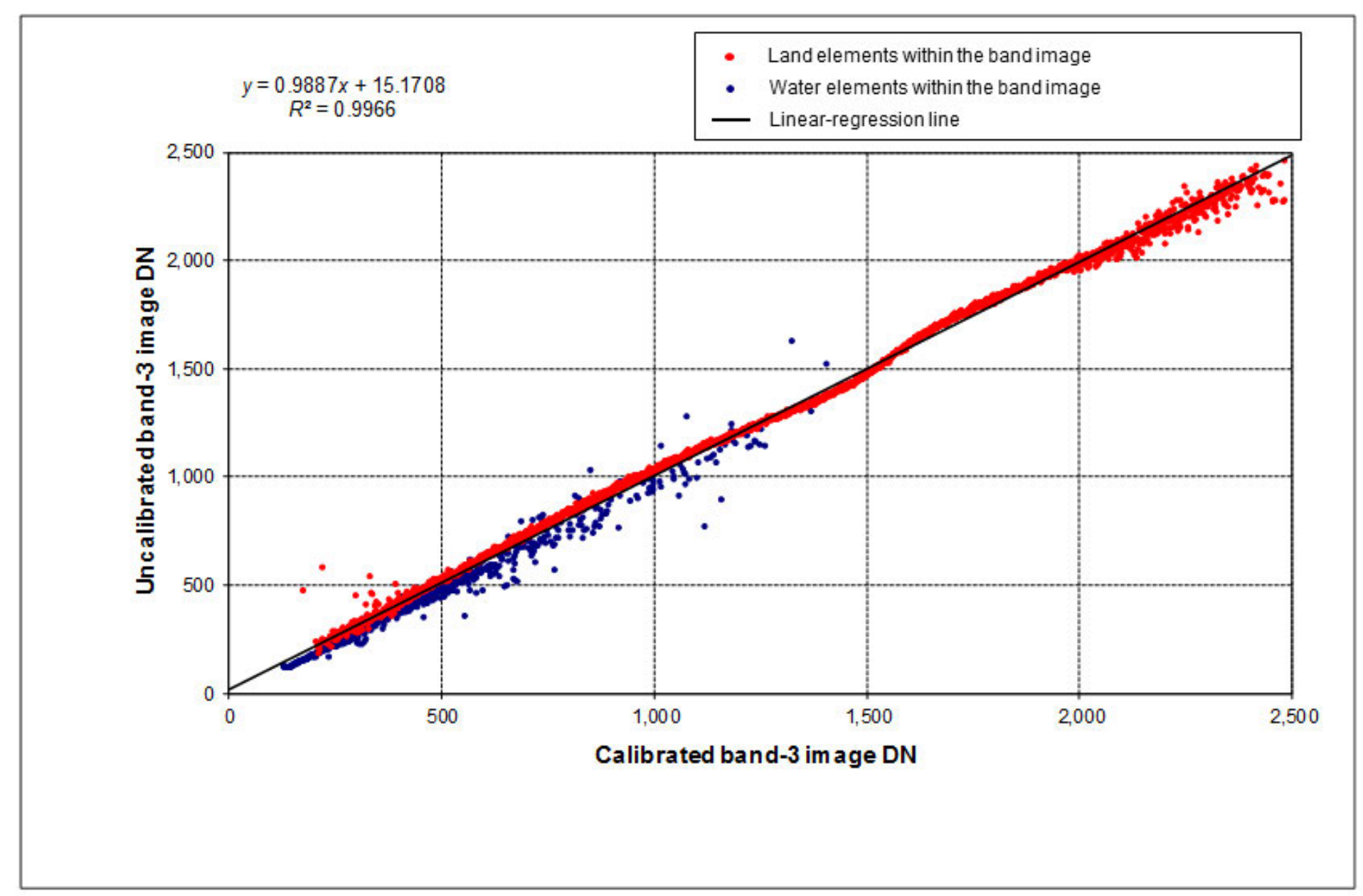

Figure 14. A, Scatter diagram of calibrated band-3 image digital numbers (DN) for flightline M5_05261918 versus uncalibrated band-3 image DN for flightline M4_05251853 within the overlap region of the two flightline subblocks. Red points are land elements (bare and vegetated ground); blue points are water elements. Water values are similar on the two dates because the subblock is north of the Little Colorado River. Least-squares solution and correlation coefficient $\left(R^{2}\right)$ for land and water elements are shown. $B$, Similar diagram comparing band-3 image DN within sidelap region between calibrated flightline K1_05241815 versus uncalibrated flightline K1_05282020. Water elements on the two dates were distinctly different, and thus only land elements were used in such instances. 


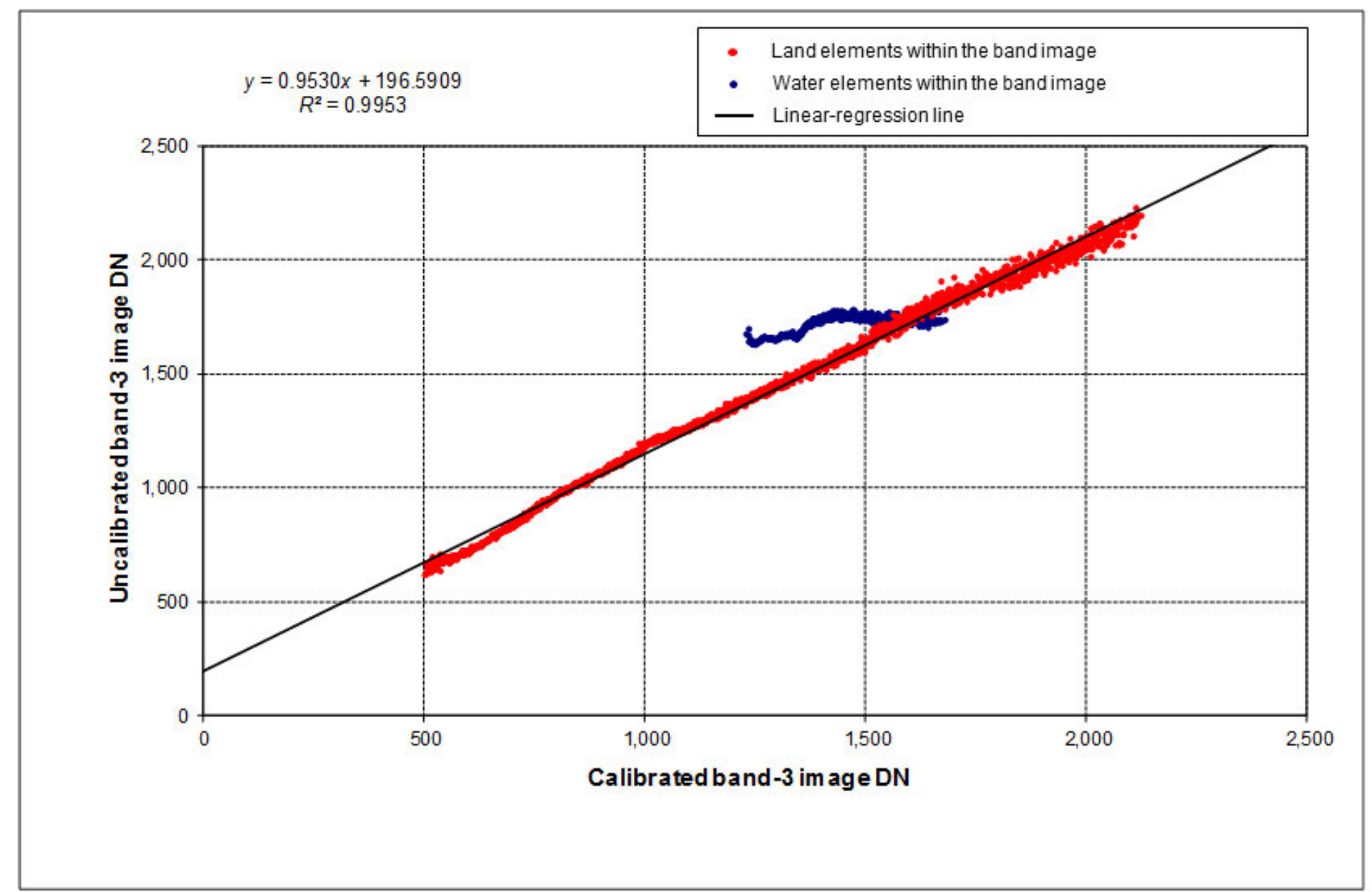

Figure 14.-Continued. 


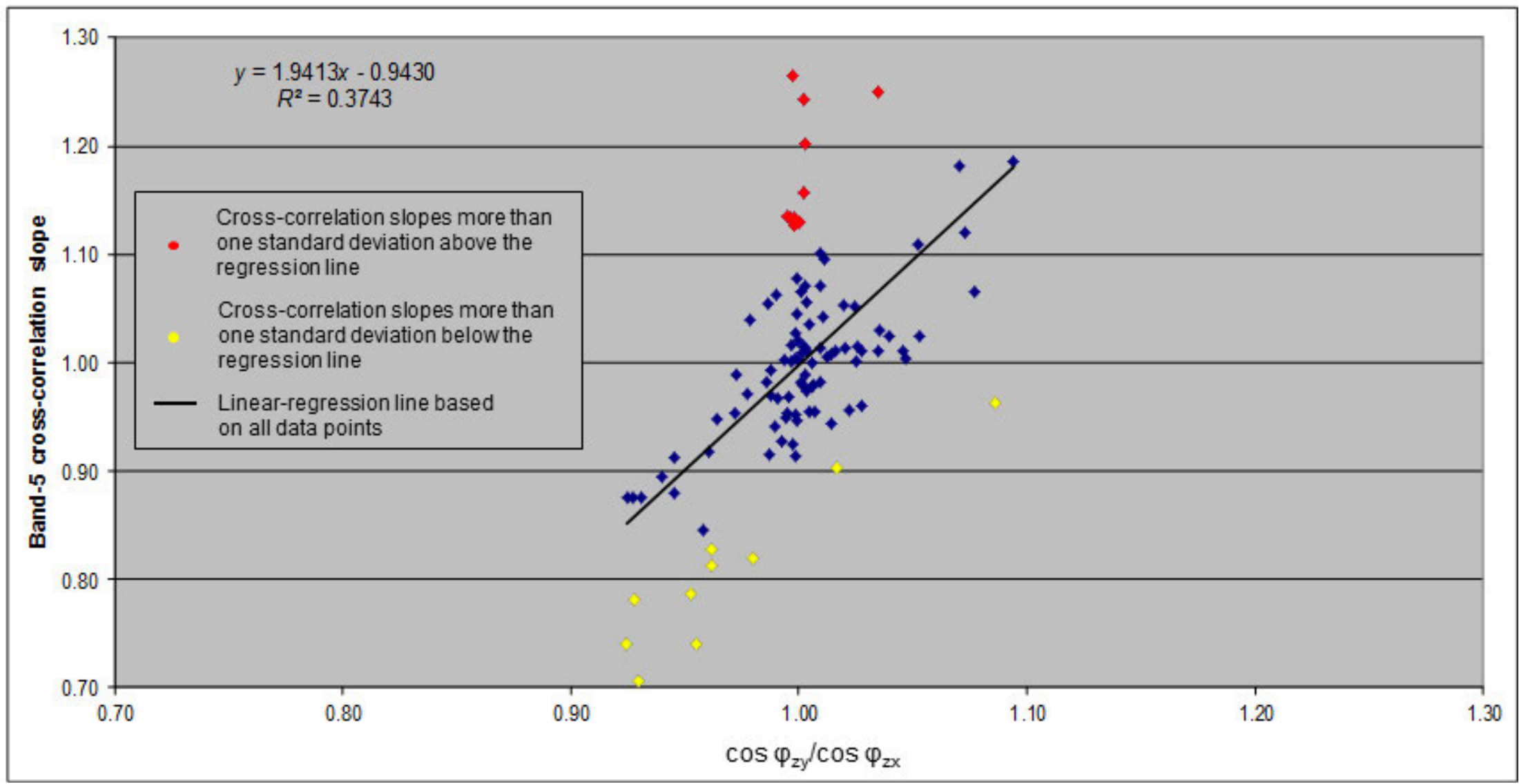

Figure 15. Scatter diagrams of dependentindependent-image cosine-zenith-angle ratios versus their image digital number (DN) regression slopes for the inter-subblock flightline cross correlations, where $A$ shows the simple cosine relation and $B$ shows the cosine-squared relation. The cosine of the zenith angle for the dependent image is $\cos \varphi_{z y}$; the cosine of the zenith angle for the independent image is $\cos \varphi_{z x}$. Red points are dominantly the flightlines in the M6 and M7 subblocks; yellow points are dominantly the flightlines in the K1 subblock. The black line is the leastsquares regression of all points; the regression equation and correlation coefficient for the least-squares regression are shown. 


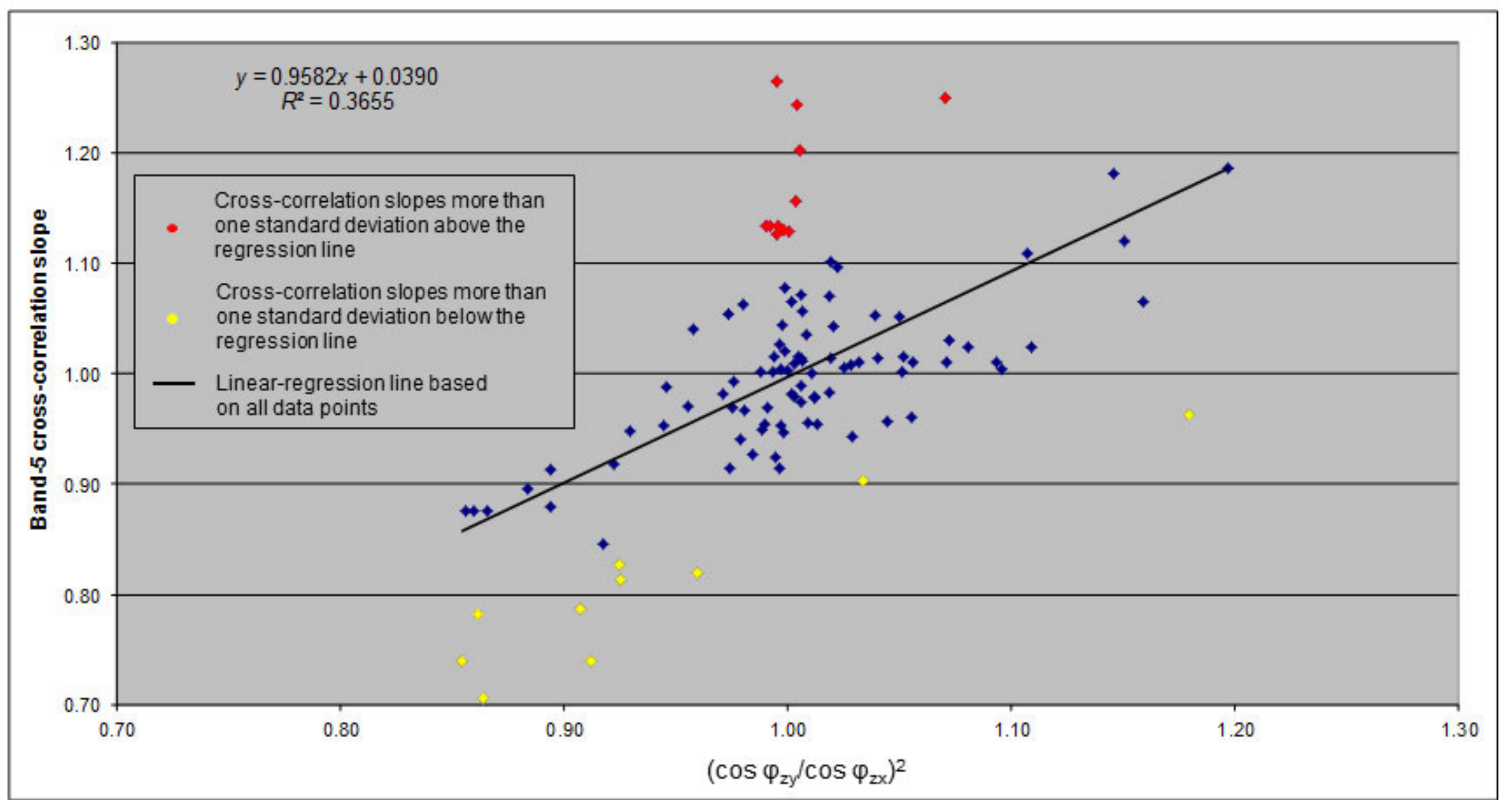

Figure 15.-Continued. 


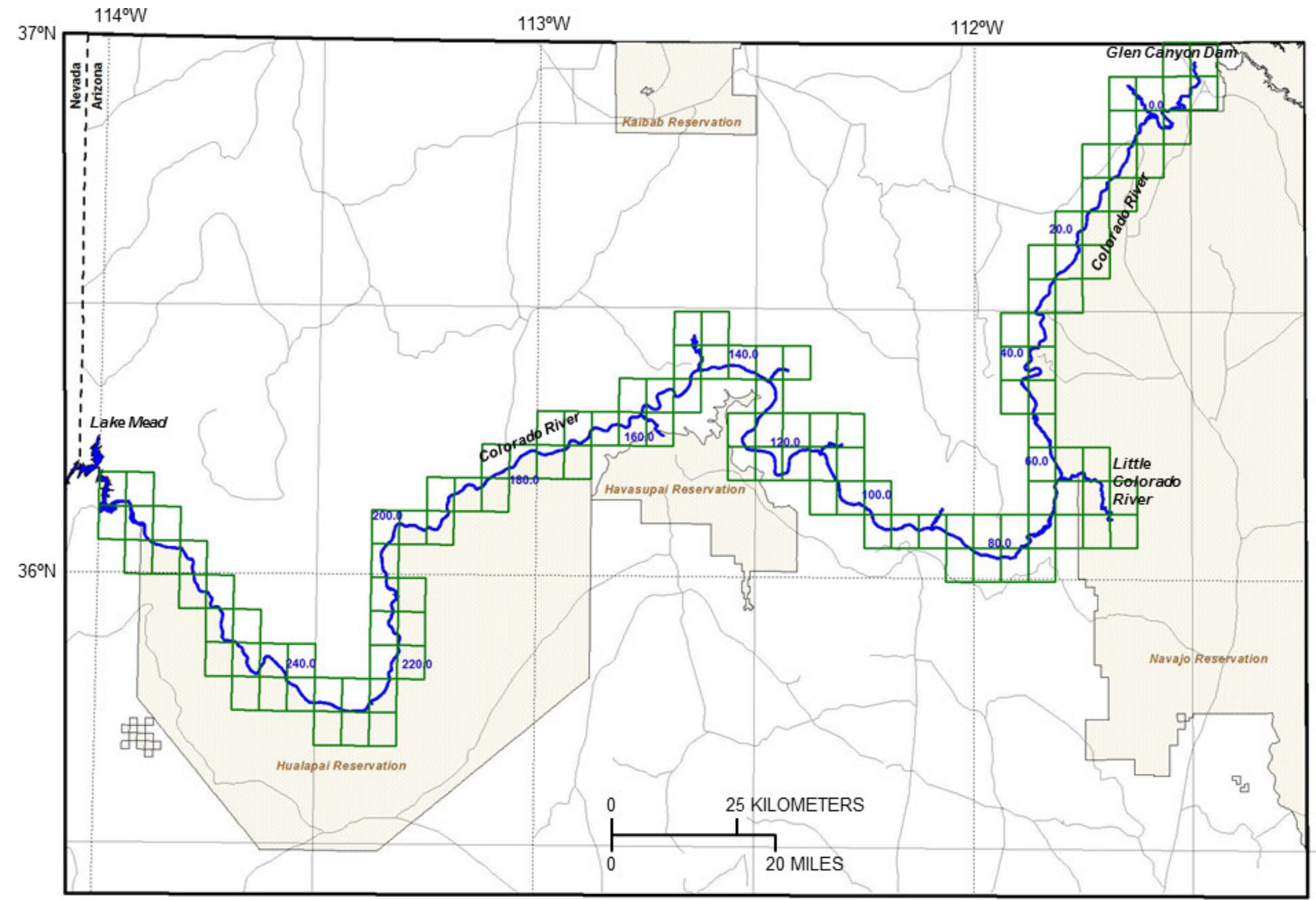

Figure 16. Map of the Colorado River ecosystem, showing the U.S. Geological Survey quarter-quadrangle map-tile scheme (green boxes) used to segment the corridor's image mosaic into image tiles. 


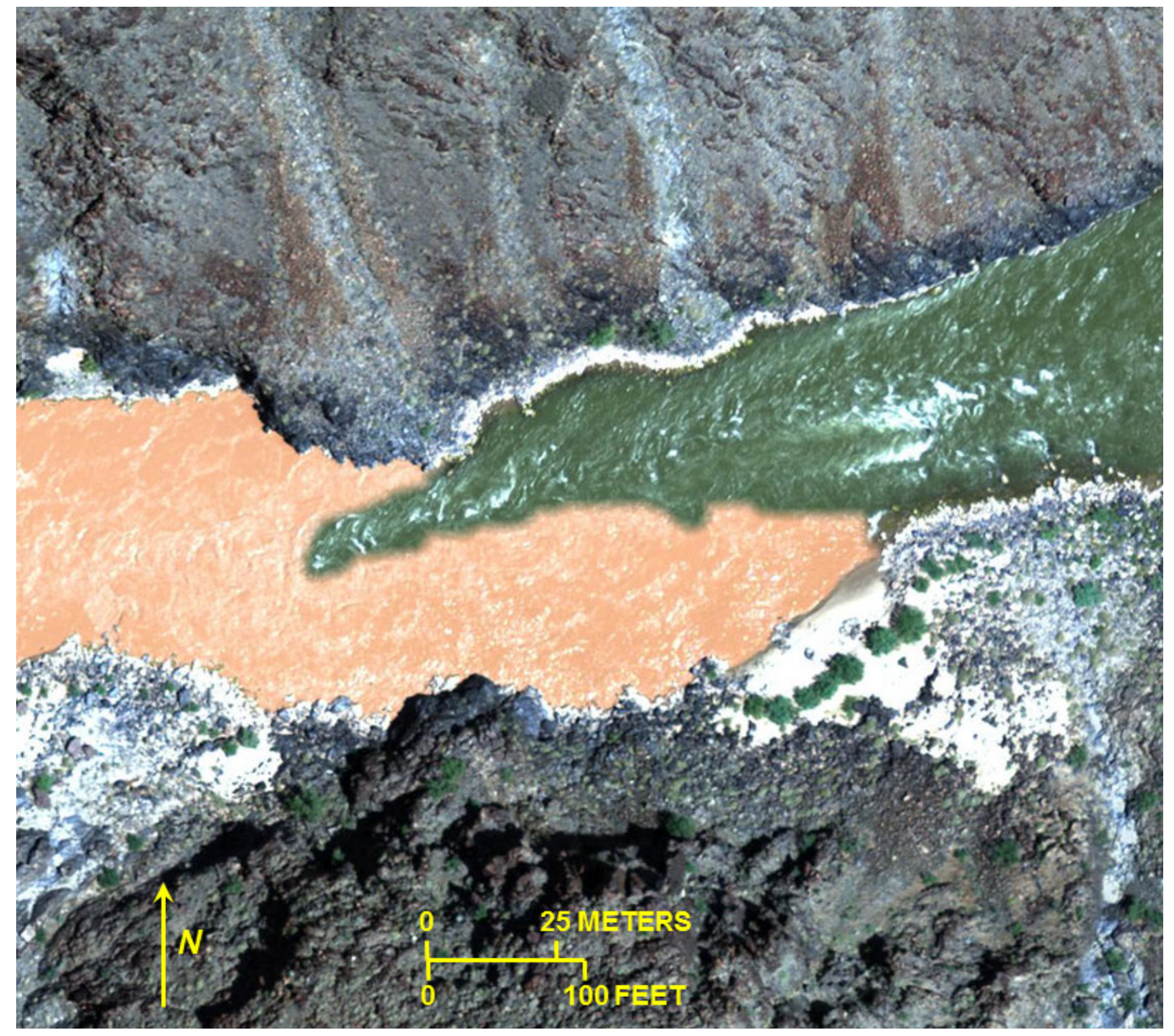

Figure 17. Natural-color image of a section of map tile SE35113G4 (river mile 230.0) showing color discontinuity within the mainstem between clear (green) and sediment-laden (brown) water, as a result of mosaicking image data collected before and after upstream tributary floods triggered by monsoonal storms. 


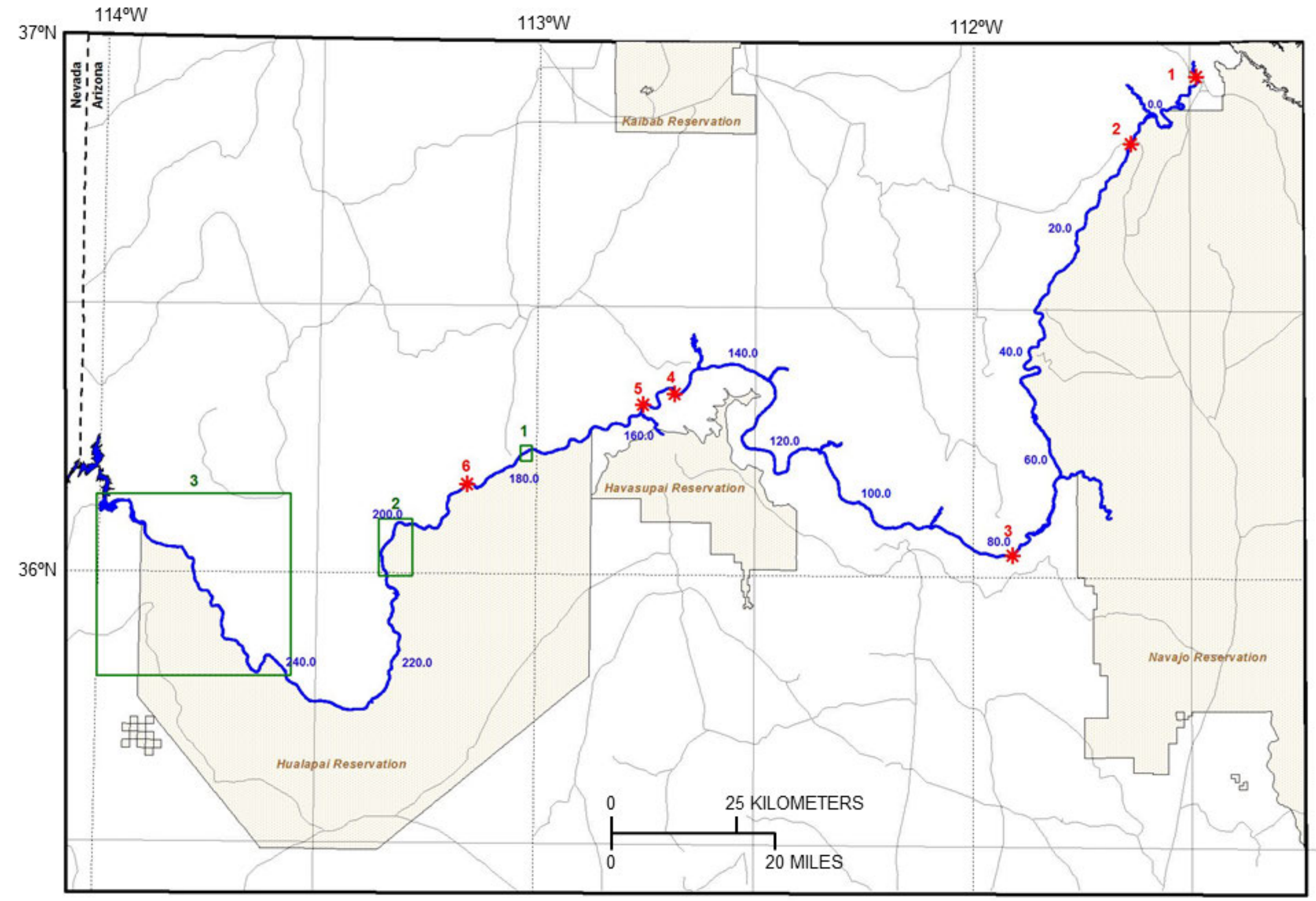

Figure 18. Map of the Colorado River ecosystem, showing locations of scarp smears (red asterisk) and areas of cloud shadow or overcast (green boxes) within the final 2009 image mosaic. 


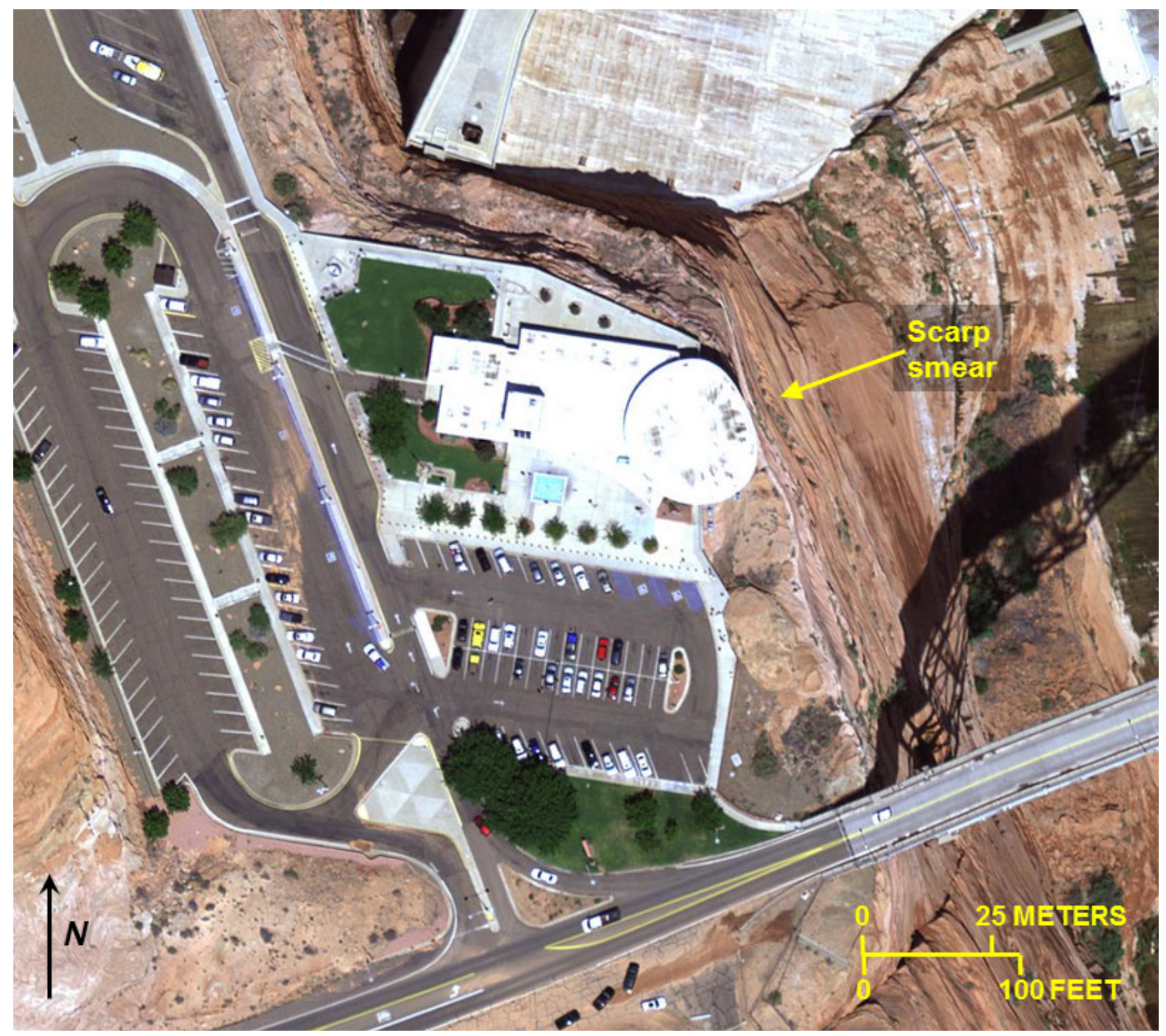

Figure 19. Natural-color image of point 1 location in figure 18 showing scarp smears and distortion of circular building at the Glen Canyon Dam within map tile SW36111H4. 


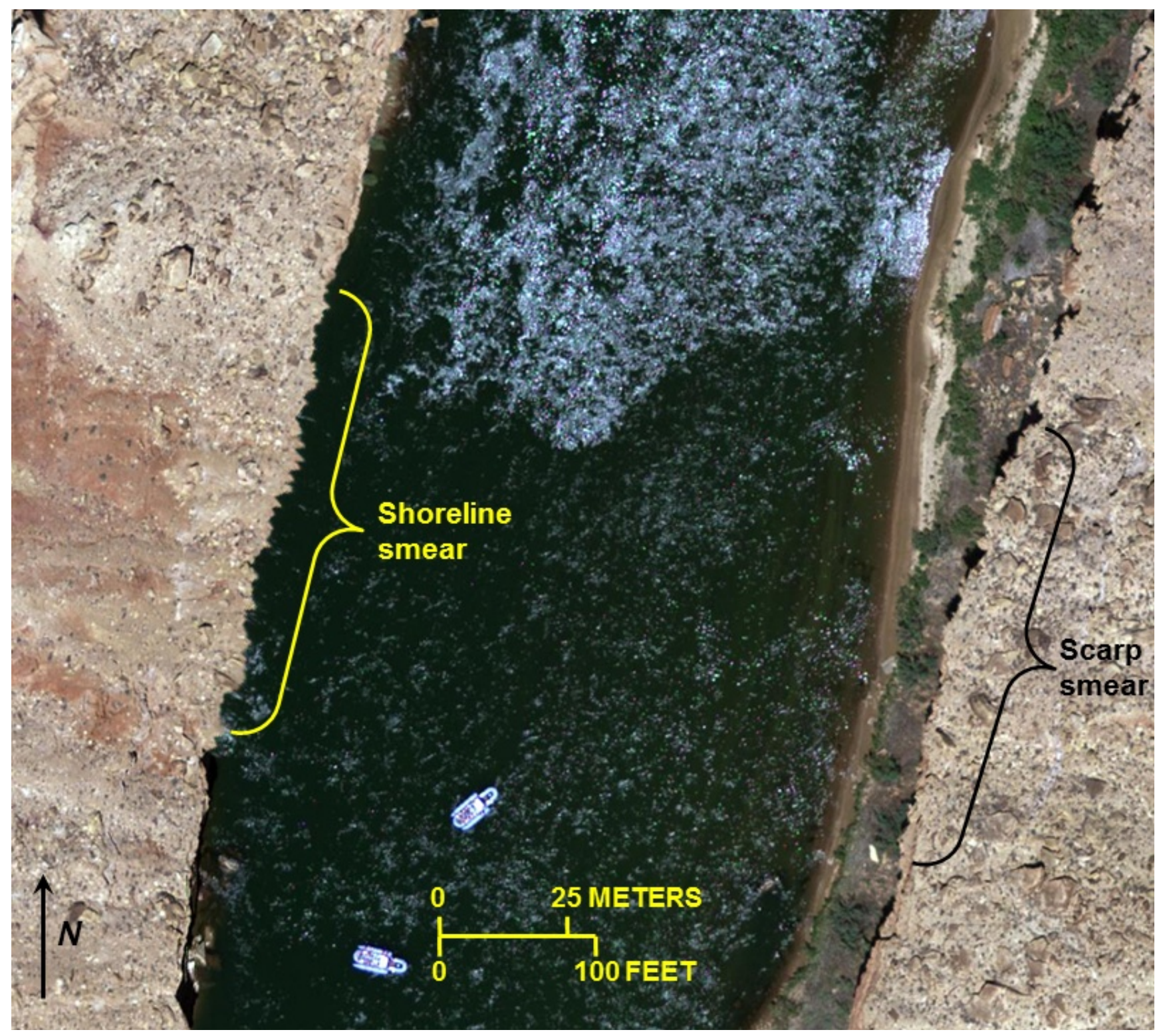

Figure 20. Natural-color image of point 2 location in figure 18 showing subtle scarp smears on the left bank of the Colorado River (river left) and shoreline smears on river right within map tile NE36111G6. 


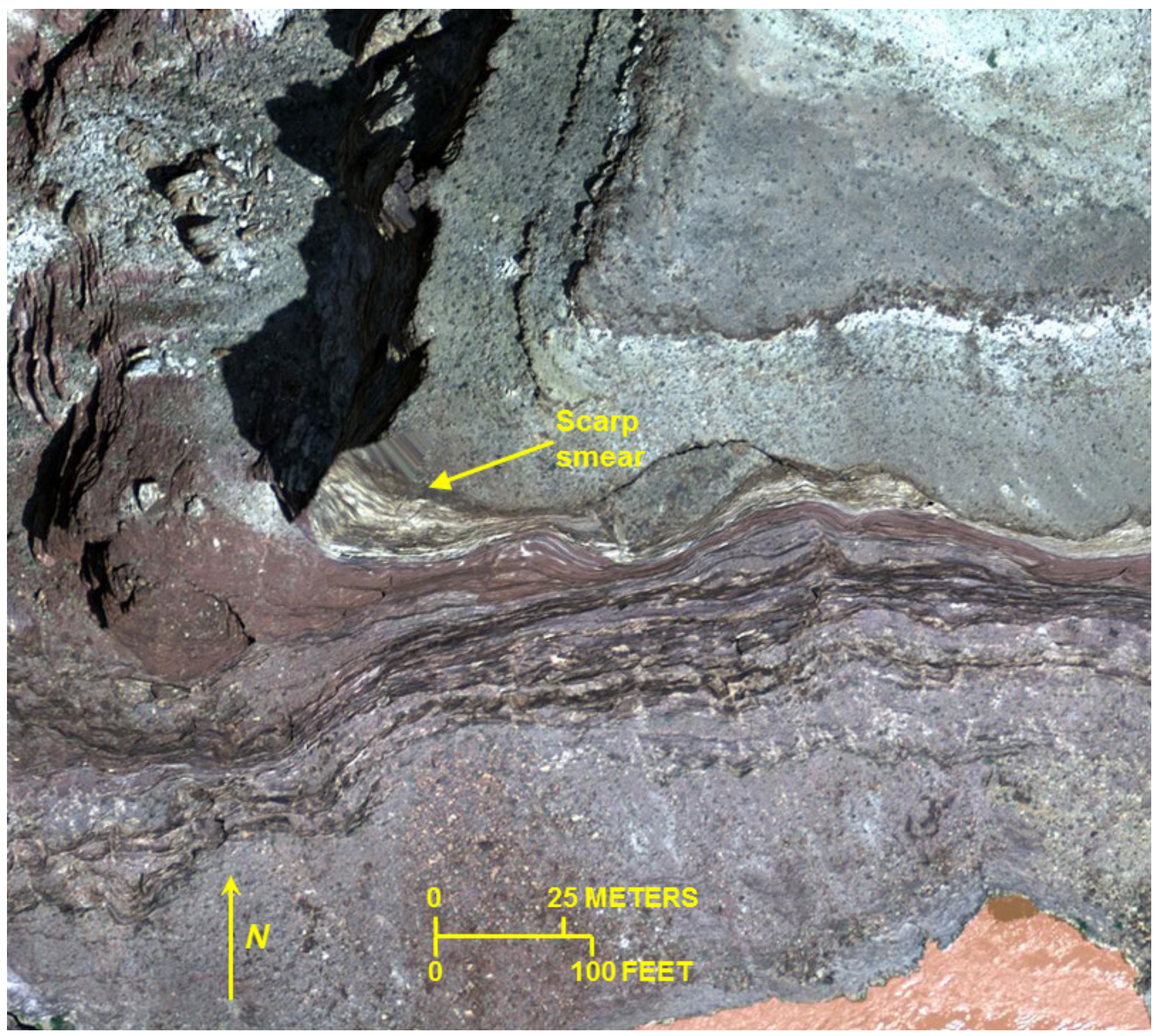

Figure 21. Natural-color image of point 3 location in figure 18 showing minor scarp smear within map tile SE36111A8. 


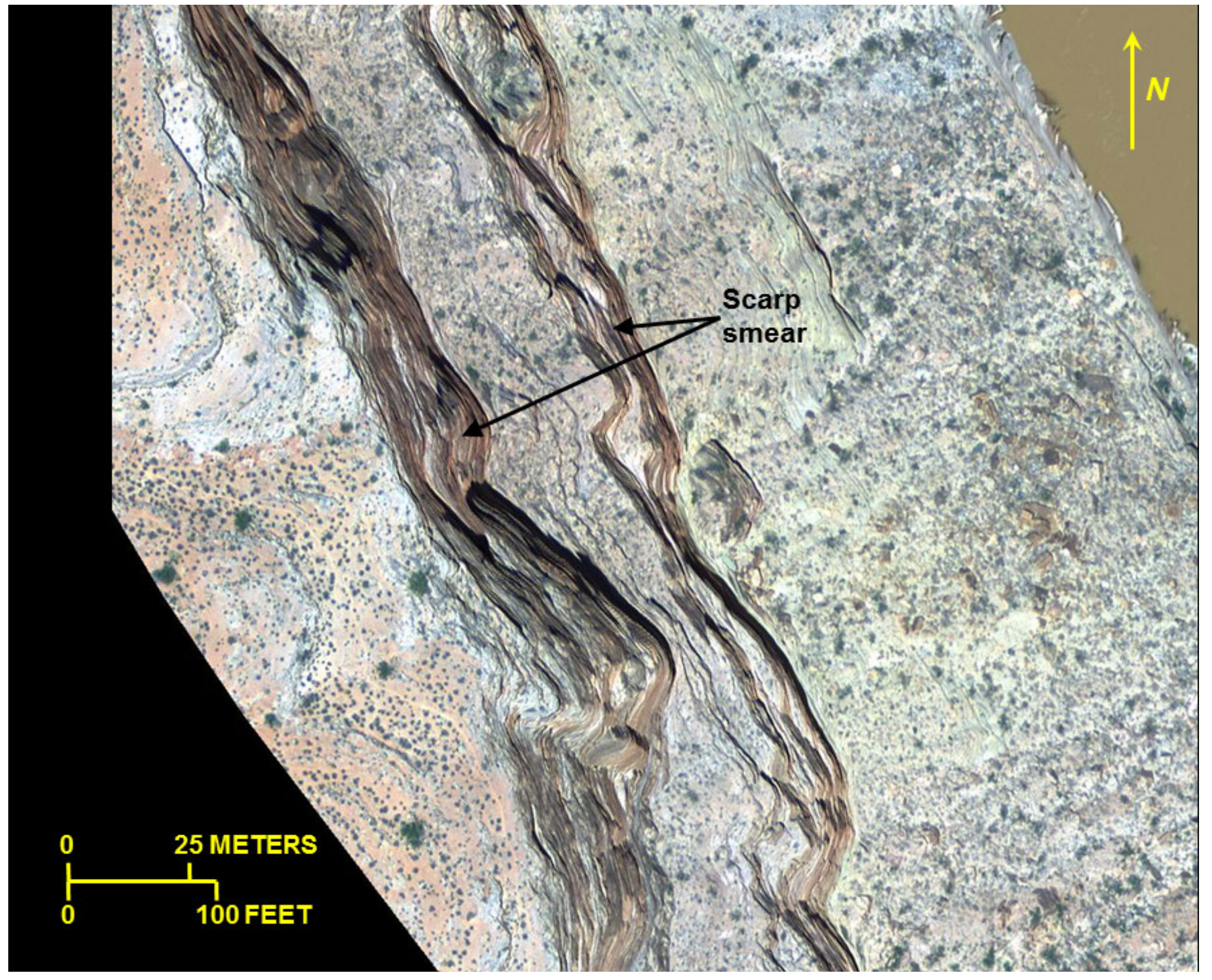

Figure 22. Natural-color image of point 4 location in figure 18 showing scarp smears within map tile NE36112C6. 


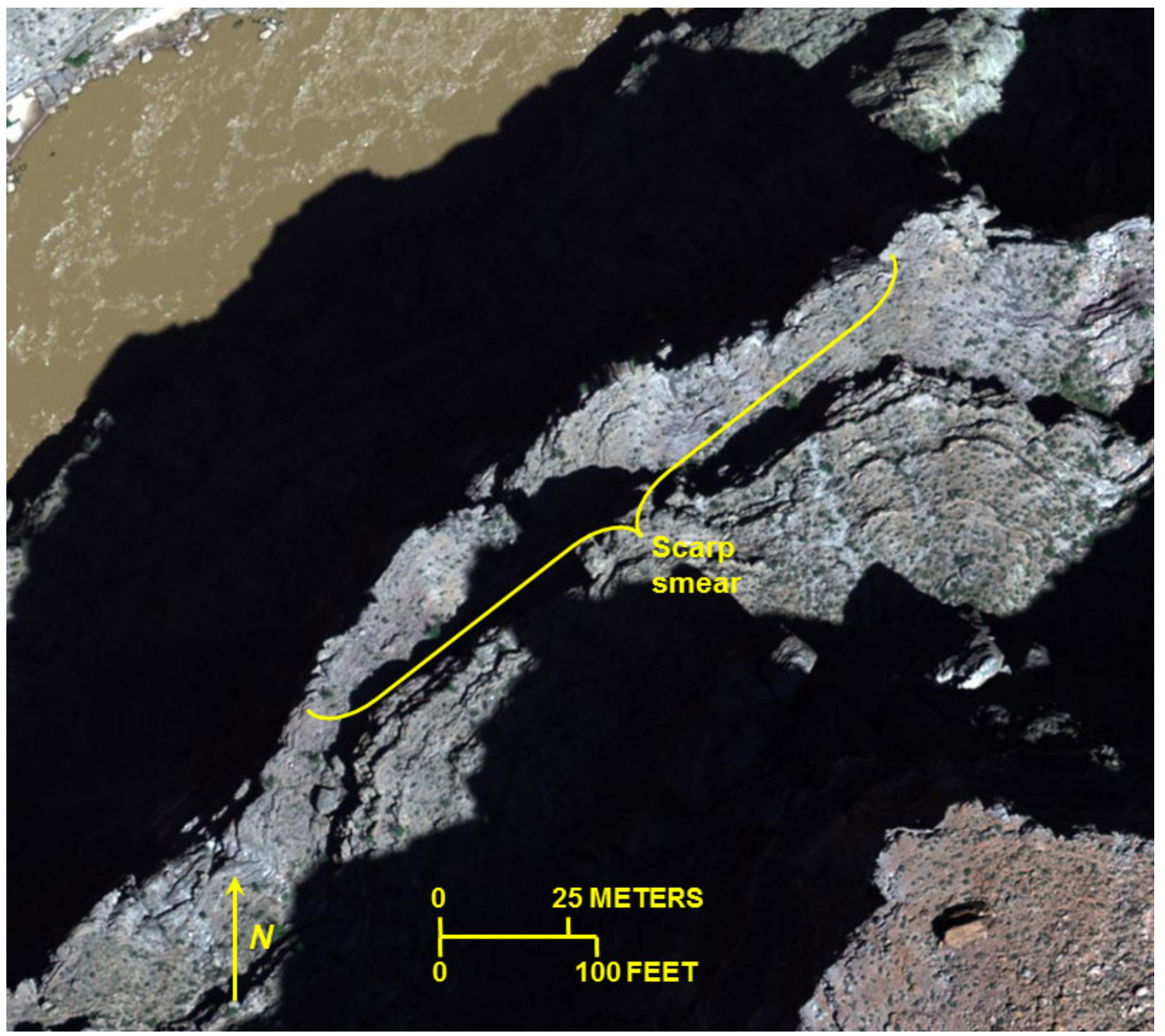

Figure 23. Natural-color image of point 5 location in figure 18 showing very minor scarp smears within map tile NE36112C7. 


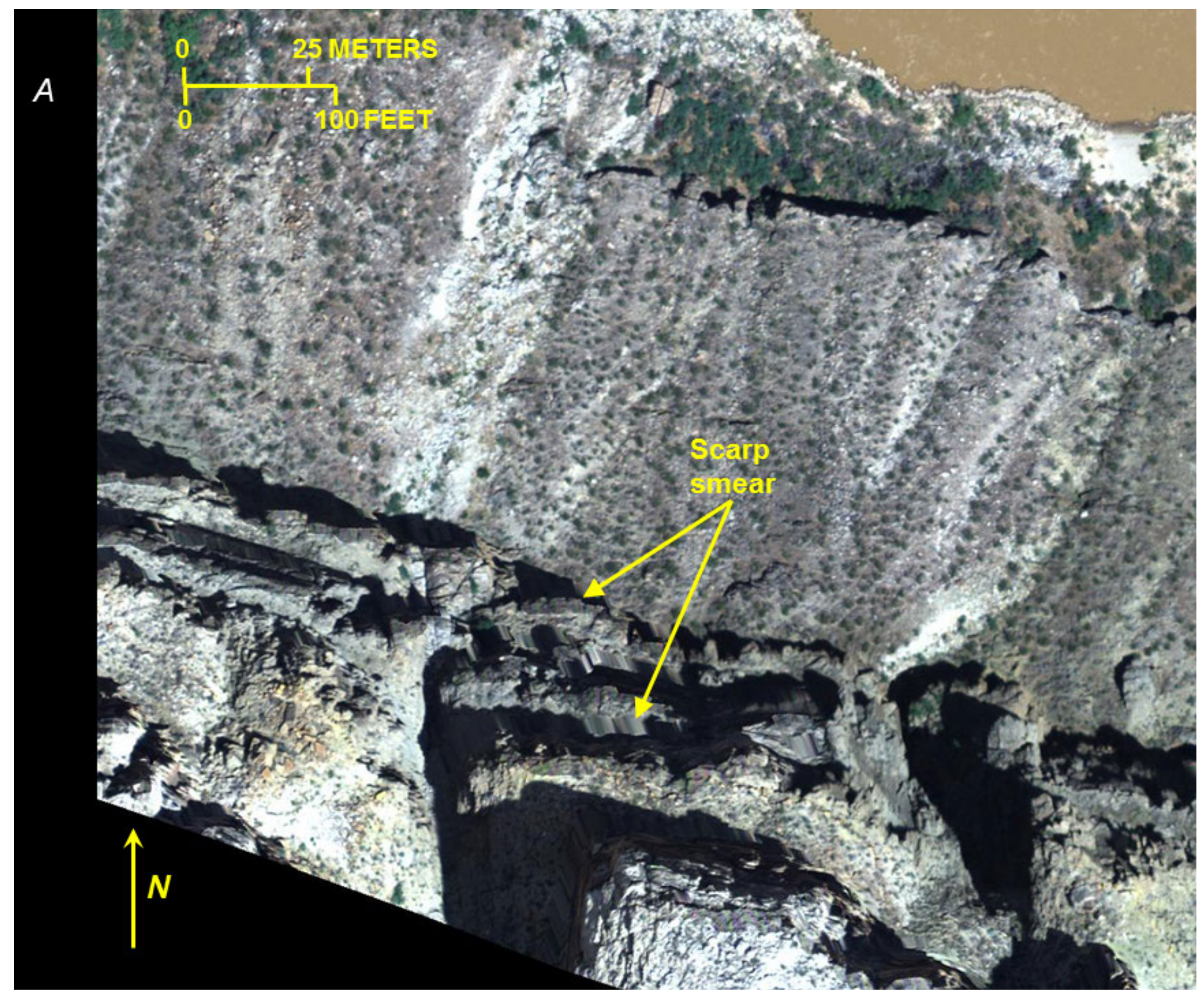

Figure 24. Natural-color image of point 6 location in figure 18 showing obvious scarp smears on (A) the left bank of the Colorado River (river left) and (B) river right within map tile SE36113B2. 


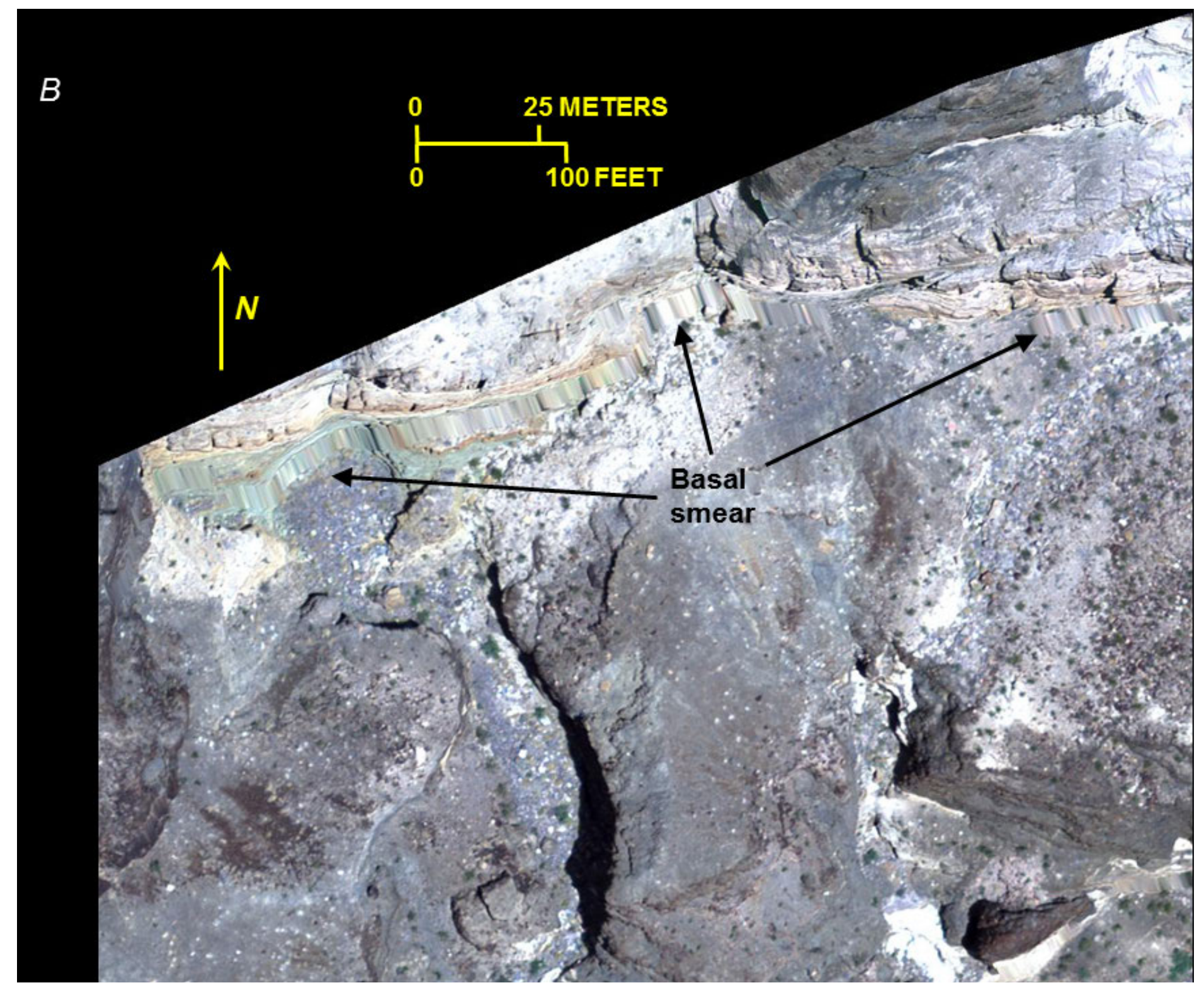

Figure 24.-Continued. 


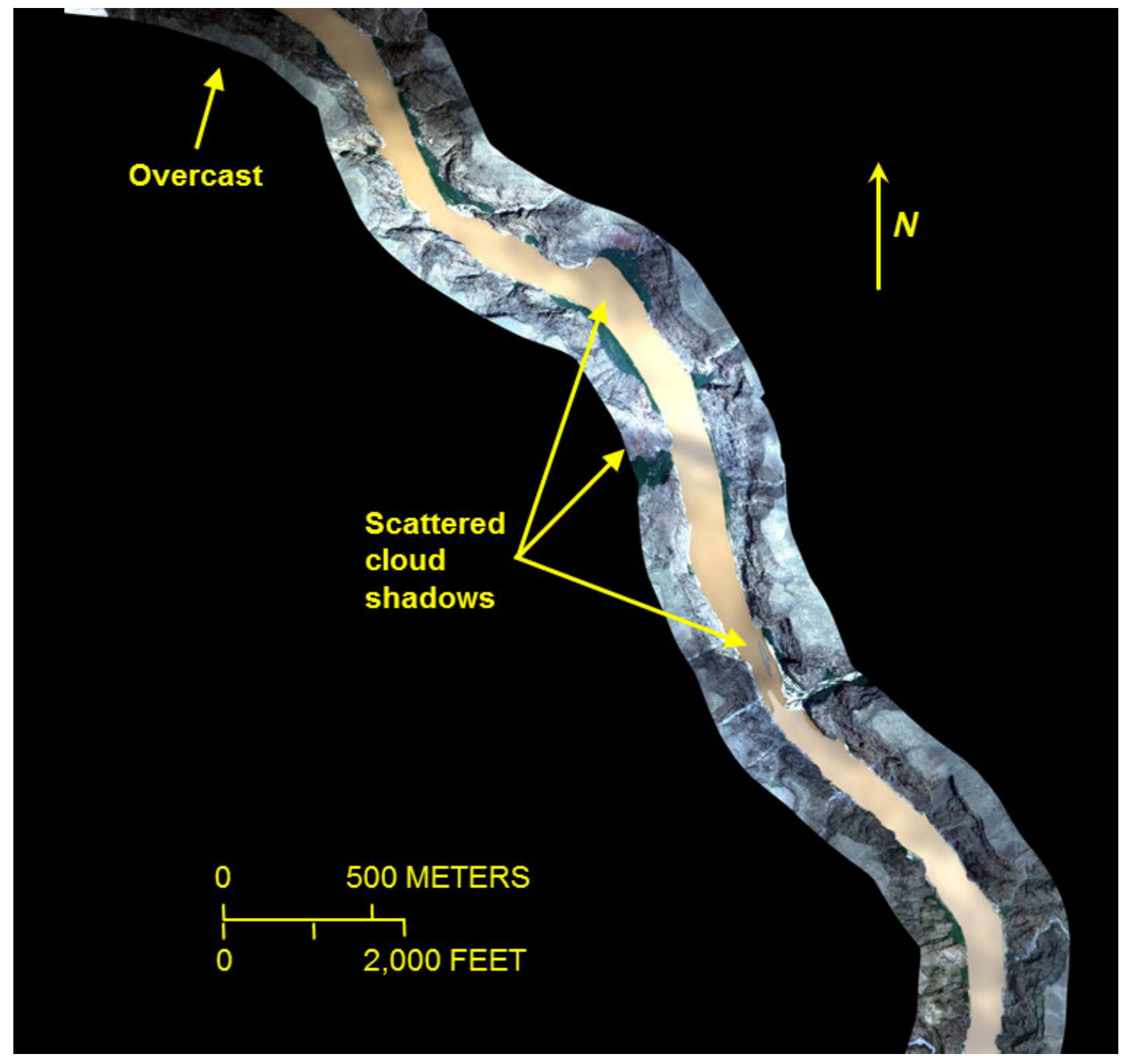

Figure 25. Natural-color image of a part of box 3 in figure 18 showing scattered cloud shadows and the east edge of a section that is overcast within map tile NE35113G6. 


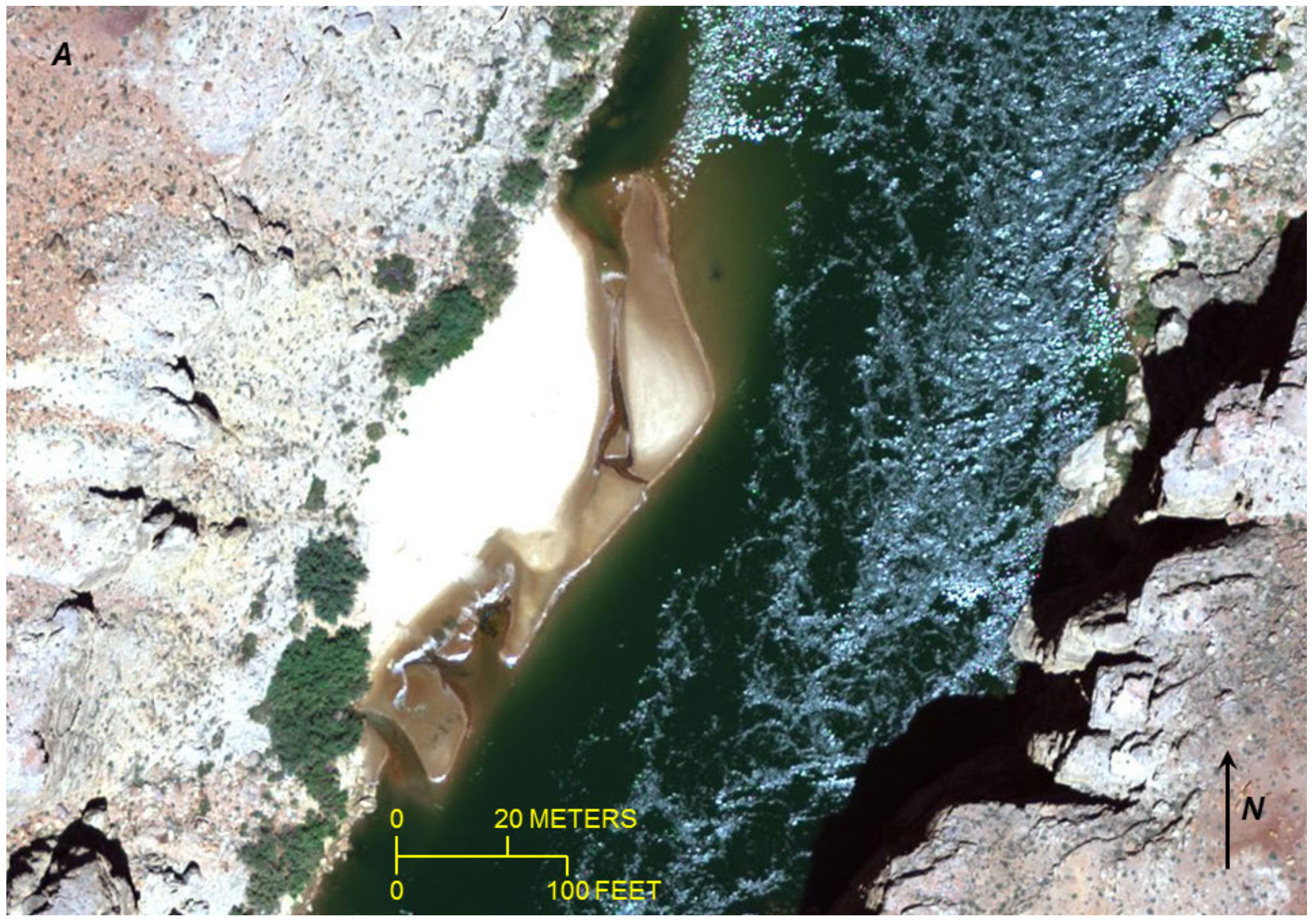

Figure 26. Comparison of $(A) 2009,(B) 2005$, and $(C) 2002$ natural-color image quality for a sandbar area at river mile 30.7 within image tile SW36000B7. 

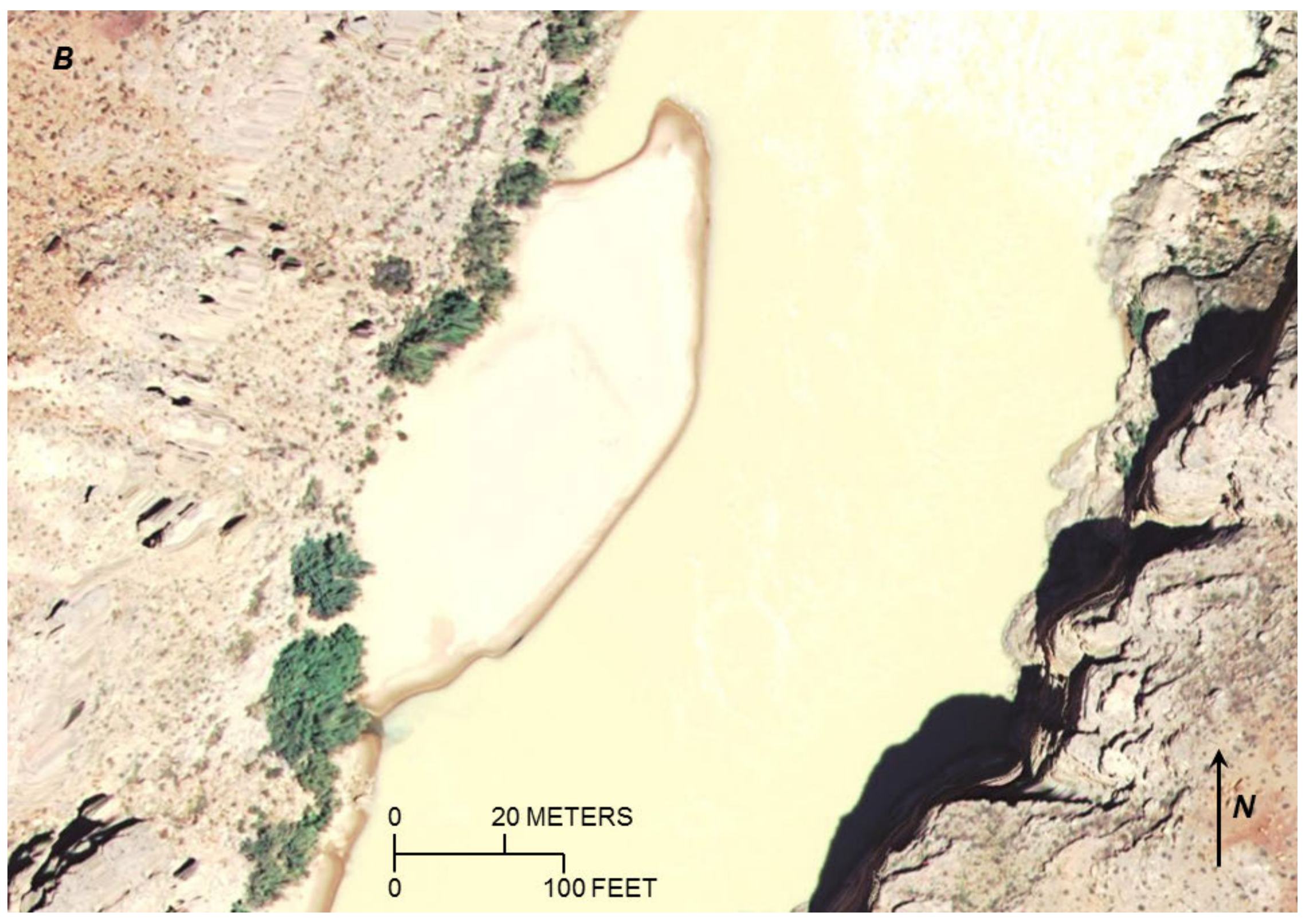

Figure 26.-Continued. 


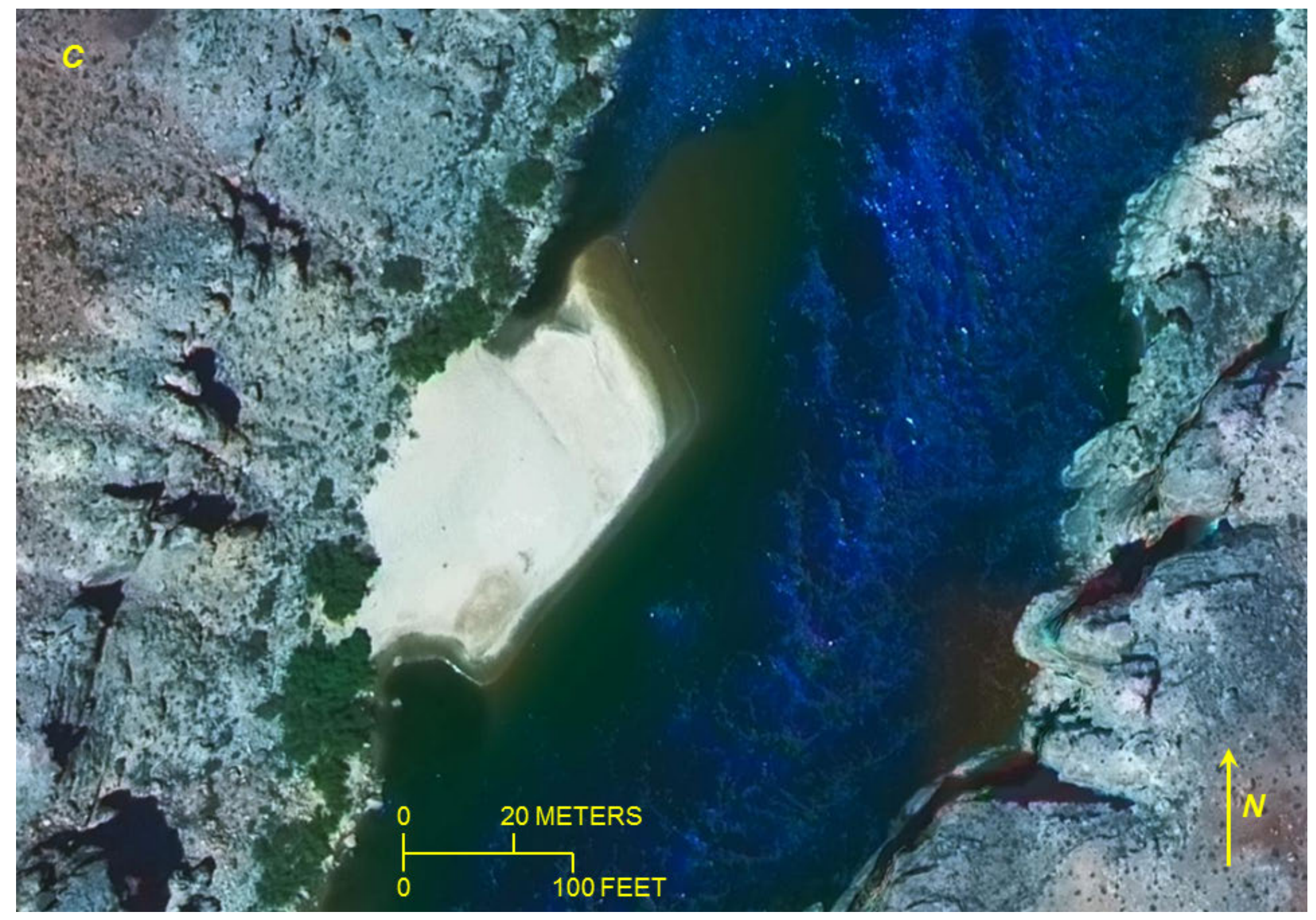

Figure 26.-Continued. 


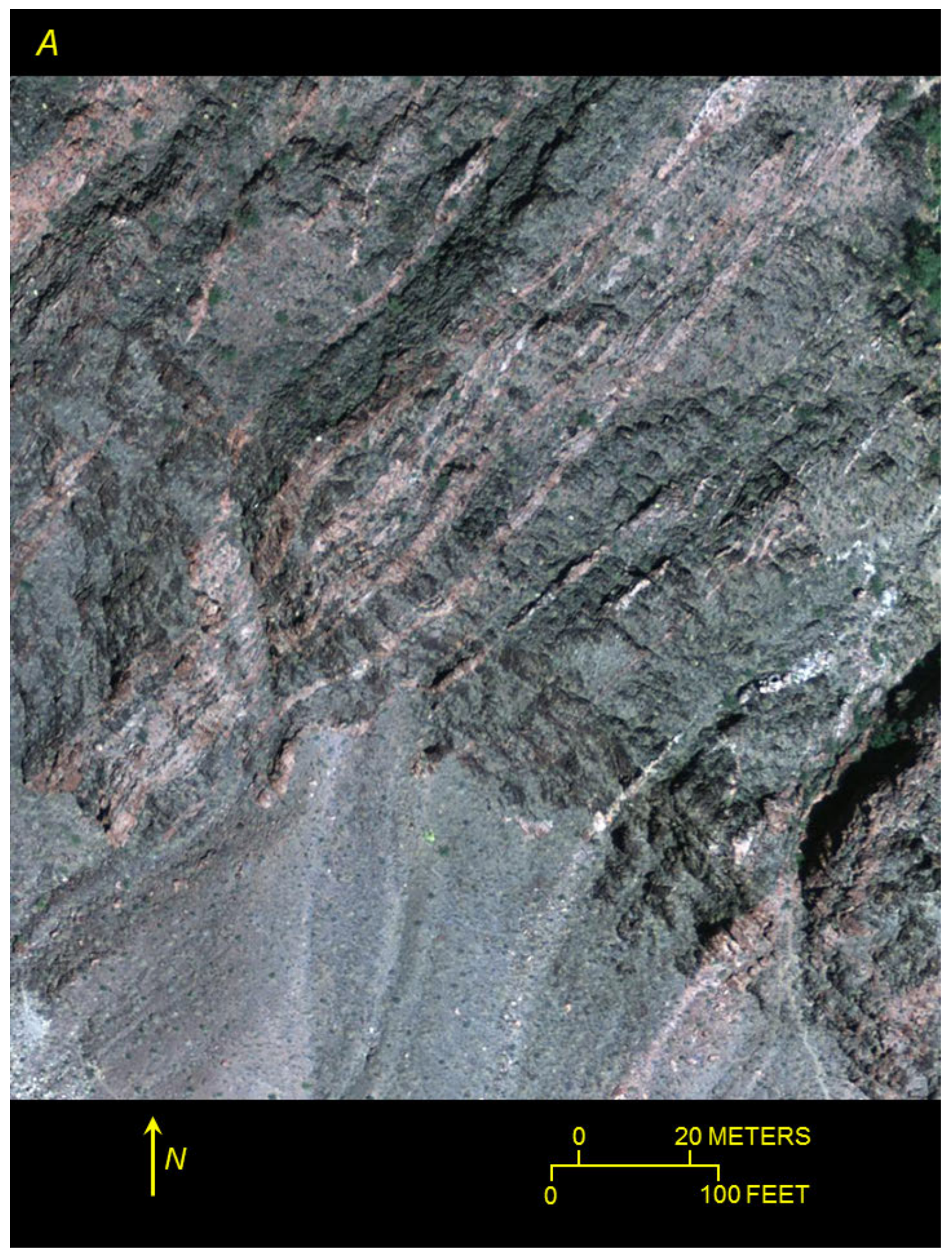

Figure 27. Comparison of $(A) 2009,(B) 2005$, and $(C) 2002$ natural-color image quality of metagranitic terrain near Phantom Ranch (river mile 87.0; fig. 1) within map tile NW36112A1. 


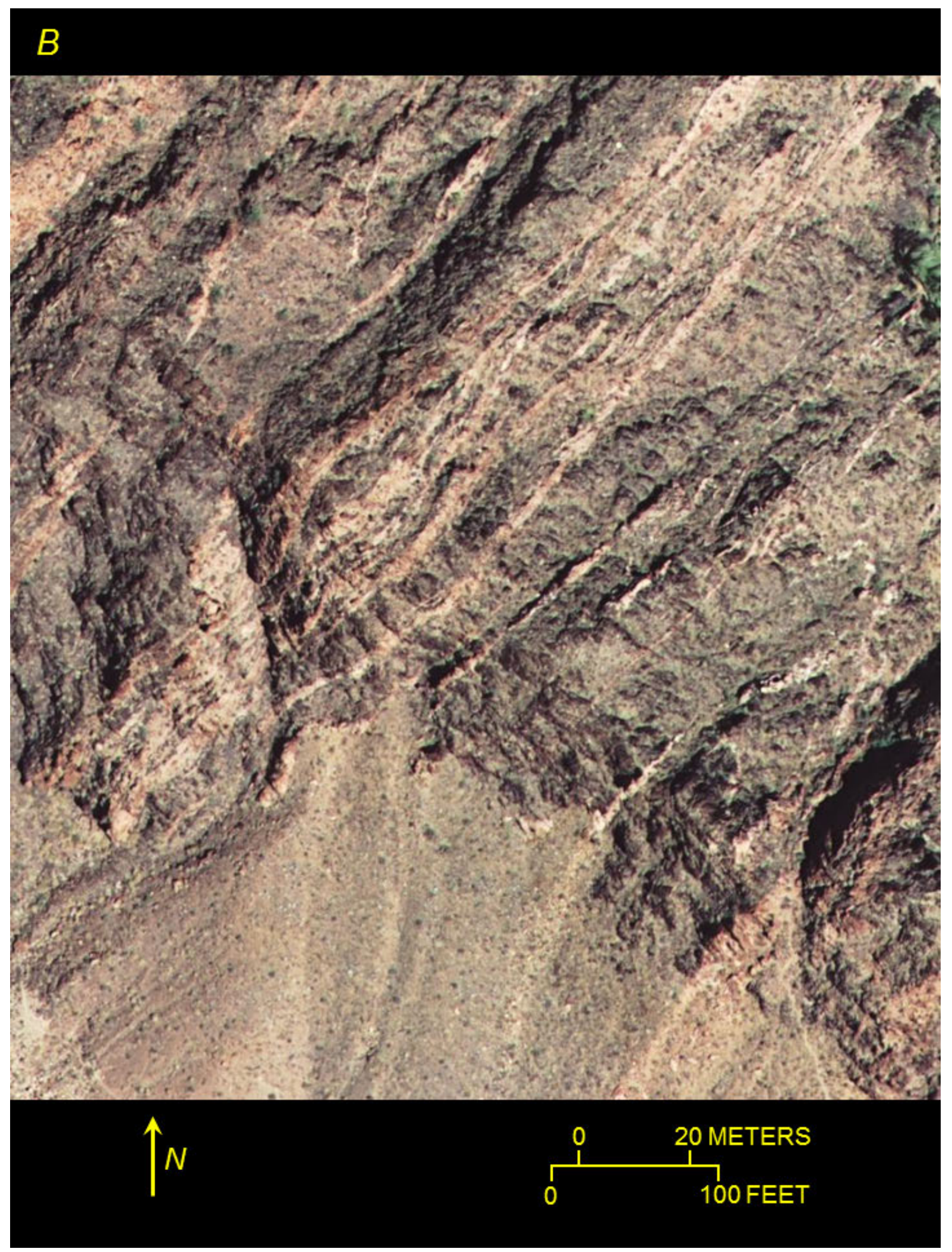

Figure 27.-Continued. 


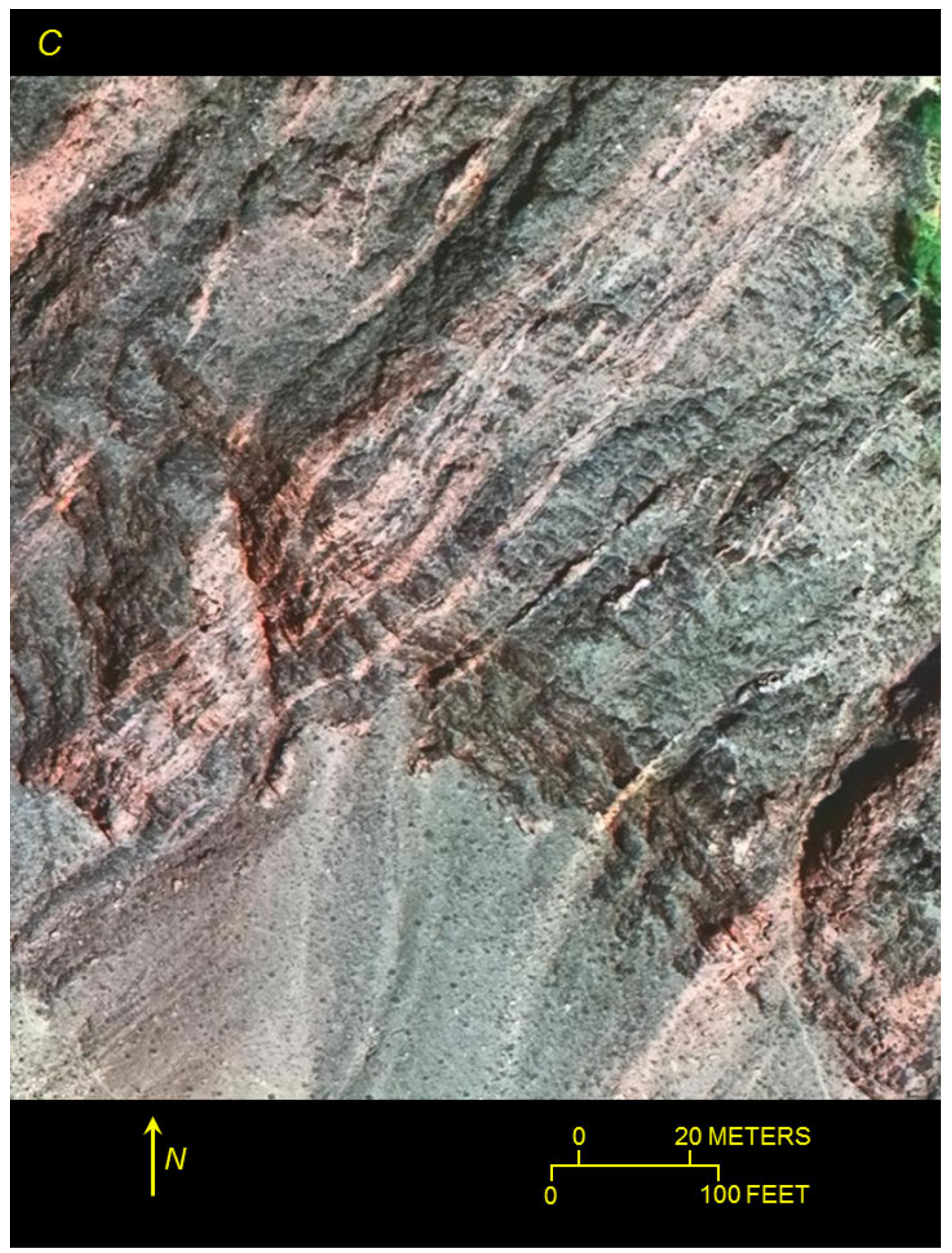

Figure 27.-Continued. 


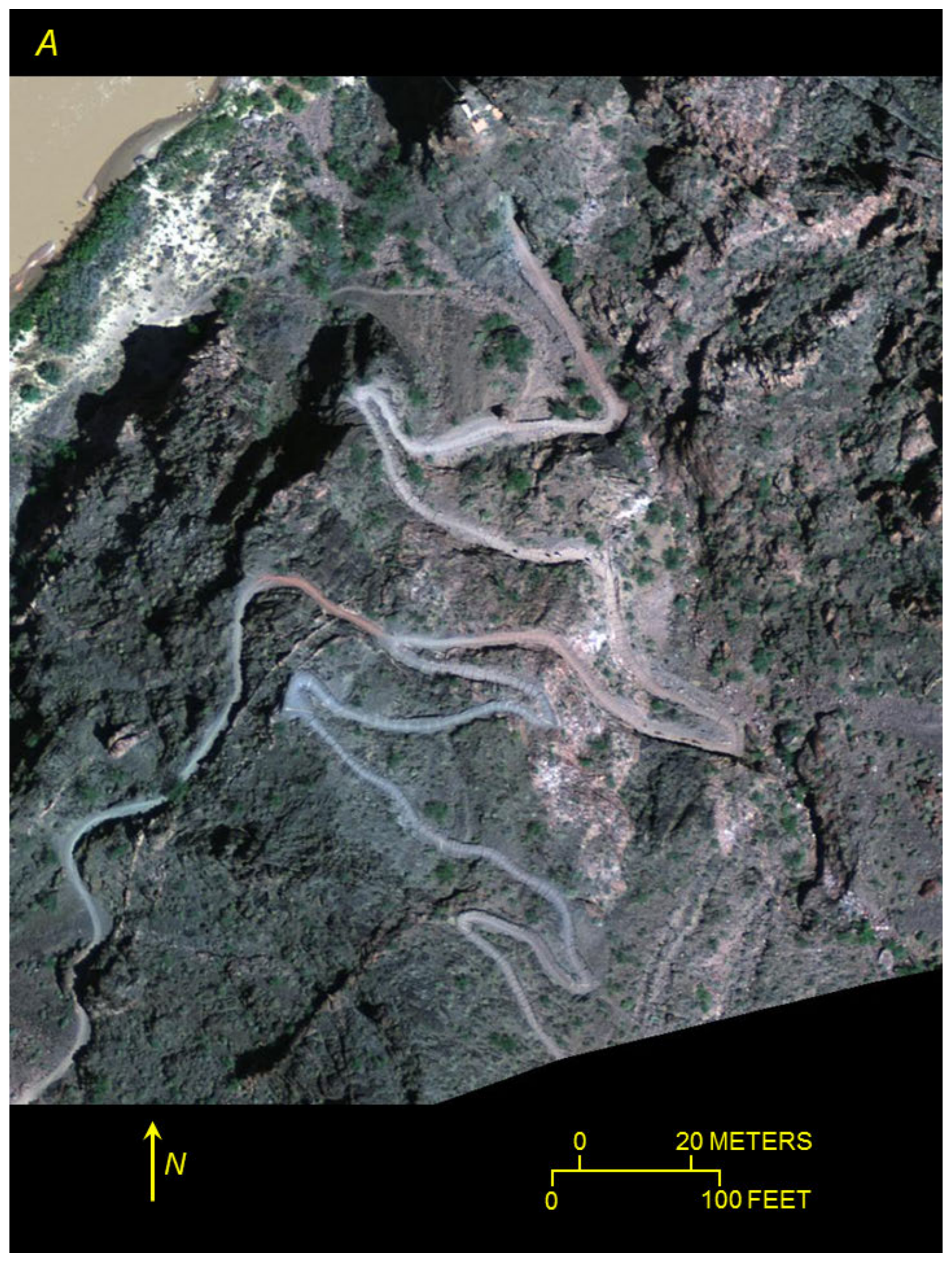

Figure 28. Comparison of $(A) 2009,(B) 2005$, and (C) 2002 natural-color image quality for anthropogenic disturbance near Phantom Ranch (river mile 87.0; fig. 1) within image tile NW36112A1. 


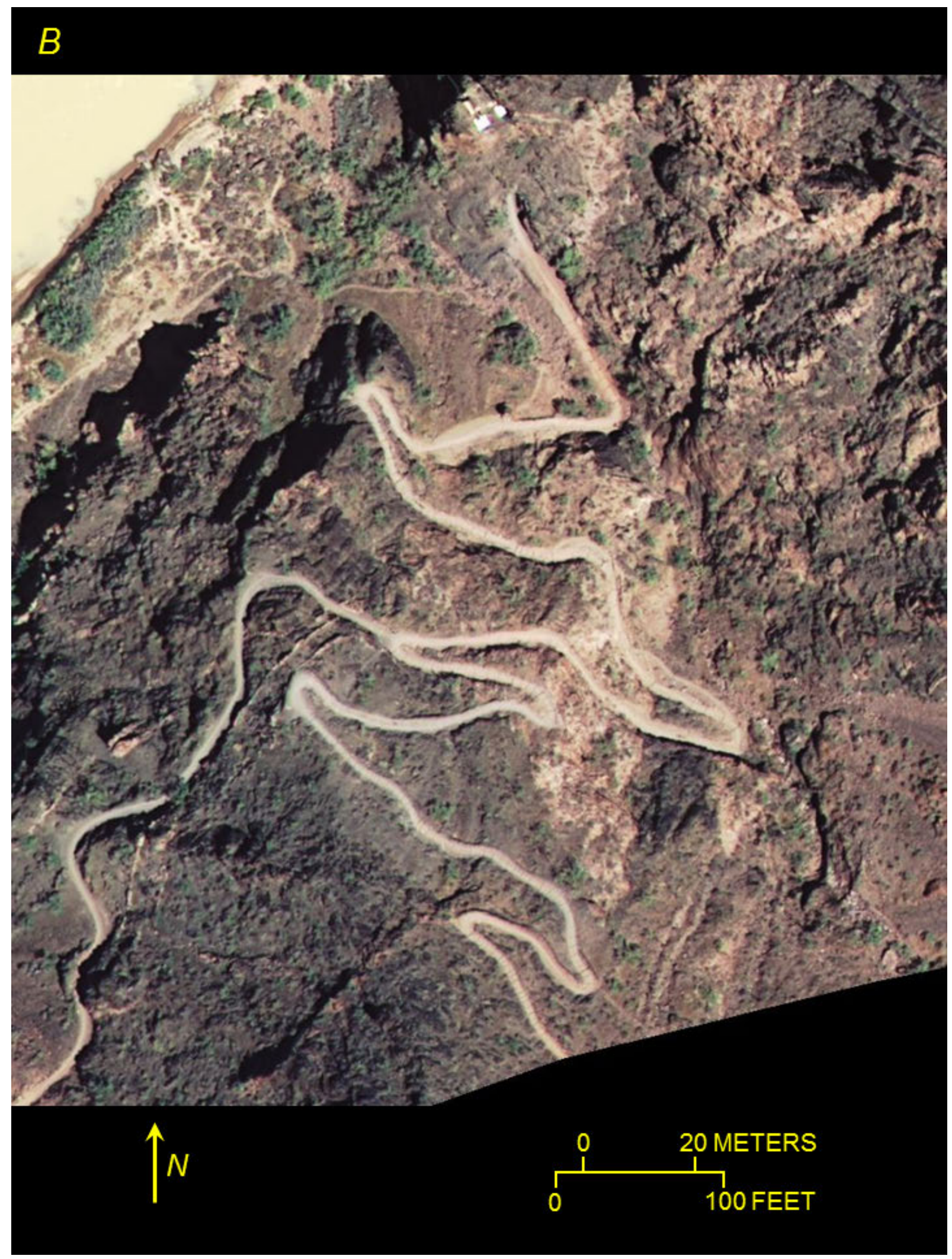

Figure 28.-Continued. 


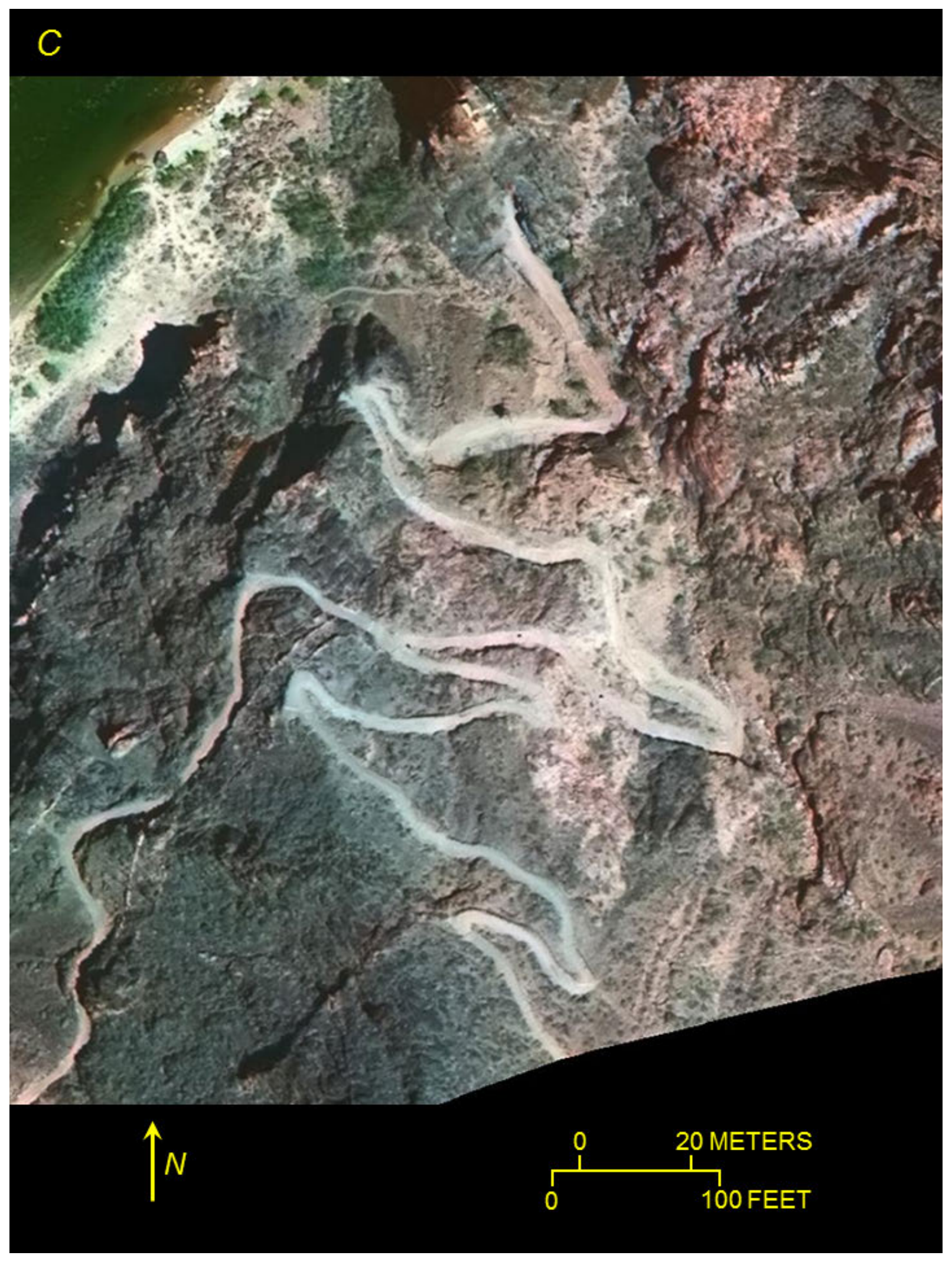

Figure 28.-Continued. 


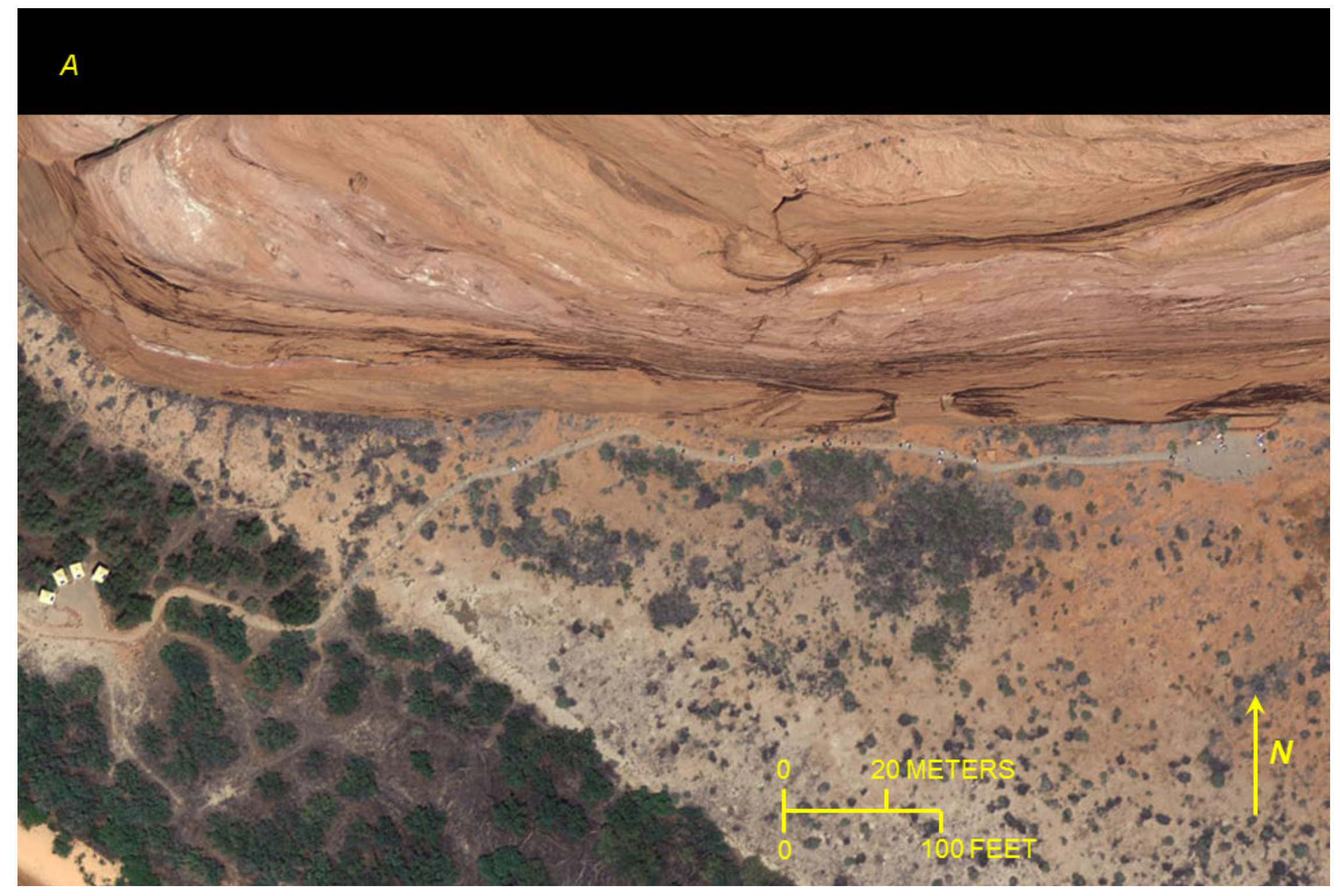

Figure 29. Comparison of $(A) 2009,(B), 2005$, and $(C) 2002$ natural-color image quality at petroglyph site at river mile -10.2 within image tile SE36111H5. 


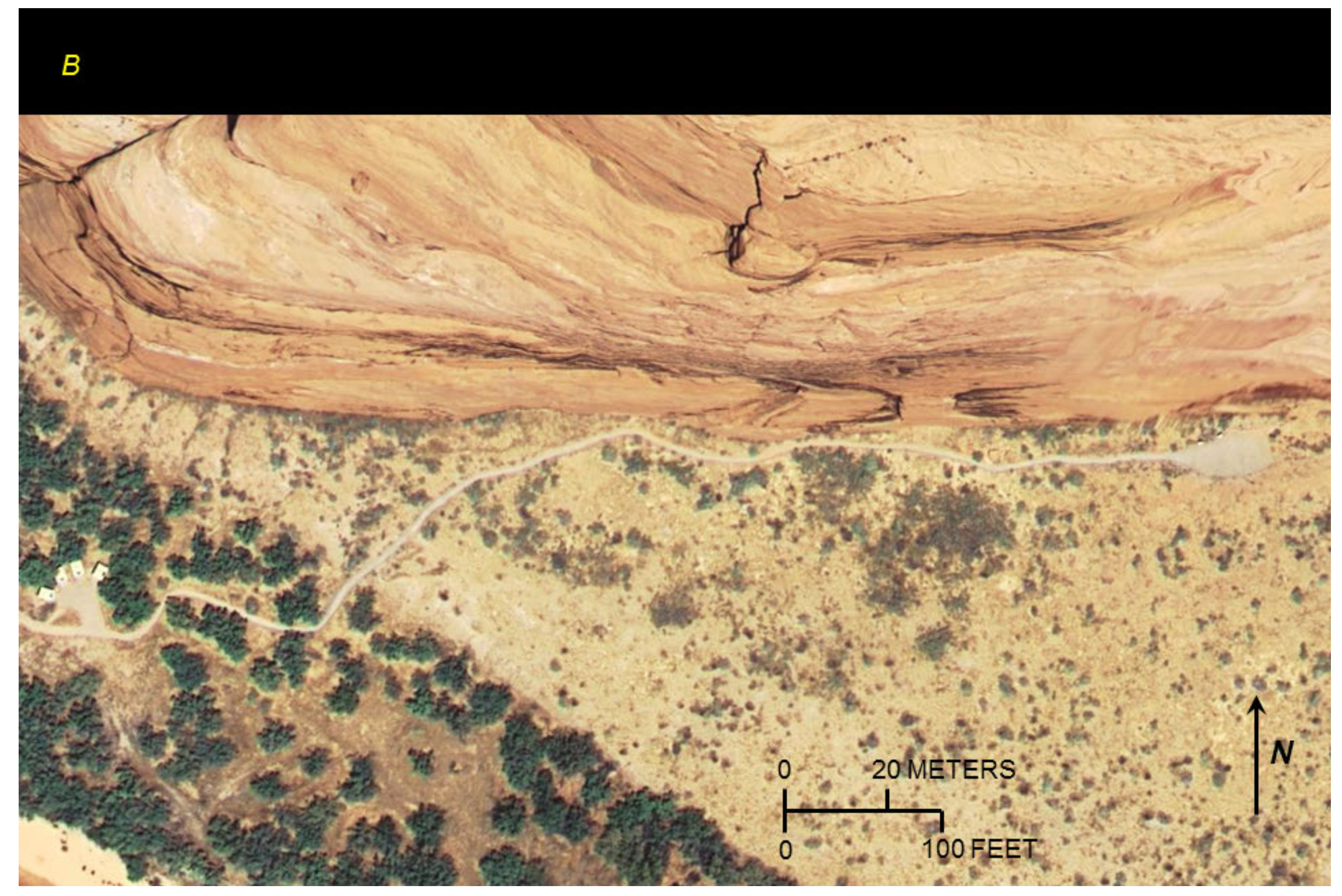

Figure 29.-Continued. 


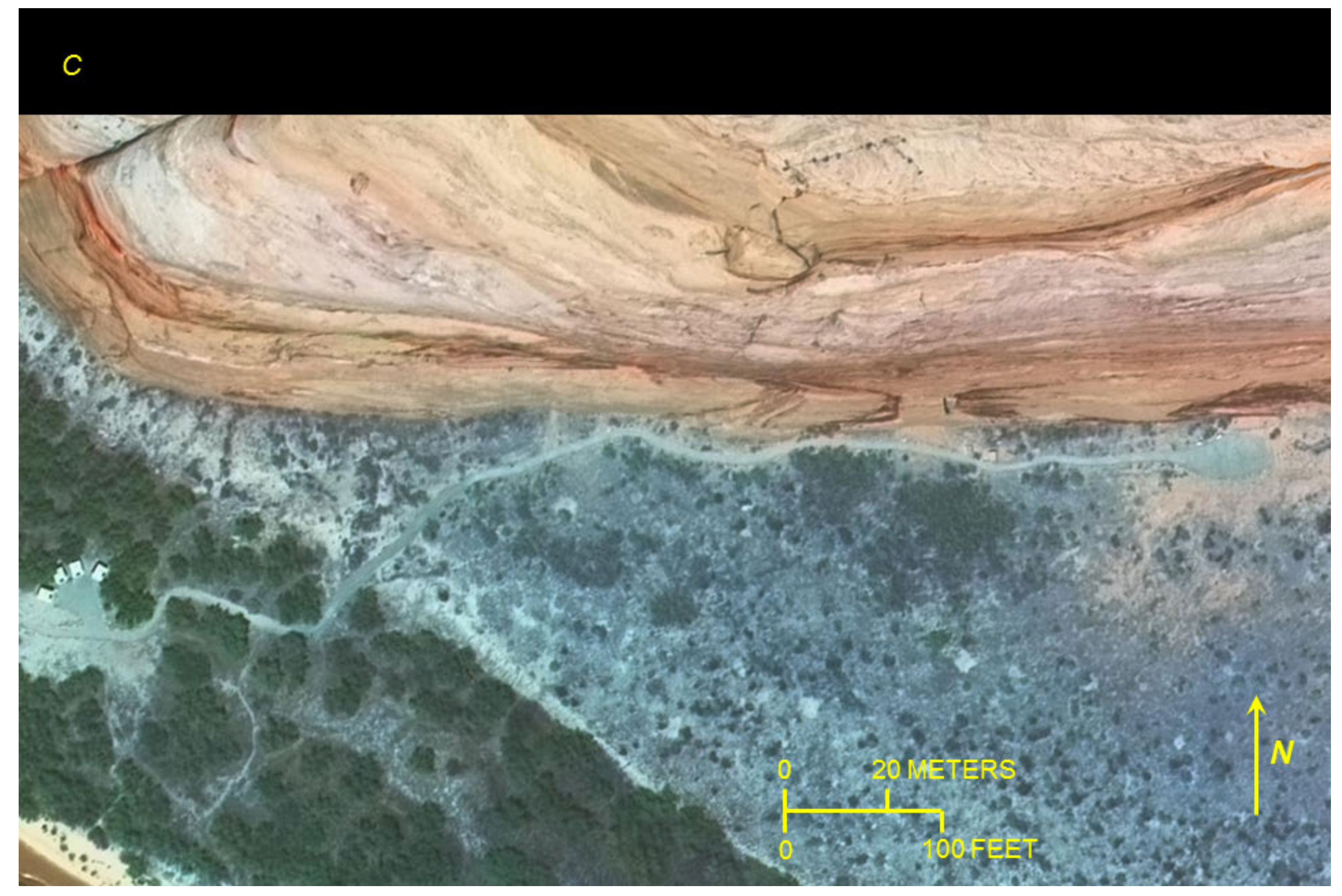

Figure 29.-Continued. 


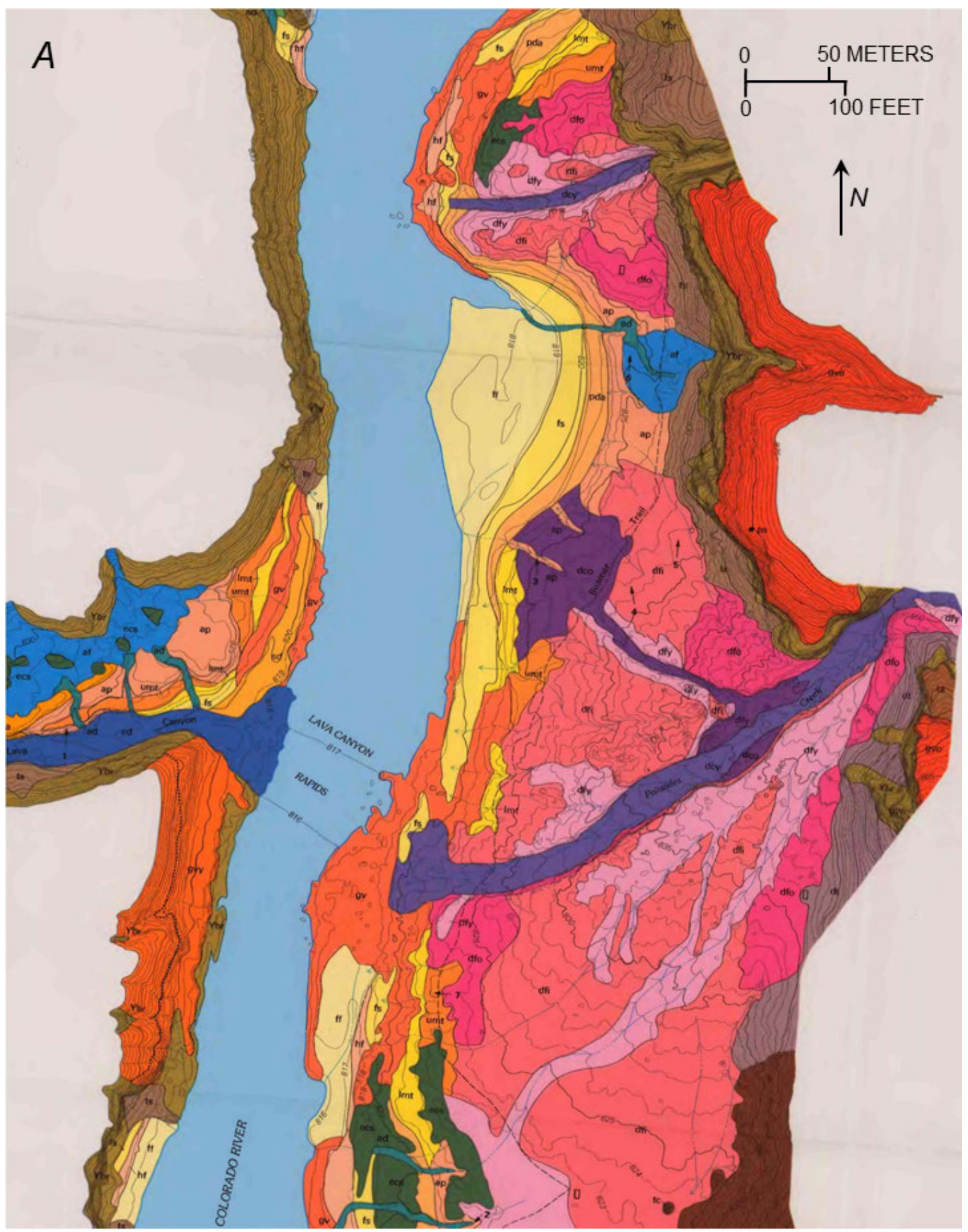

Figure 30. A, Part of Hereford's (1996) geologic and geomorphologic map of the Palisades Creek area (fig. 1) at river mile 65.9. $B$, Legend from Hereford's (1996) map describing units depicted in figure 30A. 


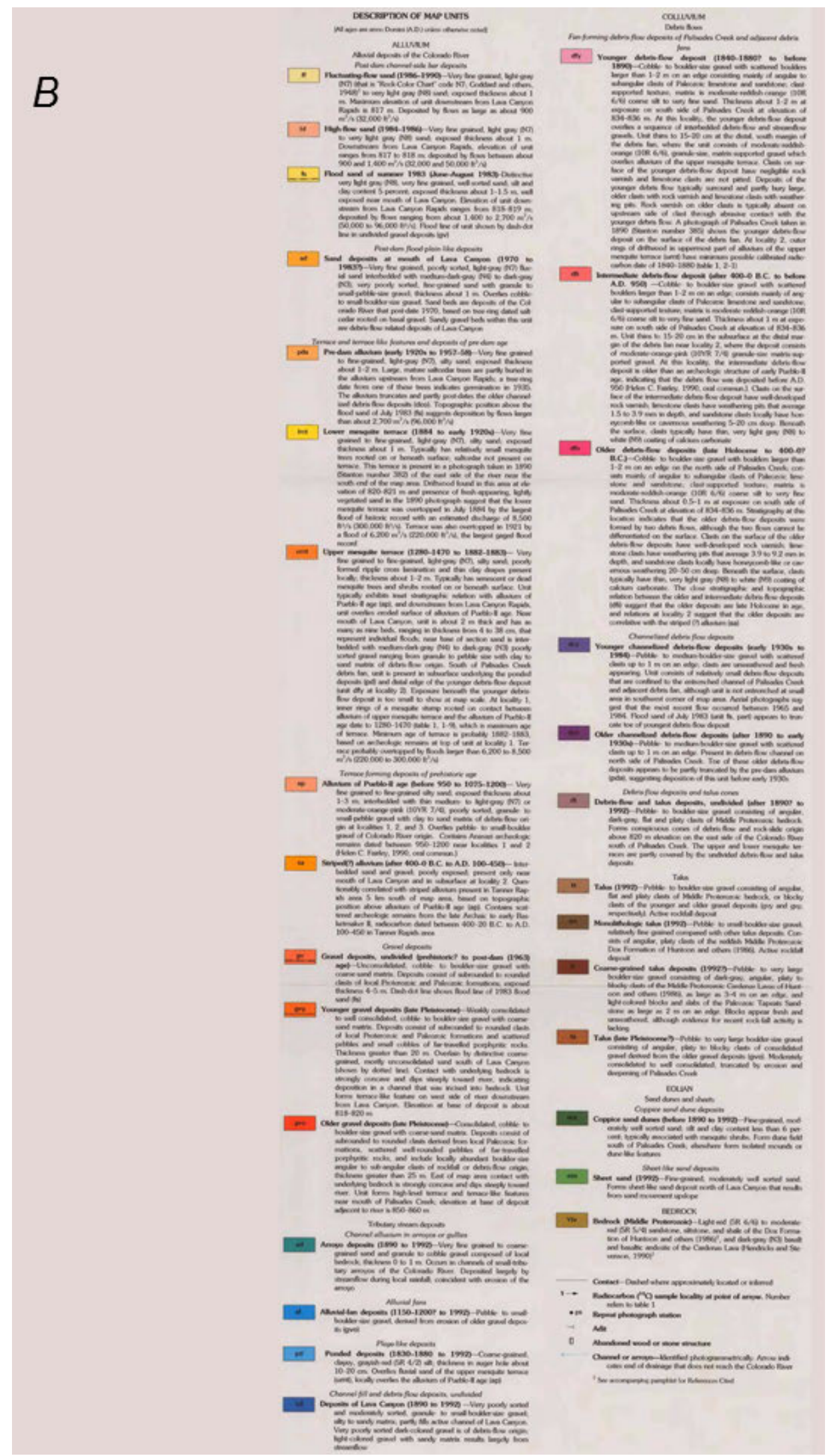

Figure 30.-Continued. 


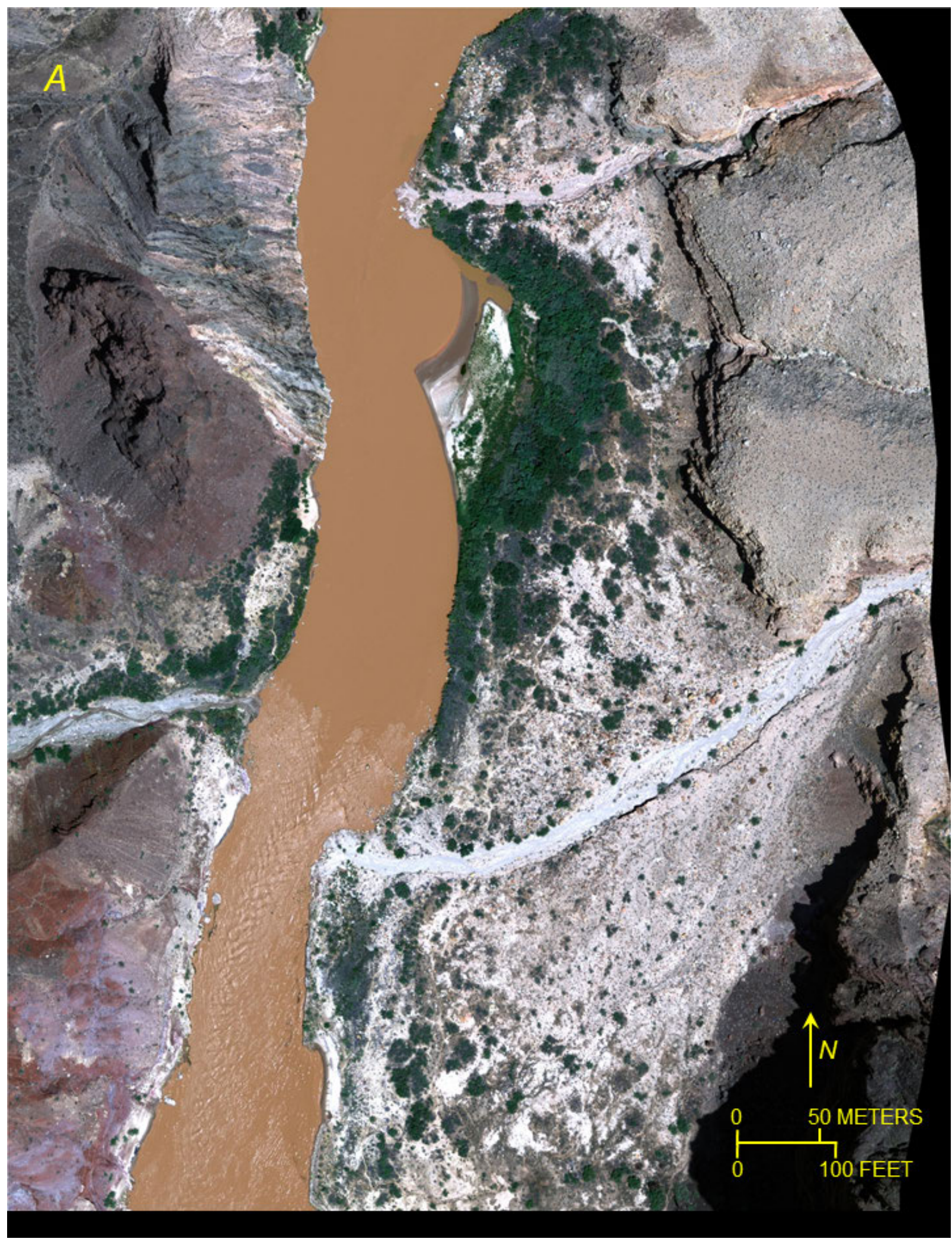

Figure 31. Comparison of $(A) 2009,(B) 2005$, and $(C) 2002$ natural-color image quality for the area shown in figure 30 within map tile SW36111B7. 


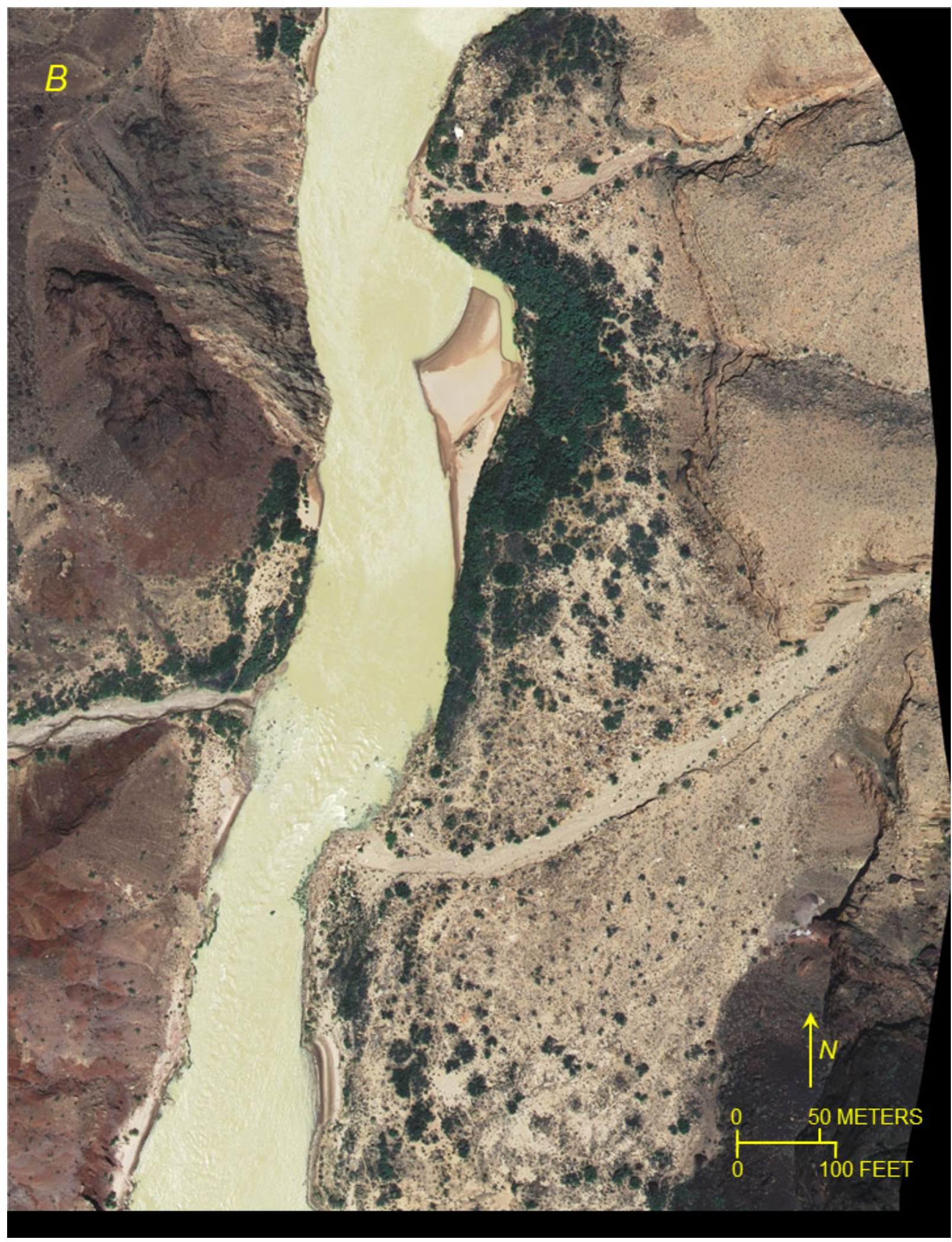

Figure 31.-Continued. 


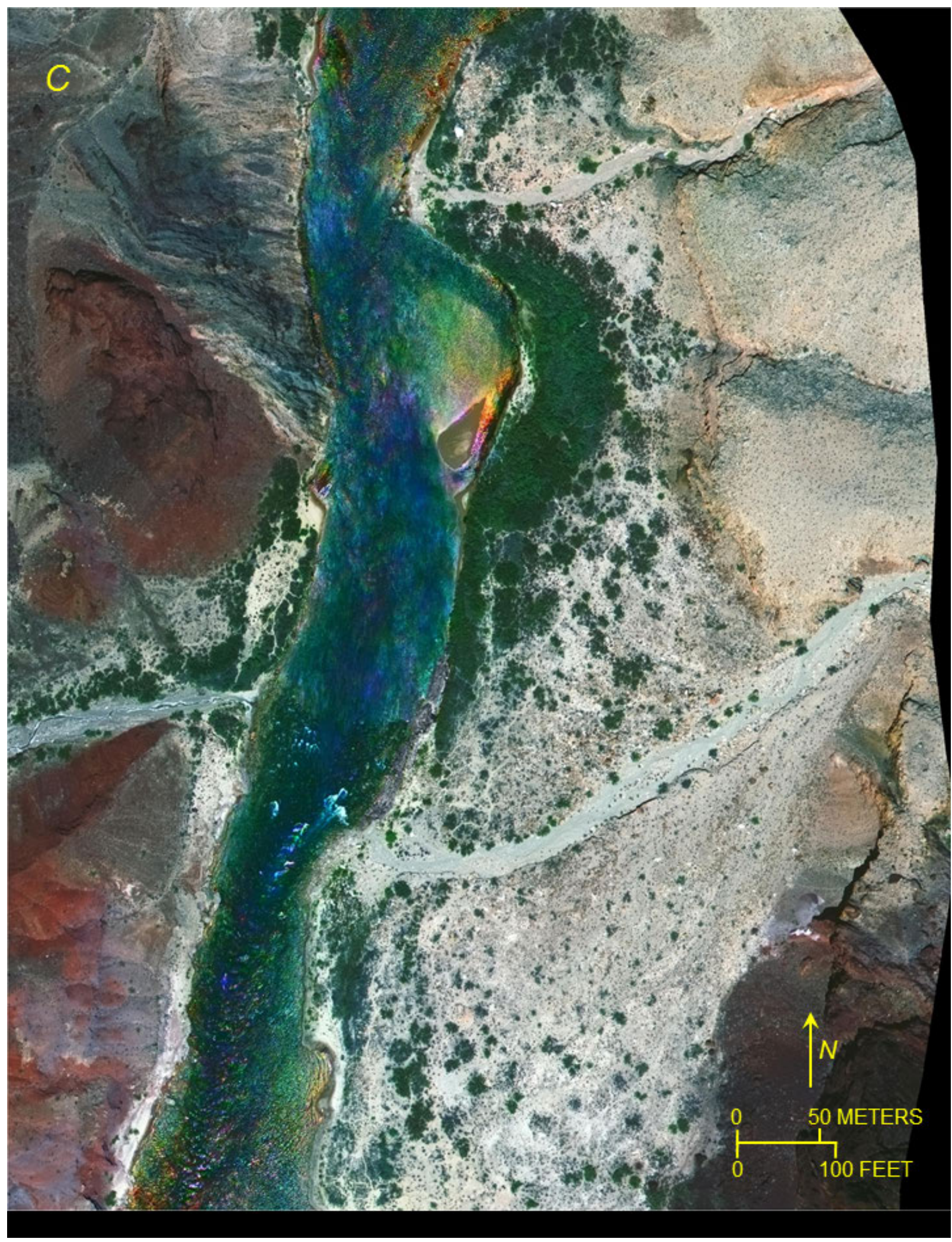

Figure 31.-Continued. 


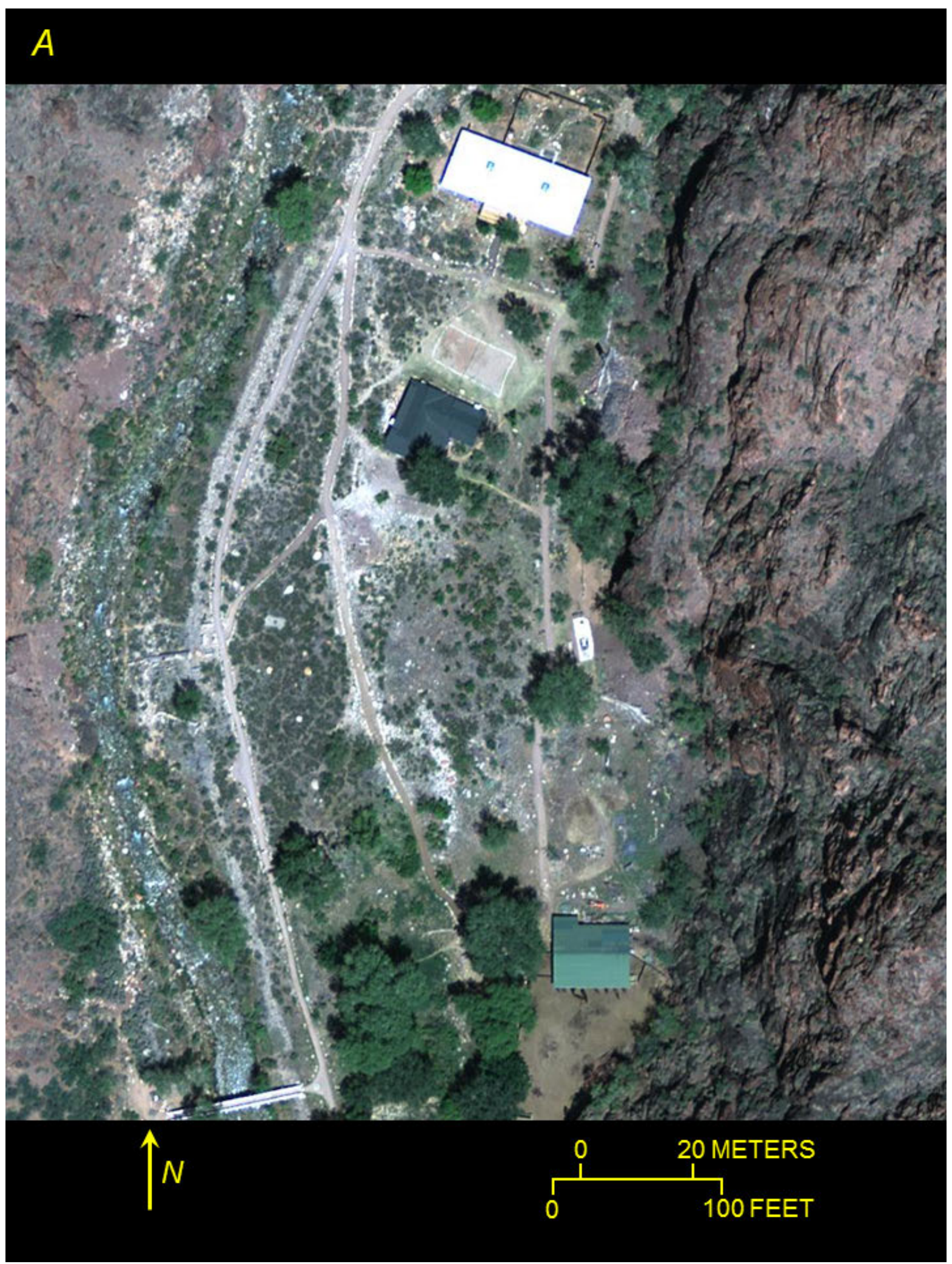

Figure 32. Comparison of $(A) 2009,(B) 2005$, and $(C) 2002$ natural-color image quality for anthropogenic features at Phantom Ranch (river mile 87.0; fig. 1) within map tile NW36112A1. 


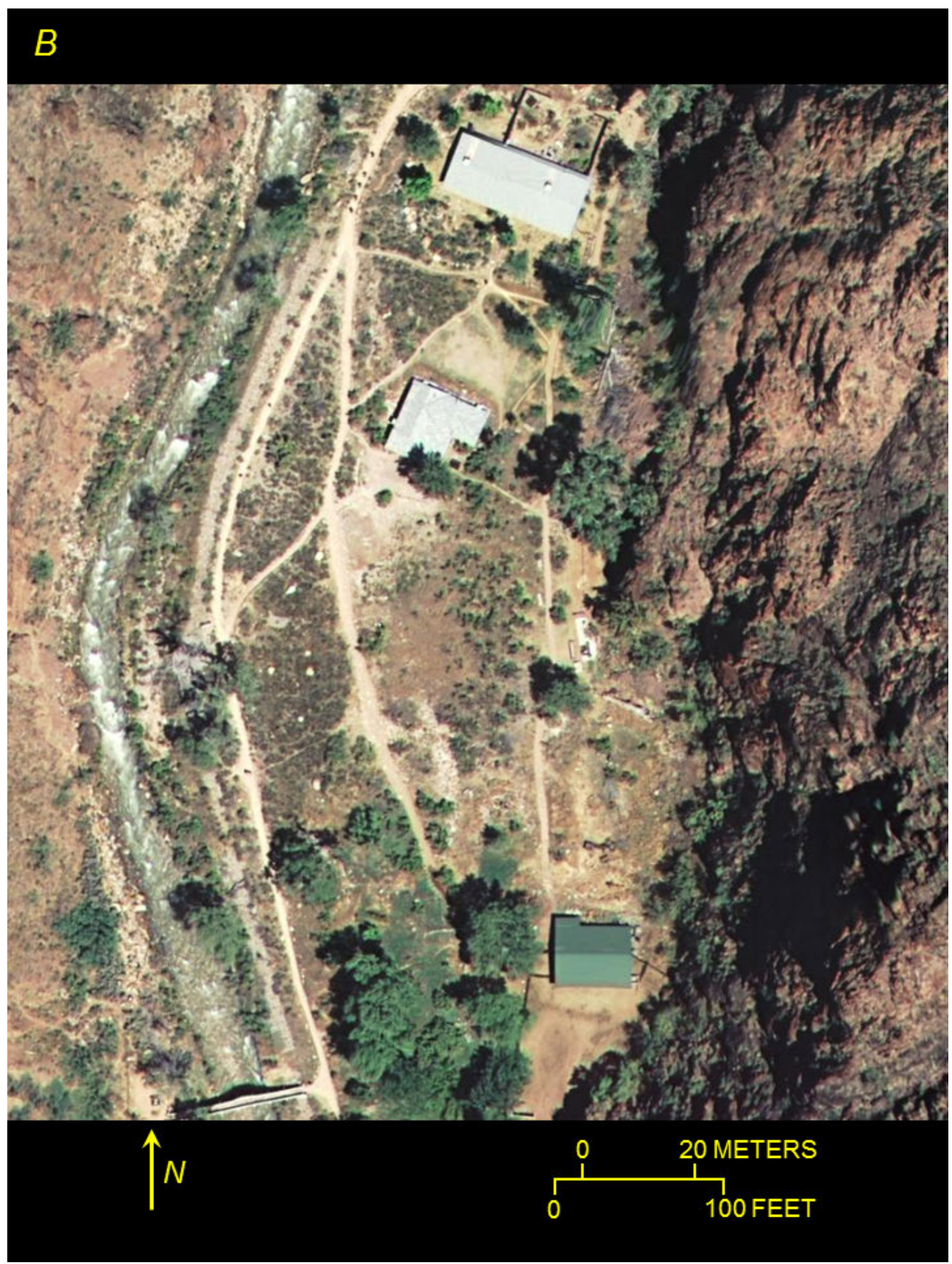

Figure 32.-Continued. 


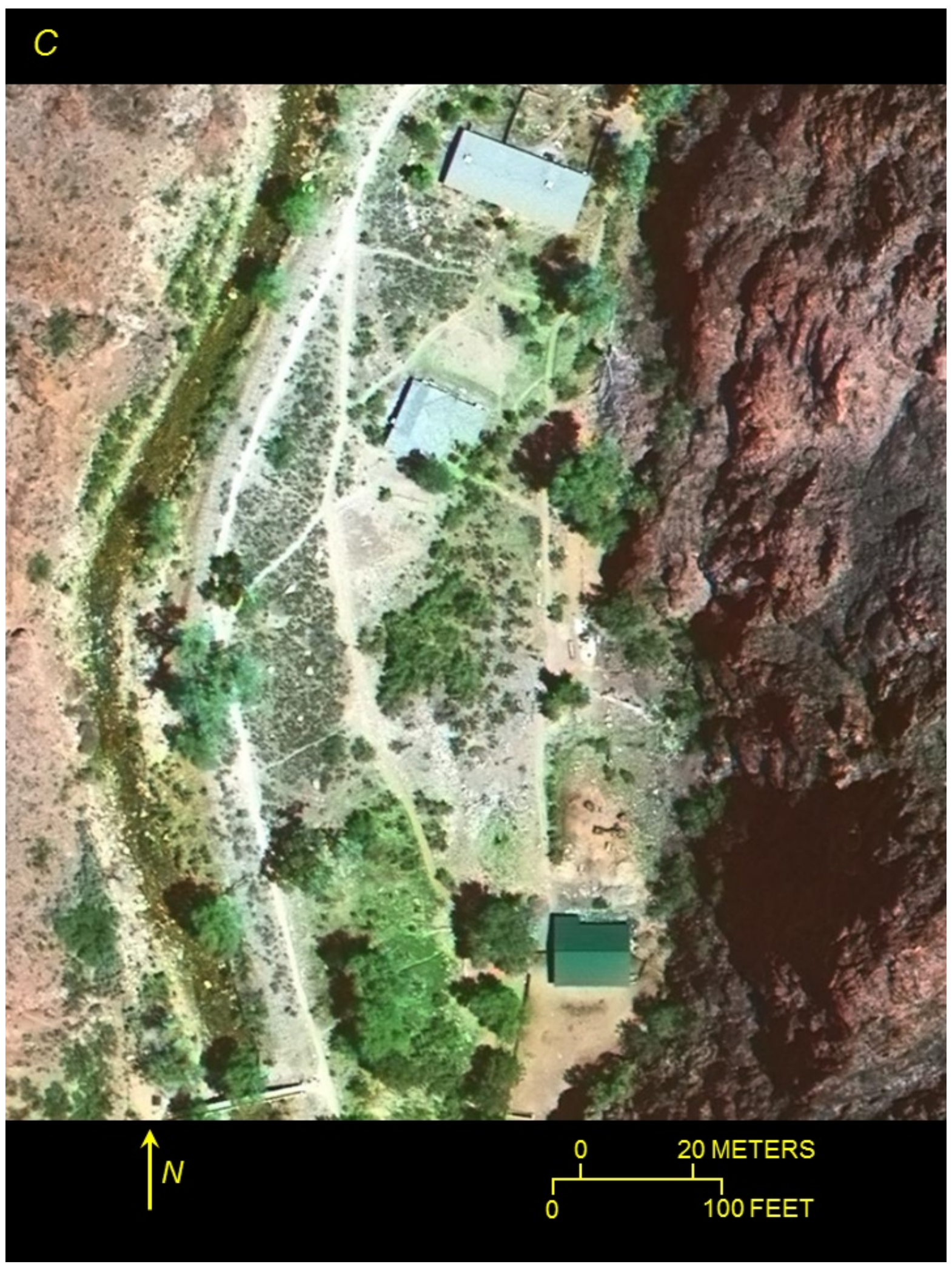

Figure 32.-Continued. 


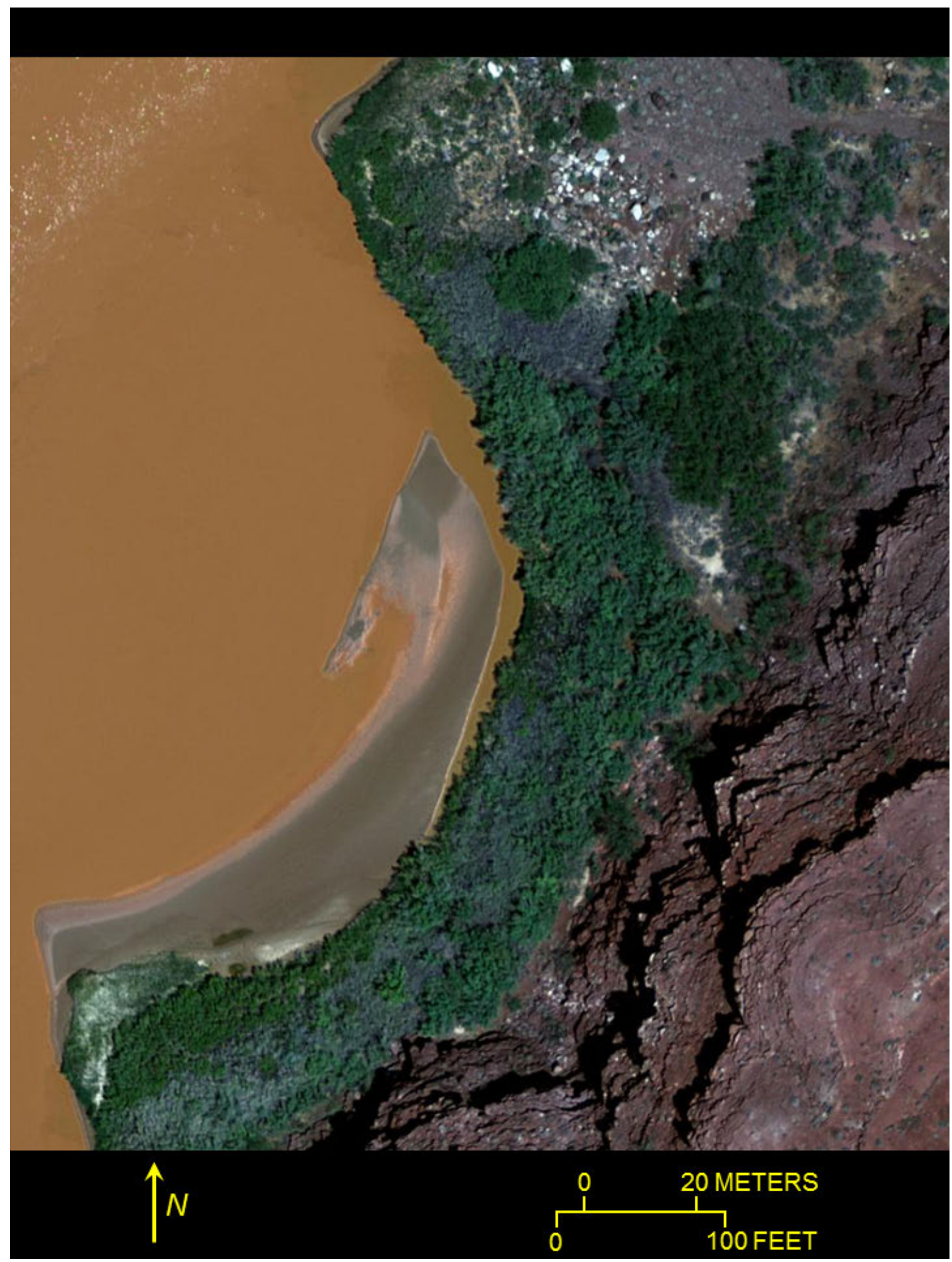

Figure 33. Natural-color image taken in 2009 of a vegetated area at river mile 68.5 within map tile NW36111A7. 


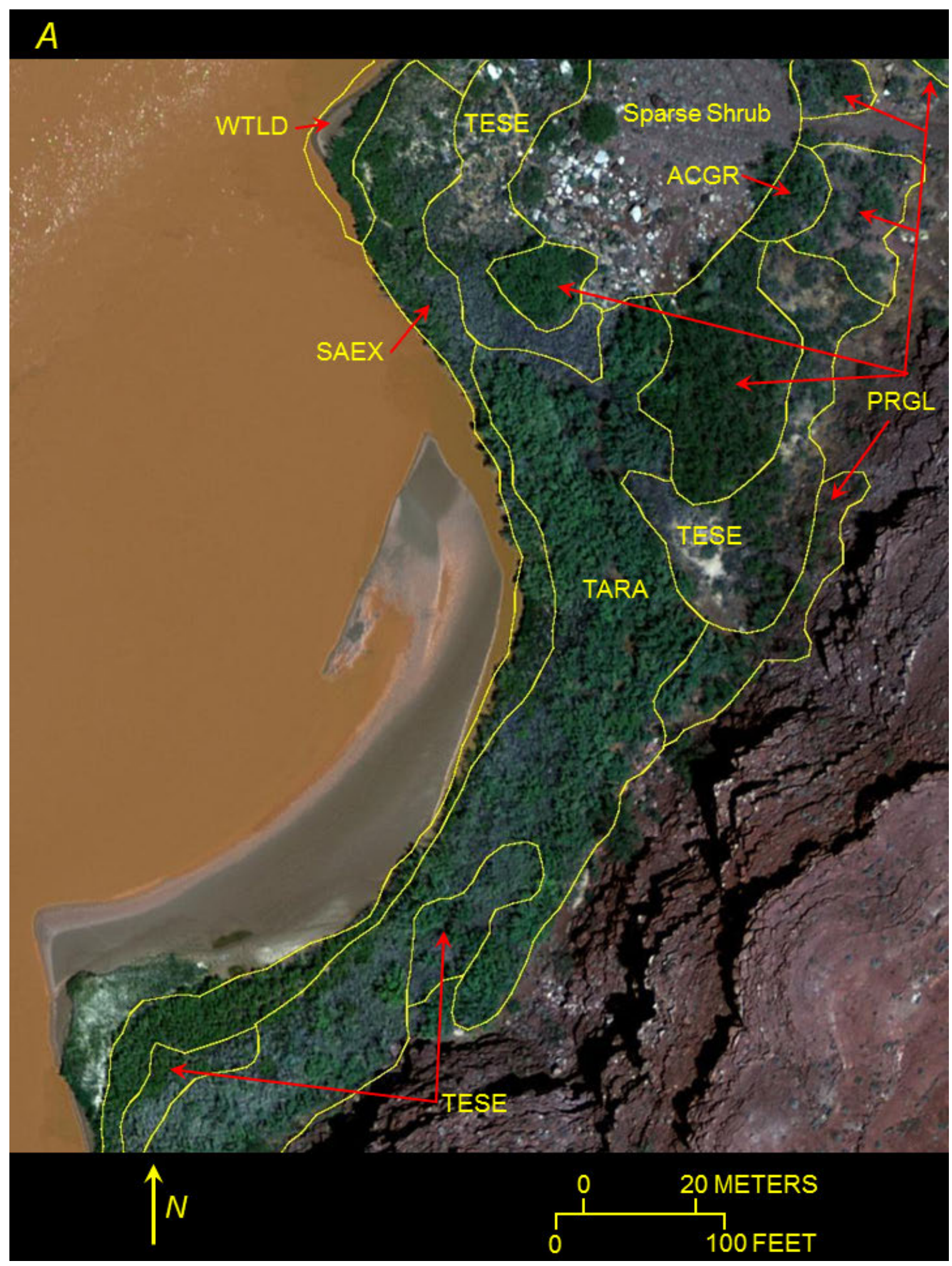

Figure 34. Comparison of $(A) 2009,(B) 2005$, and $(C) 2002$ natural-color image quality for the vegetated area shown in figure 33. Vegetation units of Ralston and others (2008) are supposed on the image (ACGR, Acacia greggii or catclaw acacia; PRGL, Prosopis glandulosa or honey mesquite; SAEX, Salix exigua or coyote willow; TARA, Tamarix ramossima or tamarisk; TESE, Pluchea sericea or arrowweed; WTLD, wetland composite). 


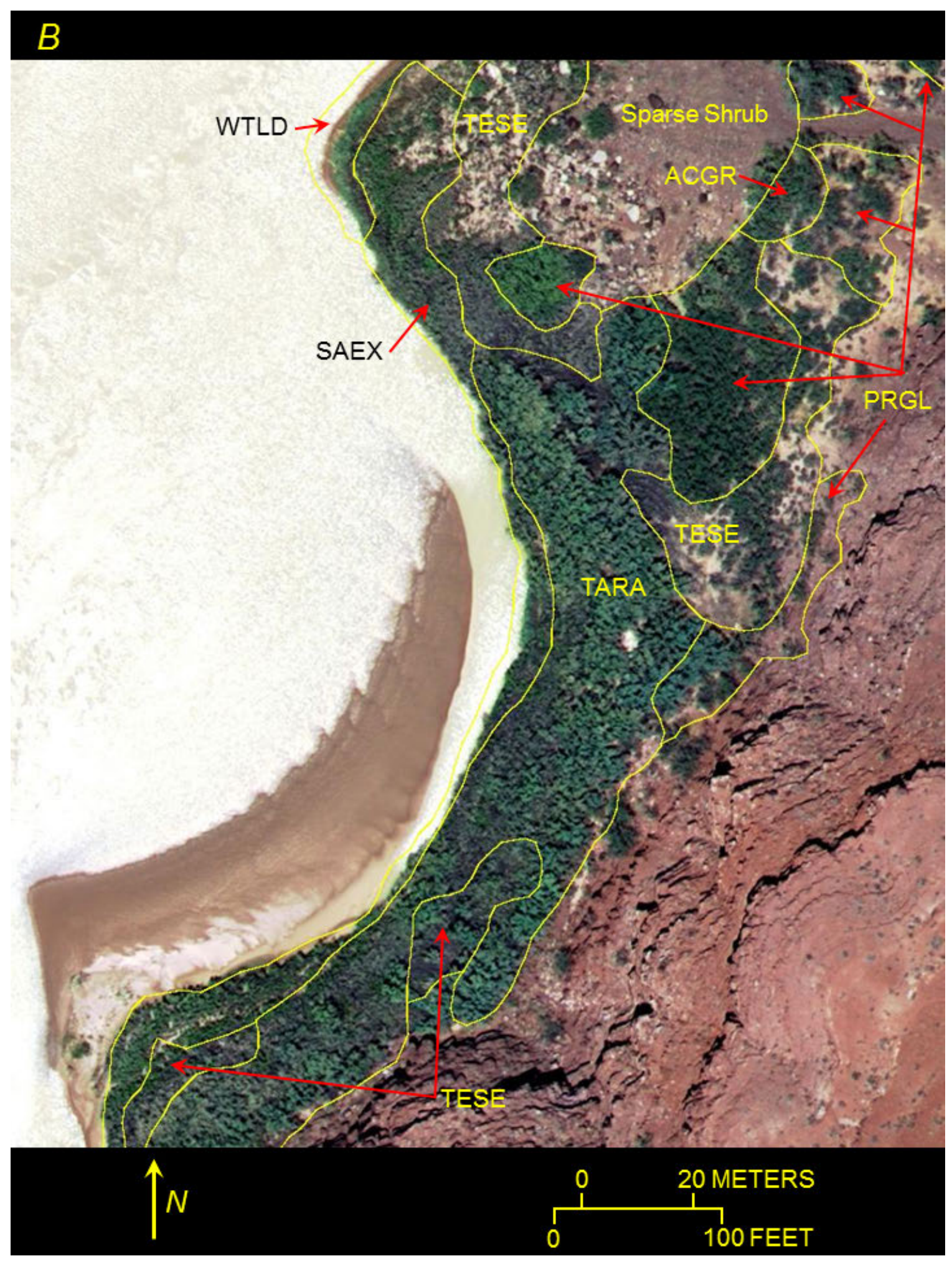

Figure 34.-Continued. 


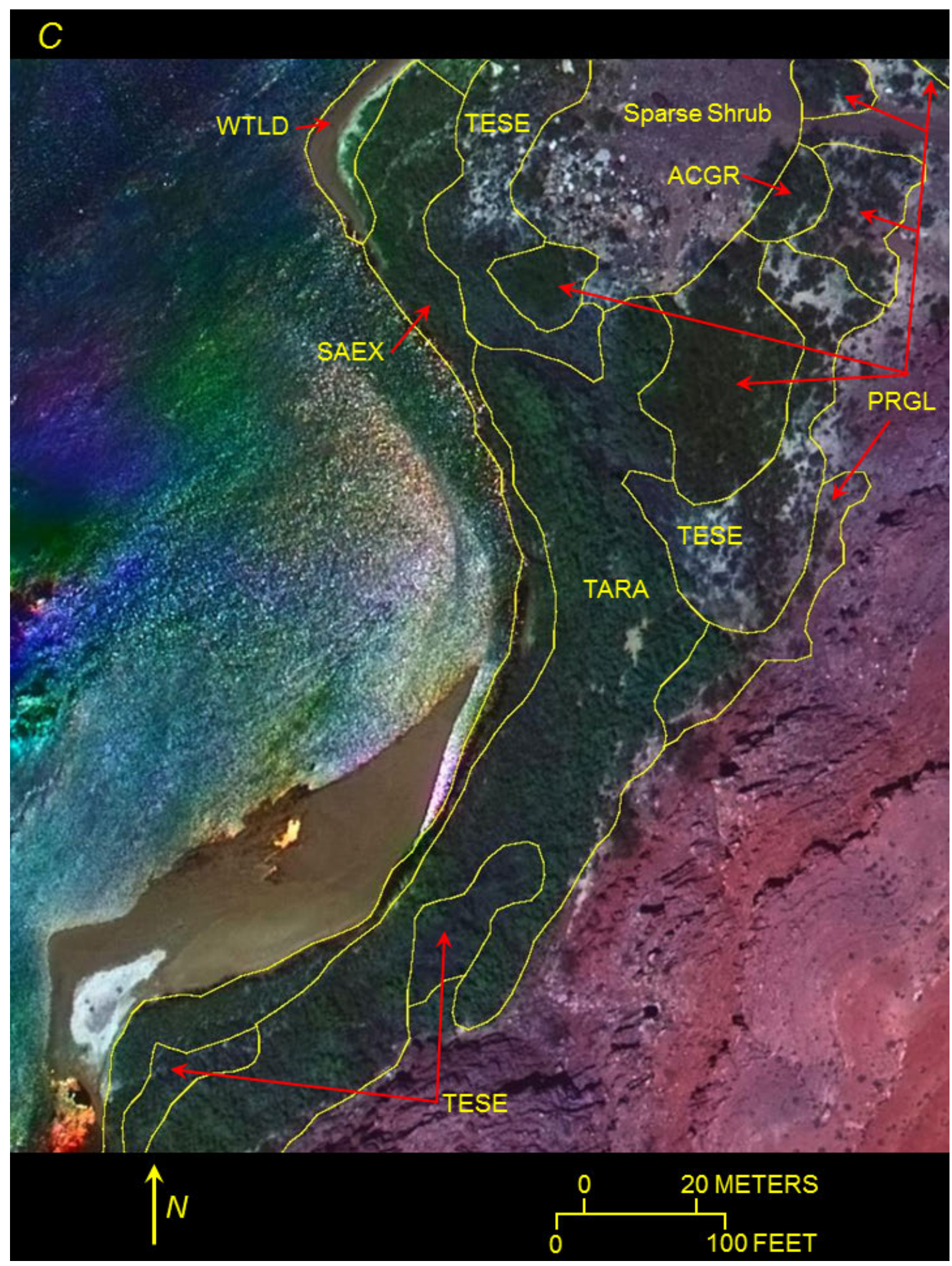

Figure 34.-Continued. 


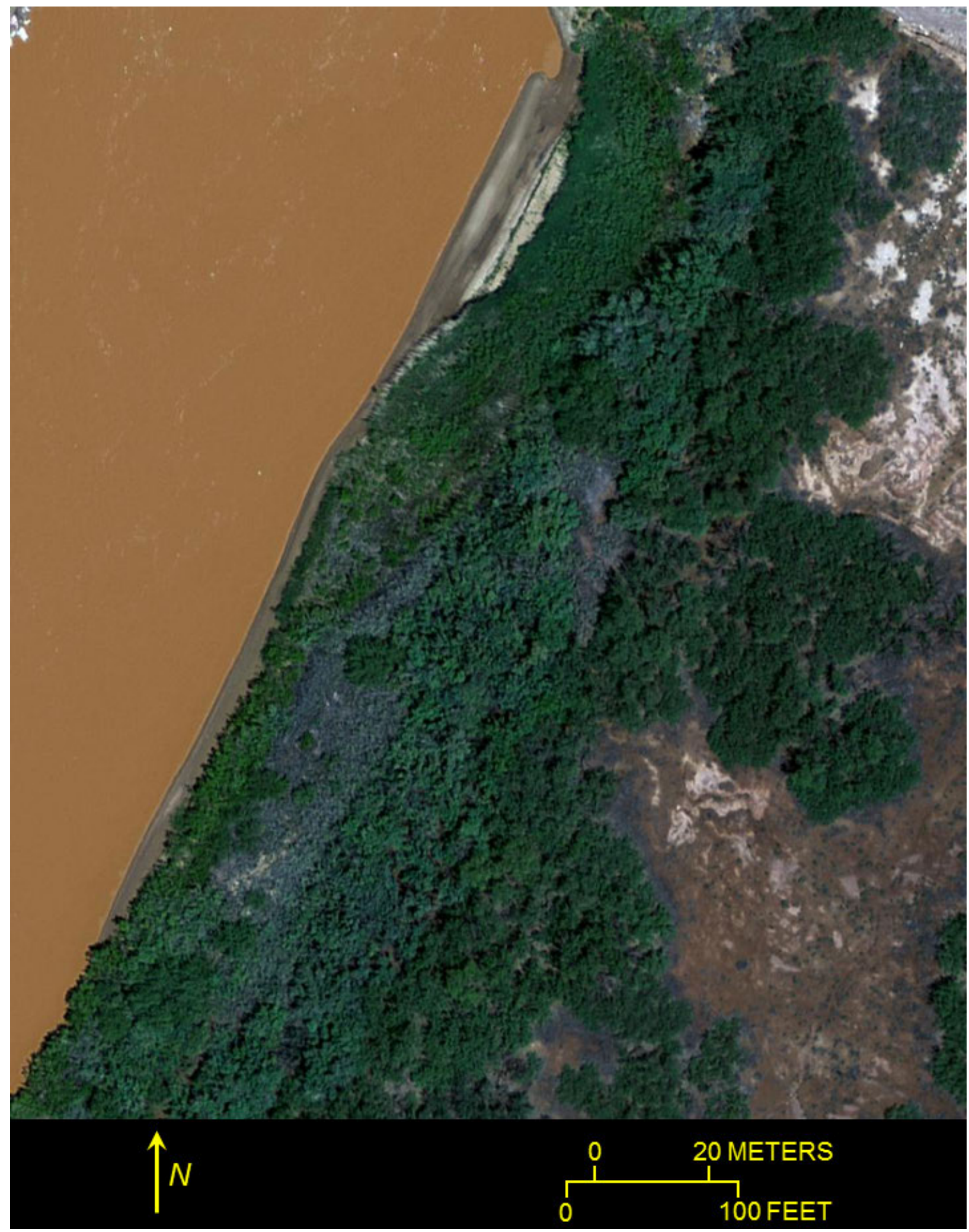

Figure 35. Natural-color image taken in 2009 of an area upstream of figures 33 and 34 at river mile 67.5 showing very distinct color differences among various types of vegetation. 


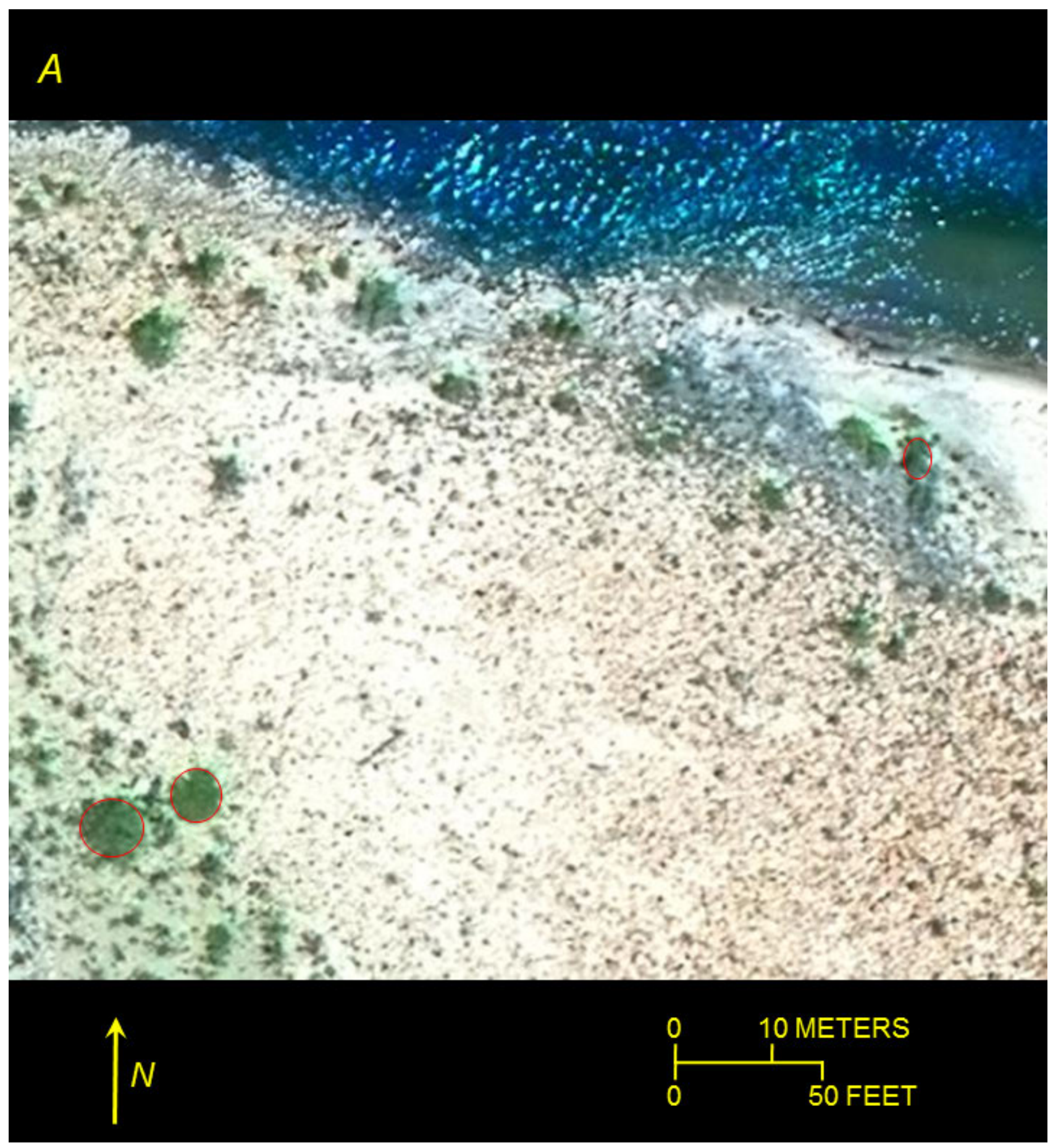

Figure 36. Comparison of $(A) 2002,(B) 2005$, and $(C) 2009$ natural-color image of a beach area downstream of Phantom Ranch (river mile 87.1; fig. 1) within image tile NW36112A1 showing steady increase in stand diameter between 2002 and 2009. Red ellipse and circles outline stand diameters in 2002. 


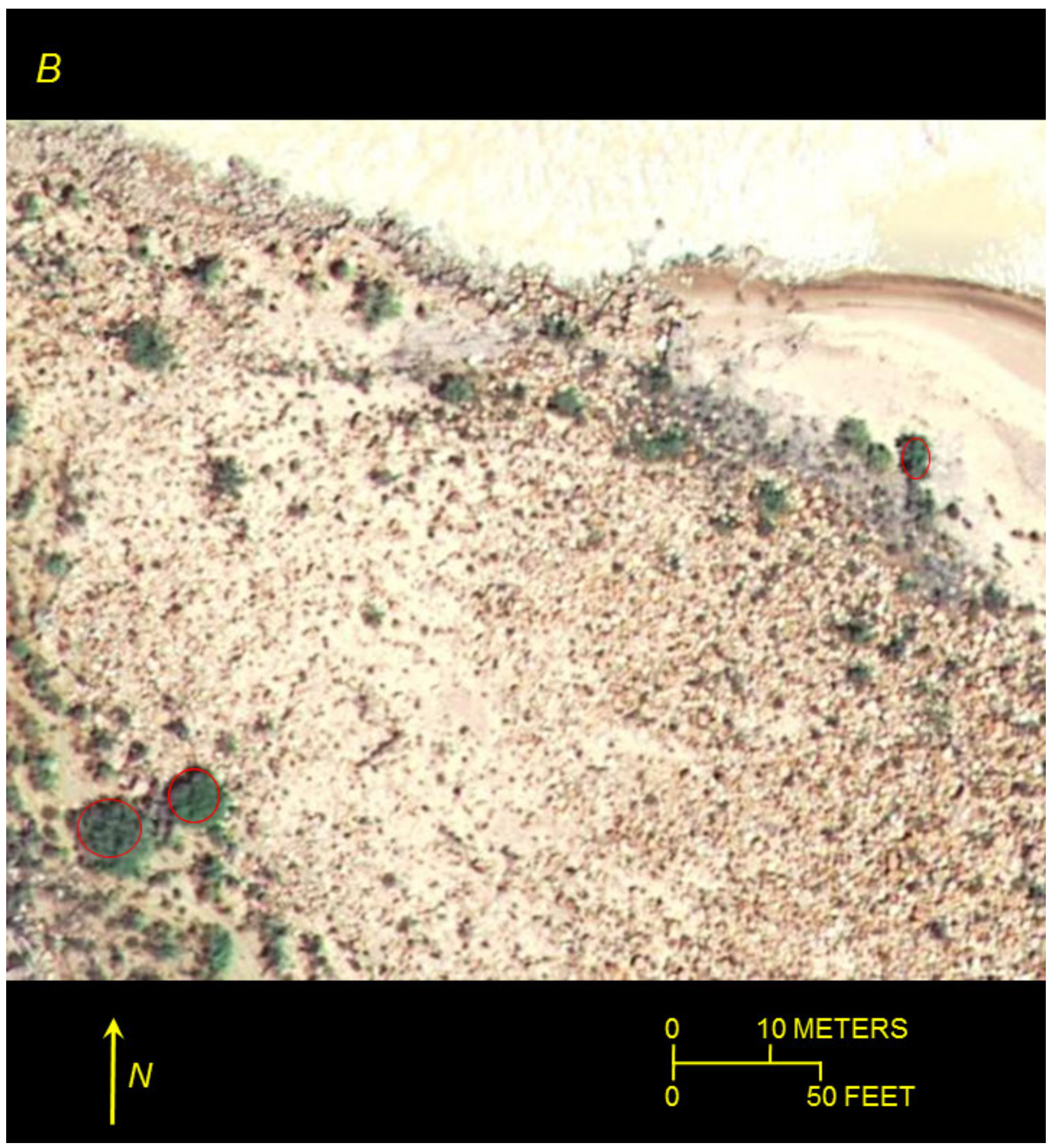

Figure 36.-Continued. 


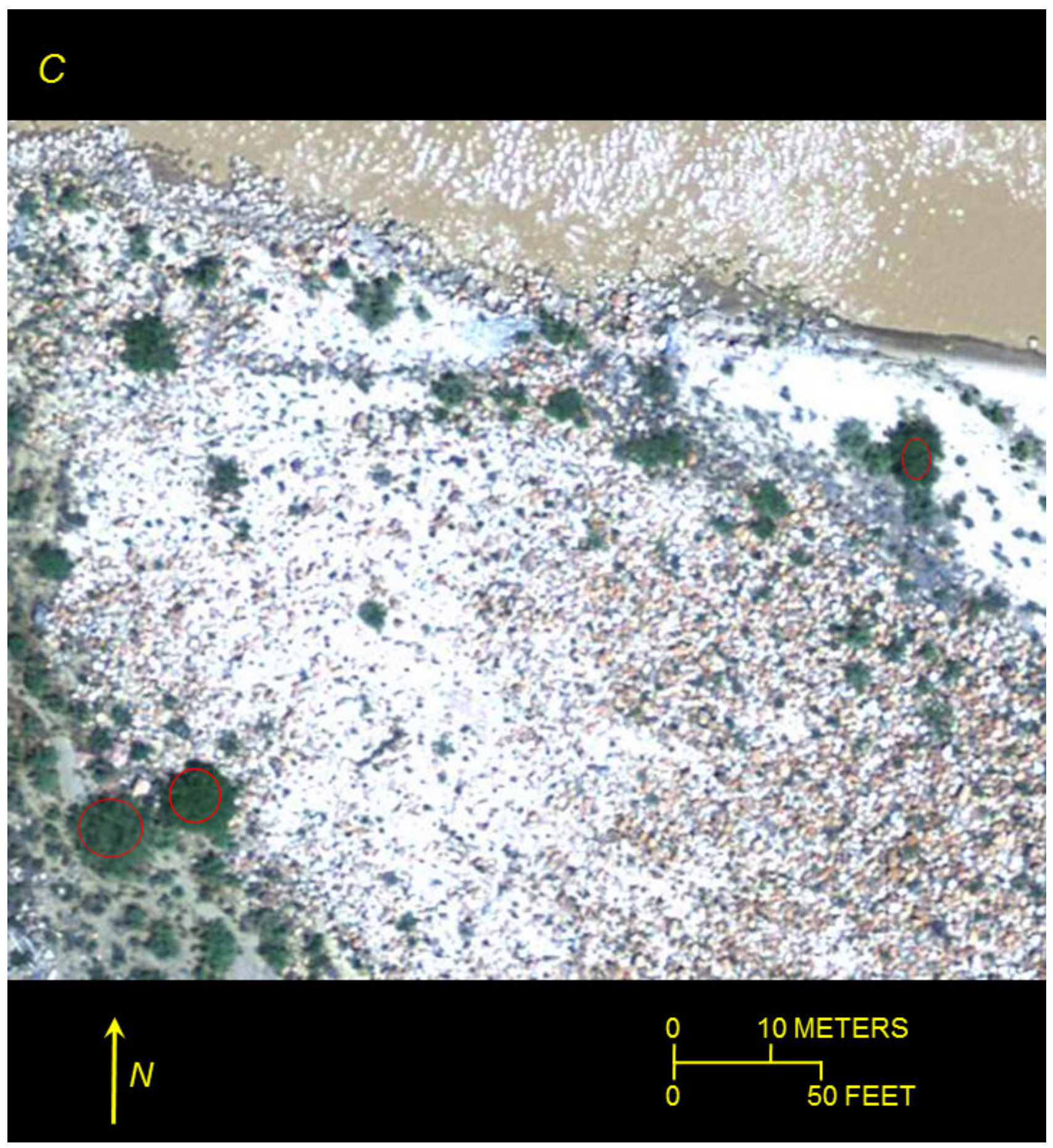

Figure 36.-Continued. 